\title{
ESTUDO SOBRE MODIFICAÇÕES INTRODUZIDAS NO TANQUE "CLASSE A" E NO MÉTODO DE PENMAN
}

\author{
ITALO AUGUSTO DE SOUZA ALBERIO \\ Engenheiro-Agrônomo \\ Auxiliar do Ensino da FCAP
}

Orientador: Nilson Augusto Villa Nova

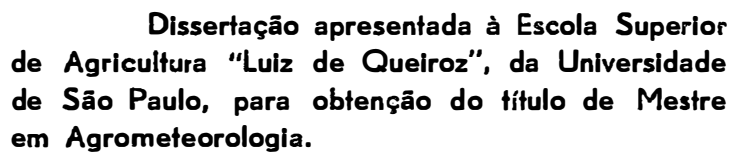

PIRACICA B A

Esłado de São Paulo - Brasil

Maio, 1979 
ii.

Aos meus queridos pais,

pela educação que me con

cederam e a quem devo 0

que sou como HOMEM,

a minha GRATIDÃO

A minha filha MELISSA, meu "tesouro", à com preensão de minha. esposa VIRGILIA e ao incentivo do meu mano CARLITO, 
No ensejo da conclusão do presente trabalho, quero agradecer às seguintes pessoas e entidades:

Primeiramente a DEUS, por ter-me concedida força e paz para a realização deste trabalho;

Ao Professor Dr. Nilson Augusto Villa Nova, pe la orientação precisa e estímulo às idēias aquí apresentadas; Ao Professor Dr. Jesus Marden dos Santos, Coordenador do Curso de Pós-Graduação em Agrometeorologia, pelos esclarecimentos;

Ao Professor Dr. Hermano Vaz de Arruda; da Sec ção de Climatologia do Instituto Agronômico de Campinas, pelá orientação na análise estatística dos resultados;

Aos demais professores do Departamento de Fí sica e Meteorologia e de outros Departamentos, que de alguma forma contribuiram para a minha formação;

Ao Departamento de Física e Meteorologia, pela cessão de seus instrumentos e da área experimental;

À Faculdade de Ciências Agrärias do Parä-FCAPà Escola Superior de Agricultura "Luiz de Queiroz"-ESALQ- e ao Programa de Ensino Agrícola Superior-PEAS-, pela oportunidade oferecida;

Aos Engenheiṛos Agrônomos Genário Josẻ da Mata, Carlos Ramires Franco da Encarnação e José da Silva Lemos, pe la colaboração e ao Engenheiro Florestal José Altino Scardua, pelas sugestões;

Ā funcionāria Āurea Benedita Michelotto, pela colaboração durante o Curso;

Aos demais colegas, pela convivência amiga. 
1. RESUMO ........................... I

2. INTRODUÇÃO . . . . . . . . . . . . . 3

3. REVISÃO DE LITERATURA . . . . . . . . . . . 6

4. MATERIAL E MÉTODOS . . . . . . . . . . . 19

4.1. Material . . . . . . . . . 19

4.1.1. Medida da Evaporação . . . . . . 19

4 Tanque "Classe A" (ECA) . . . . . . 19

Tanque "Classe A" sifonado (ECAs) . . $\quad 21$

4.1.2. Medida da Evaporação à sombra' . . . 21

4.1.3. Medida da Evapotranspiração . . . . 25

Evapotranspirômetros........ . 25

4.1.4. Elementos de Clima . . . . . . . 25

4.2. Mëtodos .............. 27

4.2.1. Medida da Evaporação . . . . . 27

Tanque "Classe A" (ECA) . . . . . 27

Tanque "Classe A" sifonado (ECAs) ... . 28

4.2.2. Medida da Evaporação à sombra . . . 29

4.2.3. Efeito da temperatura da água de recarga 29

4.2.4. Medida da Evapotranspiração . . . . 29

4.2.5. Estimativa da Evaporação . . . . . 30

4.2.6. Estimativa da Evapotranspiração . . . . .32

4.2.7. Elementos de Clima........ . 33

5. RESUltAdOS E DISCUSSÃO : : . . . . . . . . . 34

5.1. Relativos às medidas de Evaporação pelo tanque "Classe A" tradicional (ECA) e com a modificação proposta (ECAs) . . . . . . •

5.2. Relativos à utilização do evaporímetro Piche na estimativa do componente aerodinâmico da fórmula de Penman . . . . . . . . . . .

5.3. Relativos ao confronto entre a Evapotranspi ração potencial estimada pelo método de Penman simplificado e a Evapotranspiração potencial medida . . . . . . . . . . . . 
5.3. Relativos ao confronto entre a Evapotranspi ração potencial estimada pelo método de Penman simplificado e a Evapotranspiração potencial medida . . . . . . . . . . . .

5.4. Relativos ao teste da equação do termo aero dinâmico proposta por Penman para a estimativa da Evaporação da āgua e sua aplicabilidade às condições locais . . . . . . . . . . .

5.5. Relativos aos coeficientes determinados para a relação Evaporação estimada/Evaporação me dida . . . . . . . . . . . . . .

5.6. Relativos à marça da Evapotranspiração po tencial diāria para o periodo Fevereiro/Março em Piracicaba . . . . . . . . . . . .

5.7. Relativos à utilização do tanque "Classe A"si fonado na determinação da Evapotranspira ção potencial . . . . . . . . . . . . 75

6. CONCLUSÕES . . . . . . . . . . . . . . . 77

7. SUMMARY . . . . . . . . . . . . . . 79

8. LITERATURA CITADA . . . . . . . . . . . . 81

9. APENDICE ................ . . 86 
1. RESUMO

0 presente trabalho teve por objetivo o estudo sobre simplificação de métodos de medida e de estimativa, tanto da evaporação da água como da evapötranspiração, baseados em tanque "Classe A", no mëtodo de Penman e em evapotrans pirômetros.

Desenvolveu-se um sistema de medidas para 0 tanque "Classe A", em que sifões em paralelo mantem o mesmo nível da água a cada recarga diária, minimizando erros . pela simplificação da leitura sem perda da precisão, reduzindo o custo do equipamento.

Apresentou-se, tambēm, uma simplificação da equação de Penman para a estimativa da evaporação da água.e da evapotranspiração potencial, de modo a permitir o emprego do método em regiões caṛentes dè equipamento, servindo-se do évaporimetro Piche para a determinação do componente aerodinâmico, resultando nas seguintes equações para a região de Piracicaba:

$$
\begin{aligned}
& \text { (p/evaporação) } \frac{E a V}{\frac{\Delta}{\gamma}+1}=0,115+0,101 \text { E Eiche } \quad r^{2}=0,943 \\
& \left(p / \text { evapotransp:): } \frac{\frac{E a T}{\Delta}+1}{\frac{\gamma}{\gamma}+1} .\right.
\end{aligned}
$$


Os coeficientes entre a evaporação estimada pe lo método de Penman, tanto na sua forma original como na sim-.. plificada e os tanques "Classe A" tradicional e simplificado, mostraram-se coerentes com os resultados encontrados por OLIVEIRA (1971).

Discutiu-se, ainda, a equação indicada por Pen man para a estimativa do têrmo aerodinâmico na sua forma original, em teste que se realizou com o tanque "Classe A." sifonado, dando-lhe condições de sombreamento.

Por fim, confrontou-se valores de evapotranspi ração estimada pelo método de Penman simplificado com os medidos nos evapotránspirômetros, para um melhor juizo do compon tamento da modificação proposta. 


\section{INTRODUÇÃO}

A passagem da āgua do seu estado líquido para o de vapor, constitui o fenômeno físico da evaporação.

Na natureza, o termo evaporação se aplica ao fenômeno que ocorre de perda de ägua por superfícies tais co mo lagos, rios, oceanos, etc e por superfícies porosas como o solo; entretanto, a perda de água pelo solo não ocorre apenas atravēs da superfície, mas tambëm atravēs da epiderme vegetal, recebendo nesse caso a denominação de transpiräção, muito embora, fisicamente, o processo ocorra de maneira semelhante.

A perda de ägua pelas plantas, incorrendo na diminuição das reservas do solo, se constituiu numa das preocupações dos fisiologistas e agrometeorologistas, uma vez que o elemento ảgua se faz necessärio em quantidades variä veis durante o ciclo de uma cultura e a reposição pela natureza, via de regra, não se faz com a devida regularidade:, havendo necessidade de frequente suplementação com água atravēs de irrigação a fim de que não haja reflexo: negativo no produto final.

Grande número dè estudiosos têm proposto mo delos para a estimativa da evaporação da água, baseados em leis físicas, bem como têm dessenvolvido instrumental numa 
tentativa de obter valores que melhor representem o fenômeno em questão, apresentando todos, vantagens e desvantagens; as förmulas desenvolvidas, trazem, quase sempre, o inconveniente de somente se aplicarẹ com exatidão à região cujos dados serviram de base, com caracteristicas peculiares de clima e topografia, não sendo prudente generalizar para outras regiões de condições totalmente diversas daquela. Por outro la do, o instrumental preconizado ê de instalação dispendiosa a nível de agricultor e atê certo ponto, de difícil manutenção por pessoal não habilitado.

A viabilização de qualquer projeto de irrigação è a maior justificativa para o conhecimento da dotação correta de água.

De todas as fórmulas de estimativa da evapo ração, uma das mais aceitas ê a de Penman (1963), que apre senta limitações em sua áplicação para regiões onde não existem medidas de velocidade do vento, tomadas ao nivel de 2,0 m acima da superfície do solo.

Os instrumentos de medida de evaporação, por sua construção simples e facilidade operacional, têm sido bastante empregados na determinação tanto da evaporação como da evapotranspiração, desde que, para este caso, se aplique um coeficiente adequado a cada cultura.

Dentre os evaporimetros destaca-se o tanque "Classe A", que se constitue em veículo de controle da àgua a ser aplicada por irrigação. Aos valores medidos da evapo ração aplica-se um coeficiente de correção, variāvel conforme o estágio de desenvolvimento da cultura.

No manuseio do tanque "Classe A", verifica-se, na prâtica, que o sistema de medidas com micrômetro é de difícil operação no campo, quando operado por pessoas não qualificadas. Alēm disso, outros cuidados deverão ser levados em conta, tais como o perfeito nivelamento do poço tranqui lizador, os erros devidos ao reabastecimento, os quais poderão introduzir mais incorreções nessas medidas. 
Vale lembrar que o alto custo dos accessórios necessärios ao uso do tanque "Classe A", tem desestimulado a aquisisção e o uso deste equipamento pelo agricultor.

Assim sendo e tendo em vista as restrições re lativas ao emprego da equação de Penman, as dificuldades de operação e o custo deste evaporimetro, os objetivos princi pais do presente trabalho foram:

a) desenvolver um novo sistema de medidas de evaporação para o tanque "Classe A", facilitando a leitura sem a perda da precisão, reduzindo o custo do conjunto;

b) contribuir para o estudo das relações en tre a evaporação do tanque "Classe A" e a evapotranspira ção potencial;

c) estudar a simplificação da equação de Penman. para a estimativà da evaporação da ägua e da evapotranspirração potencial, utilizando o evaporỉmetro Piche na determinação do componente a erodinâmico;

d) verificar a viabilidade de aplicação da expressão clássica de Dalton para a estimativa da evaporação da ãgua, atravēs da adaptação dos seus parâmetros às condi ções locais. 
Os estudos sobre a evaporação da ägua de superfícies naturais e a transpiração vegetal tem se constituido uma das preocupações de tẻcnicos e pesquisadores, sobretudo para fins de planejamento de êpoca de plantio e de suplementação da ägua a.travẻs de irrigação, principalmente em regiões assoladas por longas estiagens.

Segundo ROSENBERG (1974), do total de àgua re tirado do solo pelas plantas, apenas $1 \%$ é utilizado nas atividades metabôlicas, sendo o restante perdido para a atmos fera sob a forma de vapor pelo processo da transpiração, vaIor esse, segundo o pesquisador, de difịcịl determinação no balanço de ägua do solo pelo mëtodo hidrológico, dado prin cipalmente à dificuldade de medidas nos termos de escoamento superficial e de variação do volume de ăgua em um intervalı de tempo.

As têcnicas de medida e de estimativa da per- . da de ägua, desde as primeiras tentativas, tem sofrido modificações; equações tem sido propostas, umas baseadas em leis ficisas, umas empiricas e outras semi-empiricas, jpocurando solucionar o problema; instrumental tem sido desenvolvido, nas mais variadas formas, tamanho, material, cor e sistema de medidas com o fim precípuo de tornar mais fäcil a operação e menos dispendiosa a instalação. 
Sobre a evapotranspiração potencial, Penman em 1956 jä modificava o conceito de Thornthwaite-1944 que a havia definido como "a perda de água de uma superfície de solo. üido, completamente vegetado e suficientemente grande para tornar desprezível o efeito de oäsis", criando o conceito de transpiração potencial como "a perda de água por transpira ção na unidade de tempo por uma cultura de porte baixo e altura uniforme, cobrindo totalmente o solo em ótimas condi ̧̧ões de umidade". Segundo Penman, para uma cobertura homogênea, subentendendo mesmo albedo, a taxa de transpiração potencial è a mesma, independentemente do tipo de planta ou de solo, sendo regida apenas pelas condições de clima. ASSIS (1978).

A velocidade de perida de água por uma super ficie vegetada, sabemos, depende dos fatores meteorolögicos e aerodinâmicos relacionados com a arquitetura da comunidade de plantas, corno tambëm das propriedades físicas do solo e de seu teor de umidade.

Abordando aspéctos dinâmicos da disponibili dade de água no solo, DENMEAD e SHAW (1962) concluiram que, à medida em que diminui a umidade do solo, a transpiração:a-tual cai atê um valor abaixo da transpiração potencial.

Seguindo a mesma linha dos pesquisadores acima; EAGLEMAN e DECKER (1965) relacionando a umidade do solo com a taxa de evadotṛanspiração potencial, observaram infiluências das flutuações da demanda evaporativa da atmosfera sobre a taxa de evapotranspiração atual; verificaram ainda que, ao contrário do que foi sugerido por Thornthwaite, a taxa de evapotranspiração não segue uma função reta quando a umidade do solo baixa até uma tensão de -15 atmosferas, sendo regida porém por uma função curvilinea.

0 albedo é outro elemento que afeta a evapo transpiração, de acordo com SEGINER (1969), de modo que a variação do albedo da superfície evaporante implicará numa modificação das condições de refletividade, um dos artifíci- 
os empregados para reduzir a perda de água. A ünica preocupação de alguns técnicos tem sido a de diminuir essa perda de água sem se importar com o conhecimento das quantidades, - que tambêm è de suma importância. 0 albedo e a umidade existente na superficie são dois fatores que regulam a evapotranspiração, estando intimamente ligados; esse fato foi cons tatado experimentalmente, quando para um aumento de energia refletida da superfície em 1,75 mm em equivalentes de āgua e vaporada, a redução na evapotranspiração chegou atẻ 1,00 mm emrregiões ümidas,

Vários pesquisadores vem estudando o albedo de superficies vegetadas. SELLERS (1965) indicou para albedo de pastagens verdes, valores variando entre 0,10 e 0,20 e PENMAN', (1963), citando Monteith, indicou para superficies vegetadas com grama, um albedo mẻdio de 0,25 para efeito de introdução no cálculo do balanço de energia.

SANTOS (1957), entretanto, estudando novas têcnicas para à determinação do albedo de superfícies, tra balhando com grama Batatais (Paspalum notatum, Fluegg) e u tilizando-se de um espelho parabölico com um :pirheliômetro Eppley colocado em seu foco e outro na parte externa, determinou o albedo para aquele tipo de cobertura, com um ivalor mëdio de 0,17 , bastante coerente com o limite superior tabelado por sellers e já mencionado.

Estudando a energia empregada no processo de evapotranspiração, TANNER e LEMON (1962) verificaram que a maior fração do balanço de energia è bipartida entre o calor latente destinado a evaporar a água e o calor sensivel des tinado a aquecèr o ar: a distribuição desses valores, porêm, está condicionada à disponibilidade de água a evaporar, de modo que quando a superfície se encontra úmida, a parte destinada ao aquecimento do ar è pequena em relação à que se destina à evaporação da água; como a água se constitue em um dos fatores limitantes à evapotranspiração, à medida em que o solo seca, há uma forte tendência em diminuir a taxa de 
perda de água; se, entretanto, as plantas estão supridas convenientemente de água e por alguma razão de ordem bidlógáca restringem a passagem de água para a atmosfera, ou por ou = tro lado, a água se encontra em indisponibilidade para as plantas, a maior fração de energia radiante è convertida em calor sensivel, em detrimento da evapotranspiração; uma atenção especial deve ser dada ao calor sensível de adveç̧ão, . - qual afeta a evapotranspiração em locais onde a água se constitui um fator limitante.

LEMON et alii. (1957), abordando aspéctos de solo, planta e fatores meteorológicos influenciando na eva potranspiração, concluiram que a radiação líquida representa realmente a quantidade de energia disponível aos processos ra diativos que ocorrem na superfície, porém essa perda não pode ser estimada unicamente através. desse parâmetro e sim relacionando-o com a tensão de umilade do solo e com o modo com que a planta atua sobre o sistema de transferência de água pa ra a atmosfera.'

FRISTSCHEN e SHAW (1966) referiram-se a al guns métodos de estimativa da evapotranspiração, dividindo -os em três (3) grupos: um primeiro grupo dos que dependem do conhecimento dessa energia disponível ao processo, um segunque emprega simplesmente valores de temperatura como uma medida da.quantidade de energia e um terceiro que faz empre go de evaporimetros dos mais diferentes tipos. Comparando valores de evapotranspiração (ET) em milho pelos métodos de estimativa com valores de evaporação (EV) fornecidos por tan ques, verificaram que a relação ET/EV variou consideravel mente à medida em que variou a densidade do plantio, principalmente em āreas onde o termo advectivo era grande. Esse fa to, concluiram, não deverá ser tomado de imediato como.ver dadeiro, porém merece um estudo mais profundo sobre espaça mentos, fases da cultura e estado fitossanitärio.

Preocupados com os aspéctos meteorológicos da evapotranspiração, HALSTED é COVEY (1957) alertaram para a 
existência de possĩveis fontes de erro, comuns a uma sêria de equações empíricas e semi-empiricas; a parte crittica do estudo se resume na análise das frações de radiação líquida em pregada na evaporação da água e no aquecimento do ar e do solo a qual, além de depender da disponibilidade de água ao pro cesso, é influenciada pelas propriedades térmicas do solo, pela turbulência e pela razão de mistura dentro da comunida de vegetal e sobre a mesma. Durante o dia, quando o ar esitá sendn aquécido, a evapotranspiração atual è menor do que a diferença entre a radiação I Iquida e a fração destinada ao a quecimento do solo; considerando entretanto uma área irri gada, o ar cederá calor para o solo e assim o valor da eva potranspiração crescerá em relação à radiação lỉquida equi -. valente.

$$
\text { van BAVEL e HILLEL (1976) realizaram estu }
$$

dos numëricos atravês dós quais verificaram que o balanço de energia na superficie de um solo nu e o transporte de calor e de água tanto na camada limite superficial como no isolo, são combinados para fornecer a tax̀a de perda de água por evaporação. A principal conclusão foi o fato de que o conceito histörico de evaporação potencial é impreciso, uma vez que a taxa de evaporação de uma superfície de solo úmido pode variar de mais de $10 \%$, dependendo das propriedades daquele solo.

Estudando a cultura do milho, PETERS (1960)'re alizou medidas com o fim de dectar a magnitude dos fenômenos de evaporação e evapotranspiração, chegando à conclusão de que, em média, o solo nu é responsável pela metade da perda de água em um campo cultivado; entretanto, deve-se conside rar que tais medidas foram efetuadas em periodo submetido a frequantes chuvas, mantendo o solo constantementr ümido; outrossim, a cobertura de plástico utilizada para protege o solo do campo cultivado deve ter, he algum modo, alterado o albedo da superfície, modificando a temperatura do solo e, evidentemente, as condições de troca radiativa na cultura: as- 
sim considerando, a transpiração atual não deverâ representar a realidade da transpiração que poderia ocorrer em condições normais.

Thornthwaite em 1948 desenvolveu esforços no sentido de obter um modelo de estimativa da evapotranspiração potencial. o seu método pretende estimar a evapotranspiração potencial mensal, utilizando apenas valores de temperatura, em que a ETP mensal è dada por ETP $=C \cdot t^{a}$, onde $\underline{C}$ e a são constantes e $\underline{t}$ è a temperatura média do mês; a partir desse modelo, o autor chegou à seguinte expressão:

\section{ETP mensal $=1,6(10 \overline{\mathrm{T}} / \mathrm{I})^{\dot{a}} \mathrm{em} \mathrm{mm}$}

onde $\mathrm{T}$ pe a temperatura mëdia do mês ern $9 \mathrm{C}$, I é um indice de calor resultante da șomatöria dos indices $\underline{i}$ mensais durante o ano e calculados segundó a expressão:

$$
i=(\bar{T} / 5)^{1,514}
$$

e a ê uma função cúbica de I, calculado segundo a expressão:

$$
a=6,75 \cdot 10^{-7} \cdot I^{3}-7,71 \cdot 10^{-5} \cdot I^{2}+I, 79 \cdot 10^{-2} \cdot I+0,49
$$

de câlculo tedioso, muito embora para alguns locais os valores encontrados tenham se ajustado bem conforme Leeper em 1950 e Sanderson em 1950, citados por ROSENBERG (1974). Tem-se, entretanto, conhecimento da existência de tabelas, ' as quais vieram simplificar sobremaneira a utilização desse método.

PENMAN (1948, 1952, 1956, 1963) propôs um modelo teórico-empírico para a estimativa da evaporação de gran des superfícies de água, posteriormente adaptado por outcos autores para a estimativa da evapotranspiração e no qual envolve dois termos distintos: um energêtico, implicando. no " conhecimento da energia líquida disponivel na superfície e um termo aerodinâmico, implicando no conhecimentr da velocidade mêdia do vento e do défice de saturação de vapor no ar. Bàsicamente, o método de. Penman diz que: 
EV ou ETP $=\frac{\frac{\Delta}{\gamma} \cdot H}{\frac{\Delta}{\gamma}+1}+\frac{E a}{\frac{\Delta}{\gamma}+1}$ em $\mathrm{mm}$

ondes representa a tangente à curva de saturação de vapor em mmHg/oC, $\gamma \vec{e}$ a constante psicromëtrica em mmHg/oC, H è a radiação líquida disponível ao processo e resultante do balanço de energiz e Ea, calculado empiricamente, è função da velocidade do vento e do dëfice de saturação e dado em $\mathrm{mm}$.

PENMAN (1963) indicou para a determinação do termo Ea, quando se trata de estimar a evaporação da ägua, a seguinte expressão:

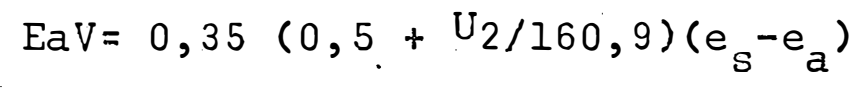

e para aplicação da sua equação à estimativa da evapotrans piração potencial (para superfỉcies rugosás como uma super fỉcie vegetada) o autor indicou para a determinação do termo aerodinâmico a expressão abaixo:

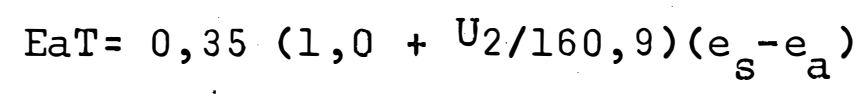

e nas quais, $U_{2}$ representa a velocidade média do vento em km.dia-l e $\left(e_{s}-e_{a}\right)$ representa o défice de saturação de vâ por em mmHg.

van BAVEL e HARRIS (1962) estudaram uma sim plificação, para tornar mais prätico o emprego da förmula de Penman, em que sugeriram duas modificações na determinação đo termo energético e compararam os resultados obtidos com me didas efetudas em lisímetros de percolação, uns plantados com grama rasteira e outros com milho. Nessas comparações, veri ficaram os autores que, de um modo geral, todas as estimati vas concordaram com os valores medidos, considerando um lon go período. Numa das modificações, sugeriram que se substi tuisse $\mathrm{O}$ valor de $\mathrm{H}$ (balanço de energia) por 0,8 $\mathrm{H}$, uma vez 
que em média, postularam os autores, apenas $80 \%$ da energia liquida disponivel è empregado no processo da evapotranspi ração.

0 método de Penman para a estimativa dos processos em apreço, encontra entretanto certas limitações em regiões com estações meteorolögicas carentes de equipamentos. Esse fato levou VILLA NOVA e OMETTO (1975) a. estudar uma simplificação do referido método para diversas localidades do Estado de São Paulo; as modificações propostas para o mëtodo de Penman resultaram em duas equações simplificadas para a estimativa da evapotranspiração potencial e duas outras para a estimativa da evaporação potericial, nos períodos de Primavera-Verão e Outono-Inverno, empregando o evaporỉmetro Piche na deṫerminação do componente aerodinâmico e tornando mais prātica a expressão para a determinação do termo energético, resultando no seguinte modelo:

$$
\text { ETP ou EV }=\frac{\Delta}{\Delta+\gamma} Q_{O}(a+b n / N)+\Omega E_{\text {piche }}
$$

vâlido para locais de clima semelhante ao das regiões consideradas ou moderadamente seco; nesse modelo, $\Delta$ e $\gamma$ têm os mesmos significados mencionados anteriormente, $E_{\text {piche }}$ representa a evaporação ocorrida no evaporỉmetro Piche e $\Omega \vec{e}$ um fator de conversão para esse evaporimetro a fim de se esti mar a contribuição do vento e do défice de saturação. Sim. plificada dessa maneira, o método de Penman passa a prescindir de dados de umidade relativa e de velocidade do vento, sendo indicada para regiöes em que não existem estações completas.

Segundo PRUIT (1966), o emprego de evaporimetros no estudo da relação entre a evapotranspiração de uma área gramada com a evaporação de superfícies de água é bas tante vâlido; torna-se, porēm, necessärio, que se domine bem - conhecimento de certos fatores tais como a forte adveç̧ão existente atuando na relação ET/EV, o que vem a demanstrar 
que o emprego de tanques se constitui apenas em uma ferramen ta a mais, de modo que, para cada local, com caracteristica prôprias de clima, torna-se necessânio uma adequação dos e= quipamentos de medida. .

0 emprego de lisimetros e de evapotranspirinô metros tem sido difundido em aplicações práticas, of erecendo resultados representativos do consumo de água pelas culturas .. SLATYER e MCILROY (1961), destachram ques. um lisimetro convenientemente construido e operado, se constitui sem dưvidas no meio mais real, direto e prociso de se medir a evapotranspirinação.

RITCHIE e BURNETT (1968), traballhandn com um lisimetro para medidas de consumo de àgua, verificaram que quando o conjunto era submetido a um periodo de escassez de ăgua, mostrou-se bactante eficiente nas medidas de fluxo para pe-uenos periodos, havendo porēm uma grande influência do vento no seu funcionamento, fato esse, segundo os autnres, já constatado por van Bavel e Myers em 1962 e Pruit e Angus em 1960 .

ENGLAND (1963), com um lisimetro modificado a partir de um tanque evaporimétrico montado sobre um sistema de pesagem, obteve medidas com uma preçisão de 0,125 mn de evapotranspiração. Efetuando leituras ao nascer e ao por do sol durante três ( 3 ) anos de observação, verificou uma variação nos valores médidos dia a dia, função da variação dos períodos diurnos.

HANS e SHAWCROFT (1965) trabalharam com um li simetro com principio de funcionamento baseadn na variação de peso; entretanto o sistema se via afetado pela temperatura e pela tração durante longos períodos, o que provocava erros de medida.

Na India, DAGG (1970) trabalhou com lisimetro hidráulico na medida da evapotranspiração de uma cultura de chá; pelos resultados obtịdos pode-se assumin que o sistema funcionou bem, mostrando-se capaz de fornecer dados consis - 
tentes.

EKERN (1966) estudando a evapotranspiriração de grama Bermuda (Cyriodon dactylon, L.Pers.) em lisimetros, ve= rificou que sob altas taxas de evapotranspiração potencial, o uso consumeivo pela vegetação foi aproximadamente iguạ loo valor de evarporação dado pelo tanque "Classe A"quando o solo se encontrała próximo da capacidade de campo. Entretanto, à medida em que diminuia a umidade, a relação evapotranspira ção potencial/evaporação do tanque "Classe A" também diminu=. . ia, variando de uñ máximo de 1,1 a um mínimo de 0,33 , eviden ciando a dependência da água pela cultura e a utilidade da quele evapoximetro na determinação da evapotranspiração po tencial, desde que se aplique um coeficiente de correção con forme o grau de umidade do solo.

No Brasil, CAMARGo (1966) realizou estudos so bre evapotranspiração potencial em três (3) localidades do Éstado de São Paúlo, empregando evapotranspirômetros de pệcolação nos quais plantou grama Batatais (Paspalum notatum, Fuegg)comparando os valores medidos com quatro diferentes mé todos de estimativa. Constatou que os valores se "' mositraram consistentes com aqueles estimados pelos mëtodos de Thornthwaite e de Blaney e Criddle modificado. Confrontando os valores medidos com os estimados pelos métodos de Penman-Bavel e de Blaney e Criddle original, verificou uma discrepância,en tre os mesmos: os mêtodos em questão, indistintamente, so brestimavam os valores no periodo hibernal e subest mavam no período estival.

Posteriormente, ORTOLANI et alii (1966) verificaram que o mëtodo de Penman sobrestima o fenômeno em apenas $2 \%$, enquanto que 0 .de Thornthwaite na realidade os subes tima en cerca de $9 \%$.

Em Piracicaba, ASSIS (1978) trabalhou com e vapotranspirômetros com sub-irrigação, empregando um alimentador para três unidades. Ao alimentador foi adaptado um sistema de registro contínuo. 0 conjunto mostrou grande sen- 
sibilidade, com precisão aceitãvel para fins präticos, șendo que o sistema de registro permitiu avaliar a marcha da eva = potranspiração potencial, atravês da determinação de valoṛes de $\Delta E T P / \Delta t$.

Com referência à evaporação de superfícies de âgua, WARTENA e BORGHORST (1961) constataram que a evapora = ção ocorrida em tanques, está intimamente ligada às condi ções de temperatura do solo e de nebulosidade. Esse fato levou-os a realizar estudos nos diferentes termos dobalanço de energia em um tanque "Classe. A", observando que, do total de energia incidente que penetra na água, $8 \%$ da radiação de onda curta é refletida e particularmente a radiação difusa è refletida pelo fundo do tanque.

FITZPATRICK e STERN (1966) verificaram a viabilidade da simplificação do método de Penman para a estimativa da evaporação de superfícies de água. Segundo os auto res, tanto o teṛmo energético como o aerodinâmico poderão ser estimados empiricamente, baseados respectivamente na relação "horas de insolação/duração do período diurno" ( $n / N)$ e nos valores obtivos com o evaporimetro Piche.

STANHILL (1962) correlanionou valores de eva-. poração obtidos com o evaporimetro Piche àqueles da fração a erodinâmica da equação de Penman, résultando numa equação do tipo "y= $a+b x "$. A contribuição do vento e do défice de saturação, estimada dessa maneira, apresentou uma diferença de aproximadamente 15\%. Assim, o emprego desse método na estimativa da evaporação de superfícies de água, tornou-se acessível a inümeras regiões carentes de anemômetros instaladosia 2,0 m da superficie do solo.

0 emprego de förmulas empiricas para a esti mativa da evaporação de superfícies de āgua para qualquer re gião não parece ser aconselhävel como bem demonstra BURMAN (1976), que comparou valores medidos pelø tanque "Classe A" com os estimados por três (3) mëtodos de estimativa, constatando que alguns deles, em certas localidades sobrestimam os valores medidos enquanto que em outras ocorre 0 inverso. 
valores medidos enquanto que em outras ocorre o inverso. Muito embora destaque o mëtodo de Penman como dos que mais fielmente exprimem a evaporação de superfỉi * es, de ăgua, LINACRE (1977) propôs um método bastante simples no qual emprega apenas valores de temperatura média do ar e temperatura do ponto de onvalho, com o objetivo de atender re giões onde não existam elementos que permitam o emprego de um método mais completo como o de Penman. Desse modo, com o mes mo modelo, variando apenas o valon do albedo e alguns coeficientes; o método se aplica à estimativa da evaporação e da evapotranspirnação.

BRUTSAERT e YEH (1970) comentaram sobre o emprego: de métodos empiricos de transporte de massa em lagos e em tanques: de evaporação ao nỉvel do solo, e em que pese as limitações inerentes a cada um, ainda se constituem nos prin cipais meios: de estimativa de evaporação de superfícies de $\underline{a}$ gua, especialmente em regiões carentes de equipamentos específicos. Tais fö́rmulas, entretanto, deverão ser devidament e adaptạdas à região para uma melhor avaliação do fenômeno.

Os evaporimetros têm sïdo usados como indicador da necessidade hidrica de culturas, com excelentes resul tados, como: $\vec{e}_{0}$ caso do tanque "Classe A", a ponto de serem recomendados: como método de maior viabilidade prática na estimativa da frequência e da quantidade de aplicação de âgu a aṭ̣avês: da irṛigação, conforme DOORENBOS e PRUIT (1975).

Ainda que apresente vantagens sobre outros evaporimetros; como bem se refere GANGOPADHYAYA et alii (1966) - emprego do tanque "Classe A" traz certos inconvenientes co mo a quantidade de energia direta e difusa recebida em suas paredes e a existência de obstäculos em sua proximidade os qua is alteram o comportamento do vento, interferindo na. representatividade dos valores medidos.

HANSON e RAUZI (1977) observaram que obstäculos prọximos ao tanque "Classe A", provocaram uma redução de cerca de $15 \%$ na evaporação. Éssa redução verificou-se devido 
à diminuição na velocidade do vento, muito embora a turbulência originada tendesse a compensar aquele efeito.

OLIVEIRA (1971) realizou estudos sobre o comportamento dos tanques "Classe A" e "GGI-3000" em diferentes condições de exposição e com a adaptação de coberturas de tela, relacionando os valores b́btidos com os estimados segundo o método de Penman. Os coeficientes mensais entre a evaporaçã o estimada e a evaporação medida pelo tanque "Classe A" varia ram de 0,70 a 0,89, com uma média anual de EVPen/ECA de 0,76 para a região de Piracicaba.

CAMPBELL e PHENE (1976) adaptando cobertura de tela com o fin de evitar o consumo de água do tanque "Classı. A" por animais, observaram que os valores medidos foram menores do que os valores da evapotranspiração em cerca de $2 \%$

A simplificação do sistema de leitura desse evaporimetro tem sido o objetivo de muitos pesquisadores como PHENE e CAMPBELL (1975), o que levou ASSIS (1978) a efetuar modificações no sistema de medida do tanque "Classe A" rom a vantagem de o mesmo funcionar a nível. constante e apresentar seu sistema de leituras em escala graduada bem mais simples;do que no micrômetro, apresentando correlação altamente significativa com o sistema tradicional. 
4. MATEREAL E MÊTODOS

Os valores utilizados no presente trabalho foram coletados na estação meteorológica do Departamento de Física e Meteorologia da Escola Superion de Agricultura "Lu= iz de Queiroz", na cidade de Piracicaba, Estado de São Paulo na possição de: $\cdot$

\section{Latitude $(\phi): 22943 ; 0$ 's \\ Longitude $(\lambda)$ : $047938,0^{\circ} \mathrm{W}$ \\ Altitude (Alt) : $576 \mathrm{~m}$}

no período de 01.06.1978 a 04.03.1979.

A Figura 1 representa a planta da situação ge ral da ärea em que fọi conduzido o trabalhọ.

4.1. Material

4.1.1. Medida da Evaporação

Os valores referentes à evaporação da ägua foram obtidos em evaporimetros com as seguintes caracteristi cas:

- Tanque "Classe A" (ECA) = tanque cilindrico construido em chapa galpanizada no 22 (AWG), com $120,0 \mathrm{~cm}$ de diâmetro e 25,0 cm de profundidade, tendr como accessörios para as medidas, um poço tranquilizador convencional nivelado por três (3) parafusos e um micrômetṛo capaz de medir variações do nîvẹl da âgua de até $0,02 \mathrm{~mm}$; tal micrômetro fị- 

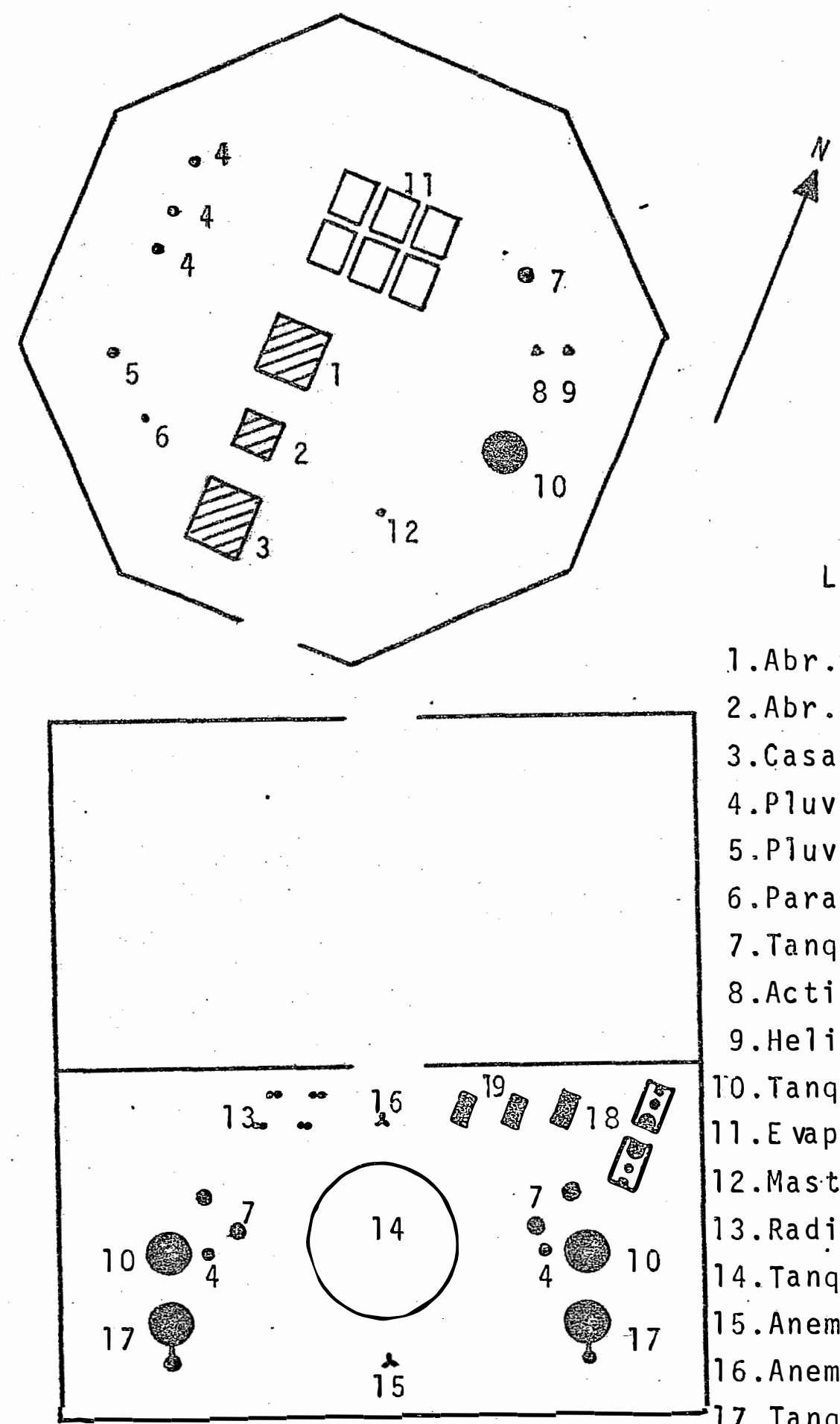

\section{LE GENDA}

1. Abr.meteorolögico

2. Abr.anemögrafo

3. Casa do observador

4.Pluviōmetros

5.PIUviografo FUESS

6 .Para-raios

7. Tanque GGI-3000

8. Actinōgrafo

9. Heliógrafo

10. Tanque Classe A

11. E vapotranspirômetros

12. Mastro

13. Radiômetros evaporm. 14. Tanque $20 \mathrm{~m}^{2}$

15. Anemômetro a $2,0 \mathrm{~m}$ 16. Anemömetro a $0,5 \mathrm{~m}$ 17. Tanque Classe A sif. 18. Evaporimetro de solo 19. Abrigos termométric.

FIGURA I- Planta baixa da ärea em que foi conduzido o experimento. 
rịações dọ nịvel da água de até $0,02 \mathrm{~mm}$; tal micrômetro fica assentâdo sobre o poço tranquilizador por ocasião da to= mada de leitura. Esse tanque está assentado sobre um estrado de madeira pintado de branco, com a superfície a $15,0 \mathrm{~cm}$ do solo, Detalhes na Figura 2.

- Tanque "Clásse A" sifonado (ECAs) - Tanque cillindrico, com as mesmas caracteristicas do anterior.

Esse tanque apresenta uma modificação no seu sistema de medidas de evaporação, como é mostrado com deta lhes nas Figuras 3 e 4 . 0 reabastecedon è construido do mesmo material do tanque, com diâmetro de $27,0 \mathrm{~cm}$, pintado de bran co, tendo pela parte externa em toda a sua altura um tubo de vidro, indicador do nível da água, devidamente acoplado a uma escala graduada em milímetros de água evaporada do tanque, oferecendo deșe modo uma leitura direta, com precisão; de $0,1 \mathrm{~mm}$, suficiente para fins práticos; um tubo de cobre, acompanhando o fundo do tanque, conduz a água do reabastece dor até o centro do evaporimetro e dispõe de uma cobertura a fim de amortecen o jato de água por ocasião da operação; a uma altura de $19,5 \mathrm{~cm}$, um conjunto de 11 sifões em paralelo, tendo a extremidade interna protegida por um poço tranquilizador de duplo fundo (câmara de sifonação), fornece a refe rência de nível. Tal como o tanque "Classe A", este tambêm es. tá assentado sobre um estrado de madeira com a mesma altura; a relação "área do reabastecedor/ārea do tanque" è de 1:20. Ambos os evaporimetros estão representados pors duas (2) unidades.

4.1.2. Medída de Evaporação à sombra

A medida de evaporação à sombra foi tomada adaptando-se a uma das unidades do tanque "Classe A" sifona do, durante os últimos três meses de trabalho, uma cobertura de lençol plástico com superfície refletora branca e com as seguintes dimensões: $2,0 \mathrm{mX} 3,0 \mathrm{~m}$; essa cobertura era : suportada por quatro (4) piquetes a uma altura de $50,0 \mathrm{~cm}$ da 


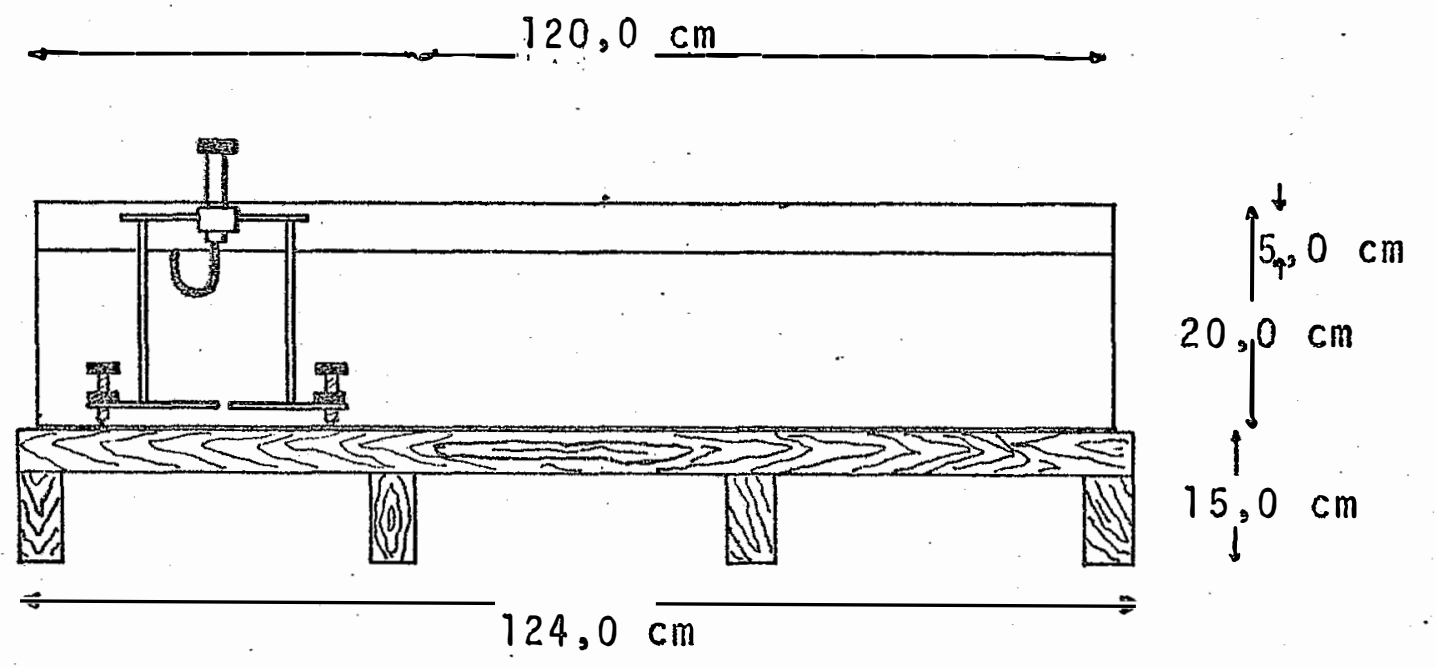

VISTA dO TANQUE "Classe A".

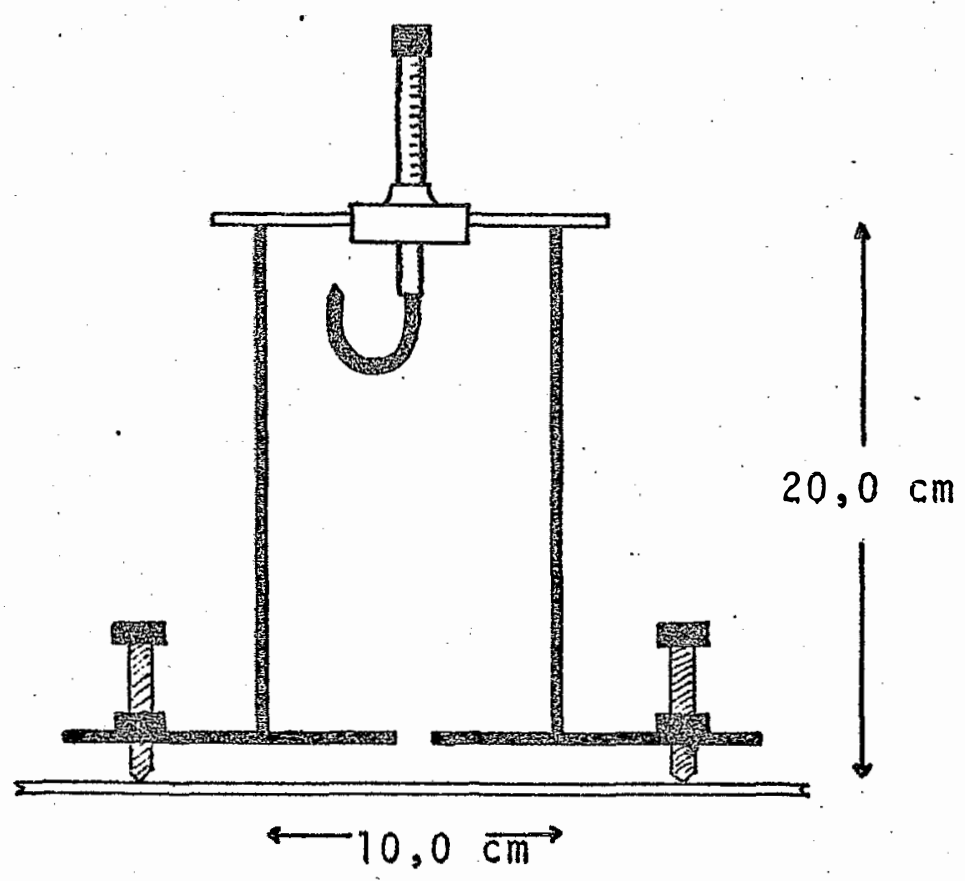

DETALHE DO SISTEMA DE MEDIDAS

FIGURA 2. Vista do tanque CLASSE A" e detalhe do sistema de medidas . 


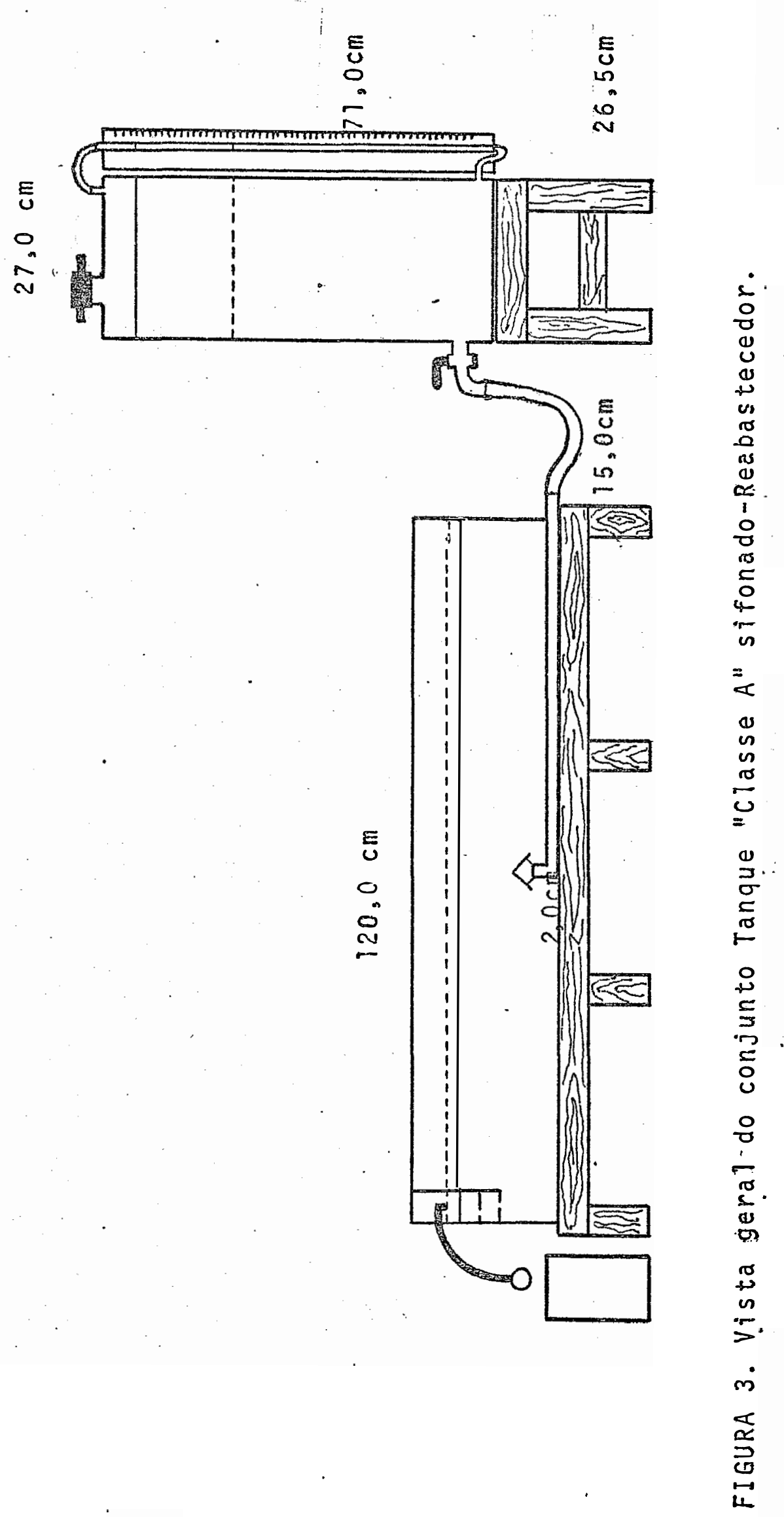



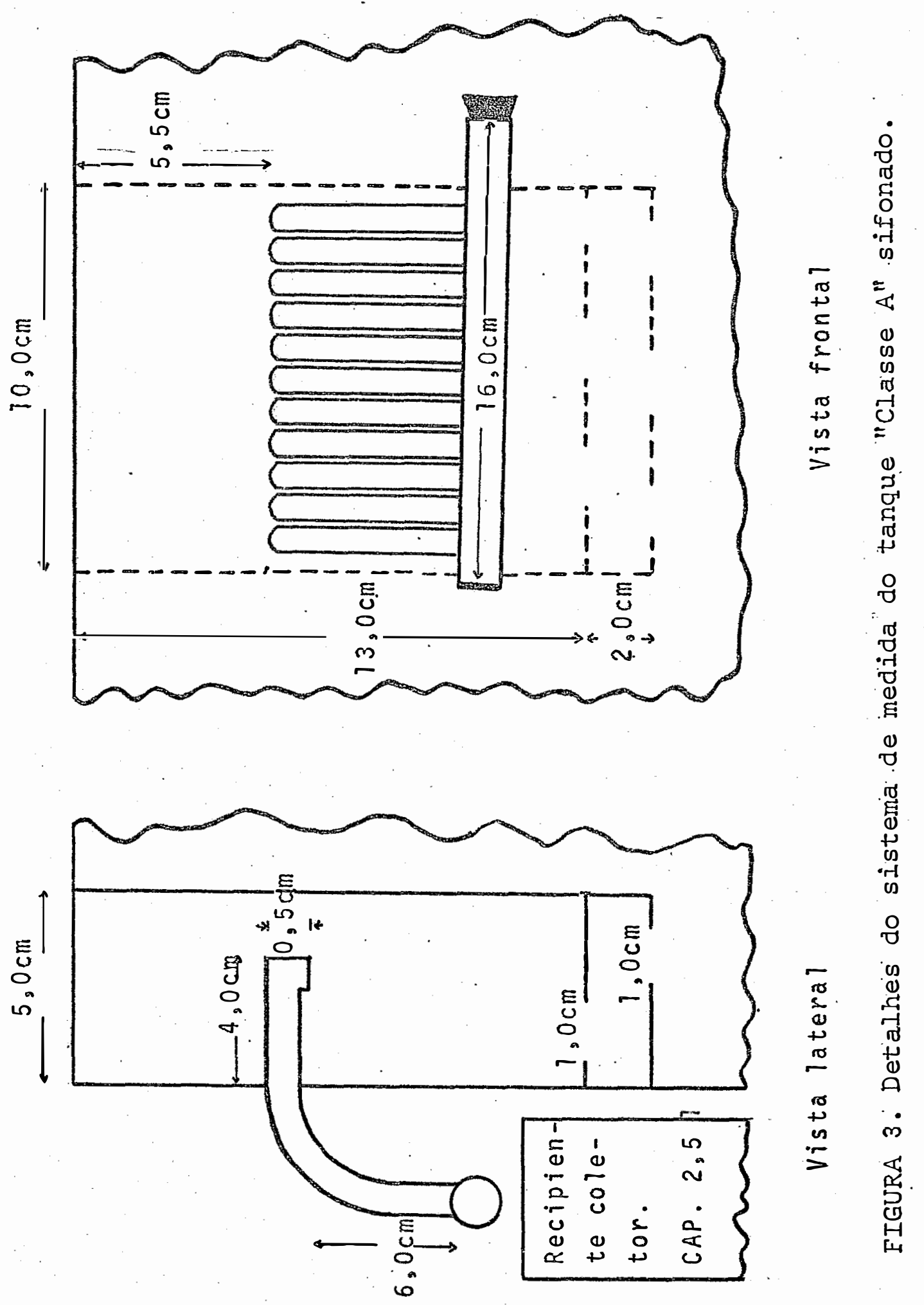
bonda do tanque, ficiando sua mạor dimensão colocada segun = do a orientação Leste-Oeste verdadeing,

\subsection{3: Medida dą Evapotranspirạạạ}

Evapotranspirômetros = Utilizou-se uma bate ria de evapotranspirộmetros constituida de cinco (5) unida = des com sub-ịrigação, os meșmos utilizados por ASSIS (1978).

Cada evapotranspirômetro è construido em chapa galvanizada, possuindo as seguintes dimensões: 184,0 cm de comprimento, $134,0 \mathrm{~cm}$ de largura e $32,0 \mathrm{~cm}$ de profundidade; no fundo foi colocada uma camada de areia de $4,0 \mathrm{~cm}$ de espessura e a seguir foi peeenchido com solo peneirado, clas sificado como terra roxa estruturada, série "Luiz de Queiroz" (Alfisol), segundo RANZANI et alii (1966) e no qual foi plan tada grama Batatais (Paspalum notatum, Fluegg), mantida com uma altura aproximada de $10,0 \mathrm{~cm}$ atravês de cortes periódi cos:

Esses evapotranspirômetros eram comunicados i nicialmente com cinco (5) reabastecedores construidos em PVC rigido, com diâmetro de $25,8 \mathrm{~cm}$ e uma altura de $50,0 \mathrm{~cm}$, es-tabelecendo uma relação de ärea entre o reabastecedor e o evapotranspirômetro de $1: 47,2$.

Pela parte externa, cada reabastecedor tinha um tubo de vidro indicador do nịvel da ägua acoplado a uma escala graduada em milímetros de altura de lâmina de água evapotranspirada no evapotranspirômetro e um vernier facili tava a leitura das frações de milimetro.:

Entre cada evapotranspirômetro e o seu rea bastecedon foi intercalada uma caixa de passagem construid a em chapa galvanizada e na qual um sistema de boia controlava a admissão de àguá; as lịgạōos "reabastecedor-caixa de passagem-evapotranspirômetrọ" forạm feitas com tubos plásticos". transparentes e flexîveis. Detalhes na Figura 5.

\subsubsection{Elementos de Clima}

$\mathrm{Na}$ observação dos elementos de clima, ifforam 


\section{FI GURA 5}

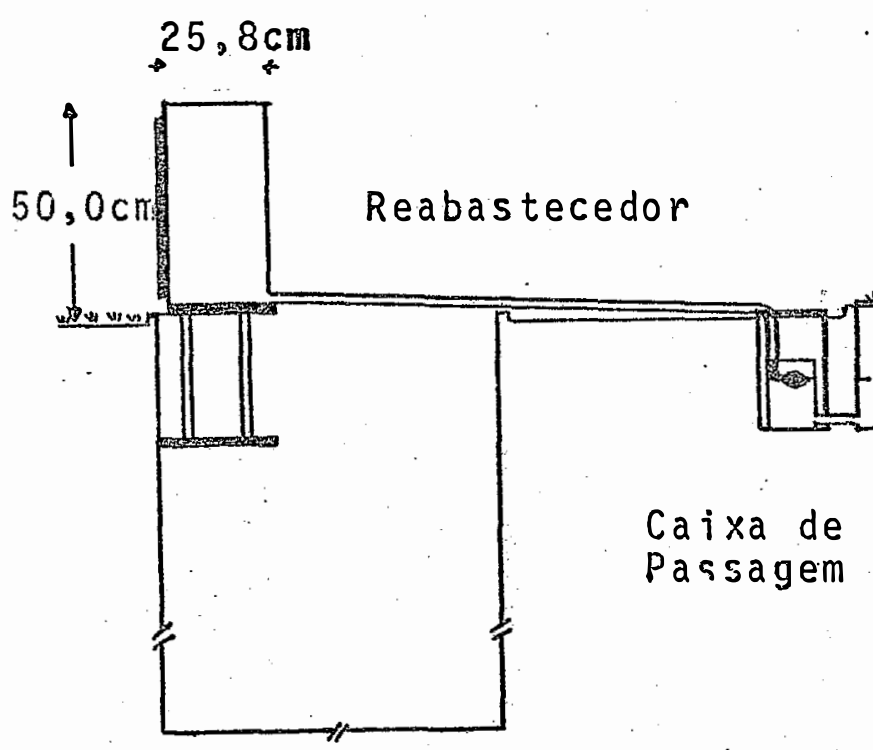

Corte do conjunto de um evapotranspirōmetro
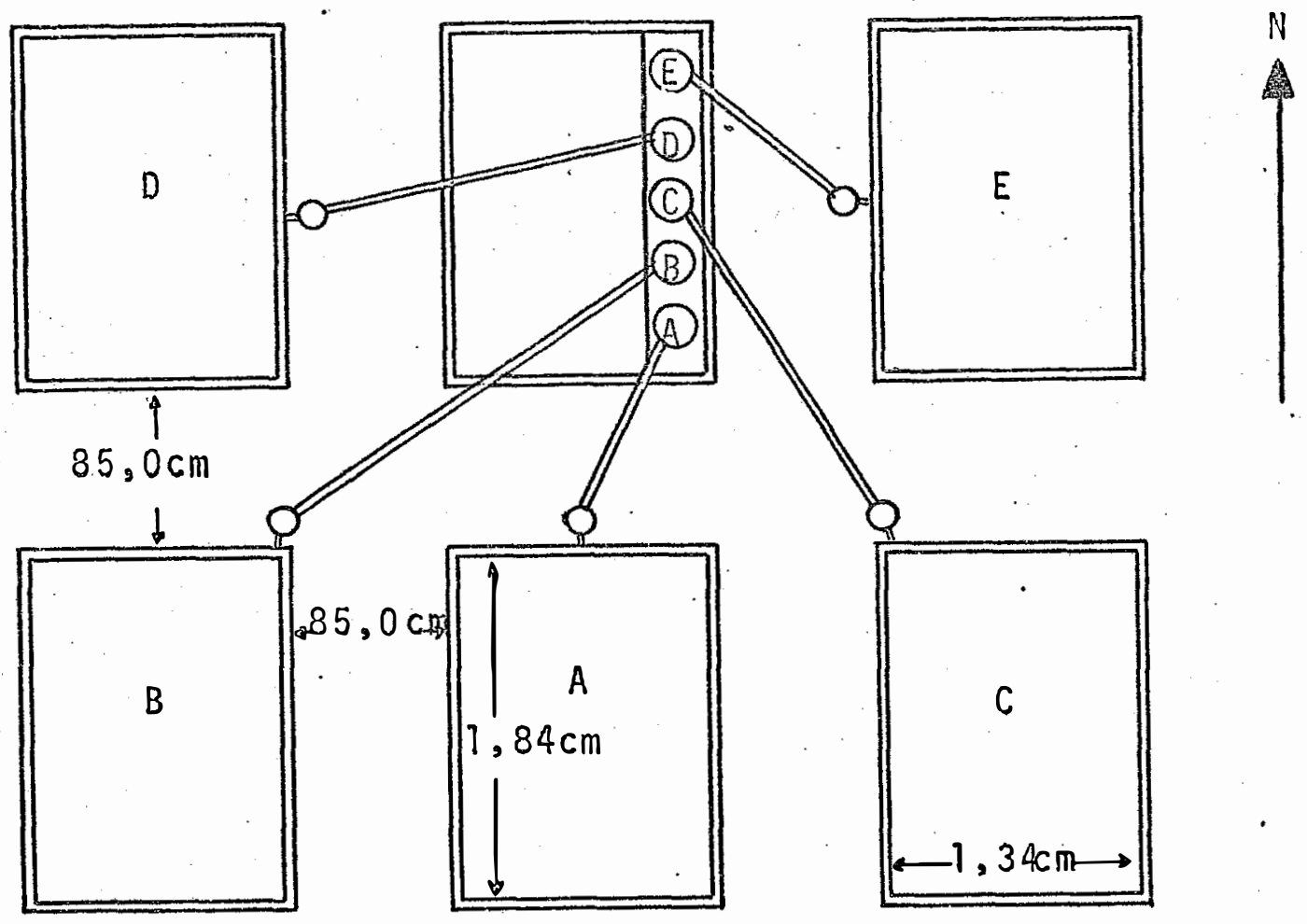

Planta baixa da bateria de evapotranspirómetros 
empregados os seguintes instrumentos:

Temperatura do ar - obtida diariamente por meio de dois (2) termômetros de máxima e de mínima de fabricação FUESS, modelos $43 \mathrm{c}$ e $43 \mathrm{~d}$ respectivamente, com escala graduada em graus Celsius e com divisão de 0,2:C, instalados no abrigo meteorológico.

Umidade relativa do ar - obtida através de um termo-higrógrafo de fabricação FUESS modelo 159r, de rotação sema nal, devidamente calibrado e apresent-ndo uma precisão de $\pm 5 \%$.

Velocidade do vento - foi medida com um anemômetro in tegrador de fabricação FUESS modelo $91 \mathrm{~g}$, instalado ao nivel de 2,0 m da superfície do solo.

Precipitação - os dados referentes à precipitação, foram obtidos com pluviômetros $\mathrm{HH}$, com leitura em proveta graduada em mililitros, posteriormente convertidas em milime tros.

Insolação - as horas de brilho solar foram obtidas com um heliógrafo Campbell-Stokes de fabricação FUESS, : modelo $96 c$.

Poder evaporante do ar - para essas medidas, utilizou se um evaporimetro Piche de fabricação FUESS, modelo :72c; instalado no abrigo meteorológico e com o disco de papel situado a 2,0 m da superfície do solo.

Temperatura da água do tanque "Classe A" - a temperatura da água foi obtida diariamente por meio de dois termôme tros de máxima e de mínima de fabricação FUEŚS, com as mes mas características dos já mencionados e montados em um suporte flutuante, ficando devidamente protegịdos da incidên cia direta dos raios solares, permanecendo os seus bulbos imersos na água a aproximadamente $0,1 \mathrm{~cm}$ da superficie.

4.2. Métodos

4.2.1. Medidas da Evanonação

Tanque "Classe A" (ECA) - As medidas da eva - 
poração foram tomadas diàriamente, ao nascer e ao por do so 1 . durante os primeiros sete (7) meses e apenas ao nascer do sol. durante os dois (2) meses.

0 nivel da água era deixado inicialmente a 5,0 $\mathrm{cm}$ da borda do tanque e restabelecido quando atingia o nive 1 de $7,5 \mathrm{~cm}$ da borda, segundo recomendação da OMM.

As leituras foram efetuadas com um micrômetrro e a evaparação do período era obtida por diferença entre as leituras de duas operações consecutivas, defasadas 24 horas.

Tanque "Classe A" sifonado (ECAs) - 0 funcio namento do tanque "Classe A" sifonado (ECAs) baseia-se em refazer o nivel baixado desde o início do periodo, para que se obtivesse o valor da evaporação das ûltimas 24 horas.

A modificação do sistema de mediras consistiu da adaptação de um conjunto de sifões em paralelo, construi dos em tubo de cobre com diâmetro de $0,4 \mathrm{~cm}$, ficando suas extremidades internas protegidas por um poço tranquilizador (câa mara de sifonação) de paredes simples e duplo fundo, cuja finalidade era a de quebrar a turbulência na entrada da âgua na câmara.

A cada dia, ao nascer e ao por do sol, abria -se o registro do reabasteceror, admitindo água na parte central do fundo do tanque, atê se observair que o nivel da ägua elevara-se atê atingir a extremidade do conjunto de sifões na câmara de sifonação; ato contínuo, o registro do reabastece dor era fechado. A seguir, tova-se com um recipiente um poíco da própria água do tanque, a qual era colocada dentro da câ mara de sifonação, elevando rapidamente o nível da āgua na mesma, acionandn assim o sistema de sifões e fazendo com que - excesso de água admitido na operação de recarga do i tanque fosse recolhido em um coletor à saỉda dos sifões; apös cessar o escnamento, esse excesso ela levado de retorno ao reabastecedor, sendo então efetuada a leitura na escala graduada em milimetros, acoplada ao tubo de vidro indicador do nivel da àgua; por diferença entre as leituras de duas operações con. - 
secutivas, obtinha-se o valor da evaporação do período anterior.

\subsubsection{Medidas da Evaporação à sombra}

Esta operação foi realizada com uma das unida. des do tanque "Classe A" sifonado (ECAs sombra) durante os três (3) ültimos meses de trabalho (dezembro de 1978 a fevevereiro de 1979). A maneira da operação acima, esta era, entretanto realizada apenas ao nascer do sol, admitindo-se àgua no tanque a fim de refazer o nivel de referência dado pe lo conjunto de sifões, o qual baixava por efeito da evaporação em função do vento e do dëfice de saturação do ar.

Cessado o escoamento do excedente de água admitido por ocasião da recarga, ena levado de retorno ao reabastecedor, após o que era efetuada a leitura na escala graduada em milimetros, acoplada ao longo do tubo de vidro no reabastecedor. Por diferença entre as leituras de duas ope rações consecutivas, obtinha-se o valor da evaporação do período, à sombra.

4.2.3. Efeito da temperatura da água de recarga

Em vârias ocasiões, foirtomada a temperatur a da âgua do reabastecedor para efeito de comparação com a tem peratura da âgua do tanque, valendo-se para isso de um termố metro de fabricação FUESS. Essas leituras eram efetuadas ao nascer do sol.

4.2.4. Medida da Evapotranspiração

Na bateria de evapotranspirômétros, o nivel do lençol freático foi mantido constante, aproximadamente $i$ a $19,0 \mathrm{~cm}$ do solo.

Diāriamente, ao nascer do sol, eram feitas as leituras do total evapotranspirado desde o nascer do sol no". dia anterior, após o que os reabastecedores eram "zerados".

0 funcionamento ocorria da seguinte maneira : com a evapotranspiração, havia um abaixamento do lençol freático de uma altura $\Delta \mathrm{h}$; esse abaixamento, pelo princípio fi- 
sico dos vasos comunicantes, fazia com que a caixa de passagem suprissse de âgua o evapotranspirômetro atë estabelecen um novo equilibrio; esse suprimento; por sua vez, provocavia um abaixamento no nível da ägua na caixa de passagem, fazendo com que a boịa liberasse a agulha, admitindo água do reabastecedor no mesmo volume correspondente à evapotranspira ção, volume esse transformado em lâmina correspondente à $\vec{a}$ rea do evapotranspirômetro, com leitura na escala graduada em milimetros, acoplada ao tubo de vidro indicador de nível da ägua no reabasteçedor.

Durante a noite, dado o dificil deslocamen to em tempo häbil e durante o dia, quando havia condições de cobertura do cêu por nüvens de chuva ameaçando precipitar, a bateria de evapotranspirômetros era protegida com uma cobertura de lençol plästico em armação de madeira, suportada por quatro (4) piquetes a $30,0 \mathrm{~cm}$ da superfície gramada, guar dando uma inclinnação para facilitar o escoamento da ägua por oc’sião da chuva.

A partir dos últimos 20 dias de observação,as repetições A, B e D foram reunidas através de uma só caixa de passagem, a qual era alimentada por um só reabastecedor, o ferecendo uma relação de 1:30, e ao qual foi adaptado um sis tema de registro à semelhando do que foi empregado por ASSIS (1978), possibilitando desse modo a determinação dos varores de $\Delta E T P / \Delta t$ em milimetros por hora, diàriamente, de modo a se estabelecer o comportamento médio da evapotranspiração poten cial diāria naquele periodo.

4.2.5. Estimativa da Evaporação

A evaporação foi estimada através do método de Penman (1963), já consagrado e tido como dos mais represen tativos do fenômeno.

Penman dâ como expressão para essa estimati -

va:

$$
E V=\frac{\frac{\Delta}{\gamma} \cdot H+E a V}{\frac{\Delta}{\gamma}+1} \text { em } \mathrm{mm}
$$


na qual os termos $\Delta, \gamma, H$, EaV foram calculados a partir de expressões e representam:

$\Delta$ - a tamgente à curva de saturação de vapor e foi cal culada para uma amplitude de temperatura de 00,09C a 28,99. derivando a expressão de Tetens:

$$
\begin{array}{cc}
\frac{\mathrm{a} \cdot \mathrm{T}}{\mathrm{b}+\mathrm{T}} & \mathrm{a}=7,5 \\
\mathrm{e}_{\mathrm{S}}=6,11 \times 10^{\circ} \times 0,75 \mathrm{mmHg} & \mathrm{b}=237,5
\end{array}
$$

onde $e_{s}$ é a tensão de saturação de vapor à temperatura do ar tomada no abrigo em grâus Celsius, resultando então na seguinte expressão:

$$
\frac{d e_{s}}{d t}=\frac{18779,5 \times 10^{\frac{a \cdot T}{b+T}}}{(b+T)^{2}} \cdot \operatorname{mmHg} \cdot 9 C^{-1} \text { APENNDICE I }
$$

$\gamma$ - è a constante psicromëtrica e foi determinada para psicrômetro não ventilado pàra úma pressão atmosférica variando na época entre 710,0 a 720,0 mmHg, obtendo-se um valor de $\gamma=0,57$ rankig/:C

H- é o valor diārio do balanço de energia e Éoi estimado segundo a expressão abaixo, em mm equivalente de água evaporada:

$$
H=\frac{Q 0}{59}(a+b n / N)(1-r)-\frac{T a^{4}}{59}\left(0,56-0,09 e_{a}\right)(0,1+0,9 n / N) \ldots
$$

e onde o termo $Q_{0}$ é, por sua vez, estimado segundo a expressão:

$$
Q_{0}=\frac{1440}{\pi} S(\bar{d} / d)^{2}\left(\operatorname{sen} \phi \cdot \operatorname{sen} \delta \cdot h_{1}+\cos \phi \cdot \cos \delta \cdot \operatorname{sen} h_{2}\right)
$$

SELLERS ( 1975$)$. APÊNDICE 3

Nas expressões para a estimativa de $\mathrm{H}$ e $Q_{0} \quad$ : '.

n- insolação diāria em horas e décimos;

N- duração do período diurno, estimado através da ex.pressão

$$
N=0,133 \operatorname{arc} \cos (-\operatorname{tg} \phi \cdot \operatorname{tg} \delta) \quad \text { APENDICE } 4
$$


r- albedo mẻdio para superfícies de água, tomado como 0,05 (Penman, 1963)

$\sigma-$ constante de Stefan-Boltzman, $8,123 \times 10^{-11} \mathrm{cal} . \mathrm{cm}^{-2}$. . $\min ^{-1} . \mathrm{oK}^{-4}$

Ta- temperatura mëdia do ar em $\$$ K. No APÊNDICE 2, tabela com o produto $\sigma \mathrm{Ta}^{4}$.

$e_{a}$ - tensão atual de vapor no ar em mmHg, determinada a - . través da expressão:

$$
e_{a}=\left(e_{s} \cdot U R\right) / 100
$$

ā- distância média Terra-Sol em unidades astronômicas.

d- distância Terra-Sol no dia considerado e nas mesmas unidades.

S- constante solar, assumida como $2 \mathrm{cal} . \mathrm{cm}^{-2} \cdot \mathrm{min}^{-1}$

$\phi$ - latitude do lugar

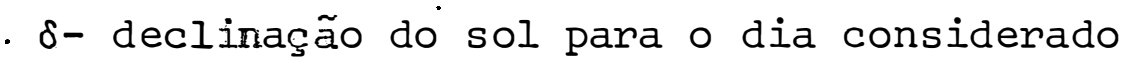

$\mathrm{h}_{1}$ - ângulo horário local ao nascer do sol, em radianos

$\mathrm{h}_{2}$ - ângulo horärio local ao nascer do sol, em gräus

a e b- coeficientes assumidos para Piracicaba e determinados por OMETTO (1973) como 0,26 e 0,51 respectivamente.

$\mathrm{E}_{\mathrm{a}}$ - poder evaporante do ar, estimado através dá expressão a seguir:

$$
E_{a} V=0,35\left(0,5+U_{2} / 160,9\right)\left(e_{s}-e_{a}\right) \text { mm }
$$

onde $U_{2}$ representa a velocidade média do vento em $\mathrm{km}$. dial. e $\left(e_{s}-e_{a}\right)$ representa o défice de saturação de vapor no ar em $\mathrm{mmHg}$.

\subsubsection{Estimativa da Evapotranspiração}

Do mesmo modo considerado para a estima - . tiva da evaporação da água, a evapotranspiração potencial foi estimada pelo método de PENMAN (1963), na qual substituiu -se. - valor de albedo médio para a grama Batatais (Paspalum nota-. tum, Fluegg) igual a 0,17, determinado para esta região por SANTOS (1957) e a expressão para a estimativa do termo Ea,pro posta para superfície vegetada, tomou a seguinte forma: 


$$
\text { EaP } \equiv 0,35\left(1,0+U_{2} / 160,9\right)\left(e_{s}-e_{2}\right) \mathrm{mm}
$$

oujas ingögnịtas jä fonam comentadas :

4:2:7: Elementos de Clima

Pana a obtenção dos valones dos elementos de clima, foram utilizados os instpumentos instalados na proppria estação meteorológica e aos quaise jā nos reportamos no parágrafo $4.1 .4 .4:$

Temperatura do an = a temperatuna mẹdia do ar foi obtida diàriamente atravếs da expressão:

$$
t_{m}=\frac{t x+t n}{2}
$$

utilizando-se os valones de temperatura māxima $(t x)$ e de tem peratuna minima (tn).

Umidade relativa do ar - a umidade relativa média diáa rio foi calculada atravês da expressão:

$$
\mathrm{UR}_{\mathrm{m}}=\frac{\mathrm{UR}_{6 \mathrm{~h}}+\ldots .+\mathrm{UR}_{24 \mathrm{~h}}+\ldots . \mathrm{UR}_{5 \mathrm{~h}}}{24}
$$

com os valores retirnados do registro do termo-higrógrafó.

Velocidade do vento = a velocidade média do vento foi obtida atravês de um anemômetro instalado ao nivel de 2,0 m da superfície do solo e obtida em km.dia-l por diferença entroe as leituras de dọ dis dias consecutivos, à mesma hora

Precipitação = os valones de precipitação foram obtidos atravês de dois pluviômetros HH com proveta graduada ein mi lilitros e posterionmente convertida em altura de lâmina de água em função da ánea do instrumento.

Insolação = os dados referentes à duração do brilho solan foram obtidos das fitas do heliögnafo, em hnras e décimos

Poden evaponante do $a \underline{n}$ = foram obtidos por diferença en $=$. tre duas leitunas consecutivas do evaporimetro Piche em dias consecutivos.

Tempenatuna da água do tanque = para esse câlculo, utilizou-se a mesma expressão para a temperatura média do ar. 
5. RESULTADOS E DISCUSSÃO

5:1: Relativos às medidas de Evaporação pelo tanque "Classe A" tradicional (ECA) e com a modificação proposta (ECAs).

Os valores de evadoração medidos pelo tanque "Classe A" com o sistema convencional de medidas (ECA) e pe lo tanque "Classe A" sifonado, estão representados na Tabela 1 (valores diārios) e na Tabela 2 (valores mëdios de cin co (5) dias.

Colocados em gráfico, o lugar geométrico dos pontos se aproximou de uma reta de 459 de inclinação a partir da origem dos eixos, parecendo com isso que a modificação proposta pana as medidas, não difere do sistema usado pa ra esse tipo de evaporimetro.

Analisando estatisticamente os desvios entre os valores obtidos com os dois sistemas, chegou-se ao se guinte quadro de resultados:

\begin{tabular}{c|c|cccc|cc}
\hline PERIODO & $\ddots$ & $r$ & $t$ & $t_{10 \%}$ & $t_{5 \%}$ & $t_{1 \%}$ & \multicolumn{2}{c}{$C V$} \\
\hline $\begin{array}{c}\text { DIĀRIO } \\
\text { MEDIAS DE } \\
\text { 5 DIAS }\end{array}$ & 0,9792 & 0,242 & 1,65 & 1,96 & 2,58 & 39,07 & 38,34 \\
\hline
\end{tabular}


Pelos resultados apresentados, verifica-se uma: alta correlação entre os dois sistemas, tanto quando se to mou para estudos os valores diários como os valores mëdios de cinco (5) dias; os desvios entre as leituras pelos dois sis temas de medidas em ambos os casos não mostraram significân cia e os coeficientes de variação comprovam o comportamento $\underline{\text { i }}$ dêntico.

Os valores de ECA versus ECAs mostram entre tanto que, na maioria dos casos $-60 \%-$ a modificação proposta sobrestimoù o fenômeno em relação ao sistema tradicional de me didas; em 32\% dos casos, subestimbu e em apenas $8 \%$ não houve diferença, de.modoique; no total, o sistema modificado apre sentou uma tendência em sobrestimar os valores de evaporação, quando considerou-se o sistema tradicional como padrão para esse tipo de medida.

O fato dessa sobrestimativa deve-se a que, na maioria dos dias, por ocasião da leitura ao por do sol, a superfície de āgua estar submetida à intranquilidade devida à ação do vento, de modo que quando o nível da àgua se enrontrạ va próximo da referência (dada pela extremidade interna $\because$ do sistema de sifões) durante a operação, o sistema de medidas a dmitia ar, prejudicando assim o seu funcionamento e consequen temente a leitura; a interferência do vento, evidentemente, crescia com a sua velocidade e a partir de $4,0 \mathrm{~m} / \mathrm{s}$ a agitação provocada na superficie, por vezes prejudicava a operação de leitura.

Essa tendêndia em fornecer valores mais eleva-dos durante o dia, como é mostrado na Tabela 3 era entretan to compensada pelo próprio sistema durante a operação ao nascer do sol, obtendn-se valores inferiores que compensavam o total diário.

o tempo máximo observado para que o instrumento completasse a operação - da admissão de āgua no tanque ao equilíbrio final após sifonar o excesso - foi de 5 minutos aproximadamente, quando então esse remanescente da operação an 
terior era sitonado.

As Figuras 6 e 7 mostram a dispersão dos valo res obtidos pelos dois sistemas, respectivamente em base diária e com base em mëdias de 5 leituras.

A Figura 8 mostra a marcha da evaporação diurna e noturna durante o periodo em que foi conduzido o ex perimento com duas observações diārias, abrangendo diferen - . tes condições de energia - baixa (junho), mêdia (setembro) e alta (dezembro) - bem como diferentes durações do período di urno.

Pelo que foi dado observar, durante o inverno (não muito rigoroso na época), com os dias menores do que as noites, a incidência de baixa energia radiante condicionava uma igual contribuição dos dois períodos para.a evaporação de 24 horas, tendo uma vez ou outra a evaporação noturna sobrepujado a evaporação diurna; à medida em que se aproximava o verão, com o aumento da energia incidente, observou-se que a contribuição diurna chegou a ser de $80 \%$ do total diārio.

Em face dicso è de se supor que em condi çoẽs de inverno mais acentuado, muito frequente a partir de mëdias latitudes, a contribuição noturna aproxima-se da diurna uma vez que o défice de saturação entre o ar e a superfície da ăgua deve ser mantido aproximadamente constante por causa do maior resfriamento noturno e da energia absorvida durante o dia. 
Tabela 1. Valores representativos da evaporação diäria medi dos pelos tanques "Classe A" (ECA), "Classe A" si fonado (ECAs) e respectiv̈os desvios ( $d=E C A s-E C A$ ) em $\mathrm{mm}$.

\begin{tabular}{|c|c|c|c|c|c|c|c|c|c|}
\hline \multirow{2}{*}{ DIA } & \multicolumn{3}{|c|}{ JUNHO } & \multicolumn{3}{|c|}{ JULHO } & \multicolumn{3}{|c|}{ AgOSTO } \\
\hline & ECA & ECAs & d & ECA & ECAs & d & ECA & ECAs & d \\
\hline 01 & 2,05 & 2,23 & $+0,18$ & 4,25 & 3,90 & $-0,35$ & - & - & - \\
\hline 02 & 1,80 & 1,53 & $-0,27$ & 2,75 & 2,55 & $-0,20$ & - & - & - \\
\hline 03 & 4,00 & 3,83 & $-0,17$ & 3,10 & 2,65 & $-0,45$ & 5,15 & 7,20 & $+2,05$ \\
\hline 04 & 3,70 & $3,6.5$ & $-0,05$ & 3,30 & 3,20 & $-0,10$ & 4,50 & 5,20 & $+0,70$ \\
\hline 05 & - & - & - & 2,95 & 3,45 & $+0,50$ & 4,65 & 4,60 & $-0,05$ \\
\hline 06 & 3,45 & 3,13 & $-0,32$ & 4,05 & 4,15 & $+0,10$ & 5,15 & 5,90 & $+0,75$ \\
\hline 07 & 3,60 & 4,35 & $+0,75$ & 3,95 & 4,10 & $+0,15$ & 4,75 & 5,00 & $+0,25$ \\
\hline 08 & & & & 4,25 & 4,45 & $+0,20$ & 5,20 & 5,20 & 0,00 \\
\hline 09 & 3,25 & $2,8.0$ & $-0,45$ & 3,30 & 3,20 & $-0,10$ & 5,45 & 5,70 & $+0,25$ \\
\hline 10 & 3,95 & 4,08 & $+0,13$ & 3,90 & 3,80 & $-0,10$ & $4 ; 90$ & 4,90 & 0,00 \\
\hline 11 & 3,15 & 3,25 & $+0,10$ & 4,20 & 4,40 & $+0,20$ & - & - & - \\
\hline 12 & 2,05 & 1,80 & $-0,25$ & 3,85 & 4,05 & $+0,20$ & 6,10 & 6,15 & $+0,05$ \\
\hline 13 & 2,30 & 2,55 & $+0,25$ & 3,70 & 4,00 & $+0,30$ & 2,20 & 2,45 & $+0,25$ \\
\hline 14 & 2,40 & 2,83 & $+0,43$ & 2,95 & 3,00 & $+0,05$ & 1,75 & 1,35 & $-0,40$ \\
\hline 15 & 3,20 & 3,68 . & $+0,48$ & - & - & - & 4,55 & 4,80 & $+0,25$ \\
\hline 16 & 3,60 & 3,93 & $+0,33$ & 2,45 & 2,55 & $+0,10$ & 4,20 & 4,55 & $+0,35$ \\
\hline 17 & 3,10 & 3,13 & $+0,03$ & - & - & - & $\therefore$ & - & - \\
\hline 18 & 4,45 & 4,25 & $-0,20$ & $\bullet$ & - & - & 5,10 & 4,85 & $-0,25$ \\
\hline 19 & 3,90 & 4,20 & $+0,30$ & - & - & - & 4,65 & 5,50 & $+0,85$ \\
\hline 20 & 3,20 & 3,10 & $-0,10$ & - & - & - & 3,15 & 4,50 & $+1,35$ \\
\hline 21 & 2,10 & 2,15 & $+0,05$ & - & - & - & 3,60 & 3,25 & $-0,35$ \\
\hline 22 & 3,50 & 3,65 & $+0,15$ & - & - & - & 4,80 & 5,55 & $+0,75$ \\
\hline 23 & 2,15 & 2,45 & $+0,30$ & 4,35 & 4,90 & $+0,55$ & 2,25 & 4,45 & $+2,20$ \\
\hline 24 & 2,60 & 3,40 & $+0,80$ & 3,80 & 4,20 & $+0,40$ & 5,70 & 3,65 & $-2,05$ \\
\hline 25 & 3,55 & 3,20 & $-0,35$ & 3,40 & 3,60 & $+0,20$ & 7,00 & 8,00 & $+1,00$ \\
\hline 26 & 3,90 & 4,45 & $+0,55$ & 4,75 & 4,40 & $-0,35$ & 6,45 & 6,20 & $-0,25$ \\
\hline 27 & 3,85 & 4,05 & $+0,20$ & 4,45 & 4,60 & $+0,15$ & 4,80 & 4,25 & $-0,55$ \\
\hline 28 & 4,20 & 4,30 & $+0,10$ & 3,90 & 4,10 & $+0,20$ & 4,85 & 5,45 & $+0,60$ \\
\hline 29 & 4,80 & 5,50 & $+0,70$ & 4,75 & 4,50 & $-0,25$ & 5,20 & 5,55 & $+0,35$ \\
\hline 30 & 4,55 & 4,50 & $-0,05$ & 5,40 & 5,30 & $-0,10$ & 7,05 & 7,40 & $+0,35$ \\
\hline 31 & & & & & & & & & \\
\hline
\end{tabular}


Tabela 1. Continuação.

\begin{tabular}{l|ccc|ccc|ccc}
\hline & \multicolumn{3}{|c|}{ SETEMBRO } & \multicolumn{3}{c}{ OUTUBRO } & \multicolumn{3}{c}{ NOVEMBRO } \\
\cline { 2 - 10 } & ECA & ECAS & d & ECA & ECAs & d & ECA & ECAs & d. \\
\hline 01 & - & - & - & 7,20 & 7,70 & $+0,50$ & 7,35 & 9,80 & $+0,05$ \\
02 & 4,75 & 3,95 & $-0,80$ & 8,90 & 9,15 & $+0,25$ & 9,40 & 9,80 & $+0,40$ \\
03 & 5,15 & 5,85 & $+0,70$ & 8,40 & 8,15 & $-0,25$ & - & - & - \\
04 & - & - & - & 8,40 & 8,55 & $+0,15$ & - & - & - \\
05 & - & - & - & 9,05 & 9,05 & 0,00 & - & - & - \\
06 & 5,05 & 3,50 & $-1,55$ & 10,50 & 10,20 & $-0,30$ & 5,05 & 5,20 & $+0,15$ \\
07 & - & - & - & 9,85 & 9,90 & $+0,05$ & 8,85 & 9,00 & $+0,15$ \\
08 & 6,30 & 5,60 & $-0,70$ & 9,25 & 9,60 & $+0,35$ & 8,10 & 8,35 & $+0,25$ \\
09 & 6,05 & 6,05 & 0,00 & 9,10 & 9,05 & $-0,05$ & - & - & - \\
10 & 4,85 & 4,90 & $+0,05$ & - & - & - & - & - & - \\
11 & 6,70 & 7,00 & $+0,30$ & 7,15 & 7,70 & $+0,55$ & - & - & - \\
12 & 6,55 & 6,10 & $-0,45$ & 10,10 & 10,05 & $-0,05$ & 2,10 & 2,40 & $+0,30$ \\
13 & 6,20 & 7,10 & $+0,90$ & - & - & - & 7,20 & 7,40 & $+0,20$ \\
14 & - & - & - & 3,35 & 3,05 & $-0,30$ & 7,75 & 7,85 & $+0,10$ \\
15 & - & - & - & 7,40 & 7,40 & $+0,10$ & 7,95 & 8,50 & $+0,55$ \\
16 & - & - & - & 5,30 & 5,40 & $+0,10$ & - & - & - \\
17 & 2,40 & 2,50 & $+0,10$ & 9,60 & 9,15 & $-0,45$ & - & - & - \\
18 & 6,00 & 6,15 & $+0,15$ & - & - & - & 6,30 & 6,50 & $+0,20$ \\
19 & 6,55 & 6,70 & $+0,15$ & 7,35 & 6,95 & $-0,40$ & 6,40 & 8,50 & $+2,10$ \\
20 & 6,95 & 7,45 & $+0,50$ & 7,05 & 6,70 & $-0,35$ & 5,70 & 5,75 & $+0,05$ \\
21 & 5,85 & 5,60 & $-0,25$ & 9,30 & 9,70 & $+0,40$ & 8,20 & 8,25 & $+0,05$ \\
22 & 7,85 & 7,70 & $-0,15$ & 8,65 & 8,10 & $-0,55$ & 7,55 & 7,50 & $-0,05$ \\
23 & 8,45 & 8,50 & $+0,05$ & 8,20 & 8,60 & $+0,40$ & 7,35 & 7,65 & $+0,30$ \\
24 & 8,50 & 7,90 & $-0,60$ & 9,65 & 10,70 & $+1,05$ & 9,40 & 9,65 & $+0,25$ \\
25 & 7,05 & 7,70 & $+0,65$ & 11,35 & 10,85 & $-0,50$ & 6,95 & 6,95 & 0,00 \\
26 & 8,10 & 8,05 & $-0,05$ & 9,80 & 9,80 & 0,00 & 9,15 & 9,00 & $-0,15$ \\
27 & 5,85 & 6,90 & $+1,05$ & - & - & - & - & - & - \\
28 & 8,00 & 7,65 & $-0,35$ & - & - & - & 10,35 & 10,50 & $+0,15$ \\
29 & 7,50 & 7,90 & $+0,40$ & - & - & - & 9,50 & 9,45 & $-0,05$ \\
30 & 7,75 & 7,45 & $-0,30$ & 6,65 & 6,50 & $-0,15$ & 7,45 & 7,35 & $-0,10$ \\
31 & - & - & - & - & - & - & - & - & - \\
\hline
\end{tabular}


Tabela 1. Continuação.

\begin{tabular}{|c|c|c|c|c|c|c|c|c|c|}
\hline \multirow{2}{*}{ DIA } & \multicolumn{3}{|c|}{ DEZEMBRO } & \multicolumn{3}{|c|}{ JANEIRO } & \multicolumn{3}{|c|}{ FEVEREIRO } \\
\hline & $E C A$ & ECAs & $\mathrm{d}$ & $E C A$ & ECAs & d & $E C A$ & ECAs & d \\
\hline 01 & 11,70 & 10,20 & $-1,50$ & - & - & - & - & - & - \\
\hline 02 & & - & & - & - & - & 7,15 & 7,30 & $+0,15$ \\
\hline 03 & 8,70 & 8,80 & $+0,10$ & - & - & - & 9,05 & 9,10 & $+0,05$ \\
\hline 04 & 10,60 & 10,50 & $-0,10$ & - & - & - & 8,50 & 8,50 & 0,00 \\
\hline 05 & 9,30 & 9,10 & $-0,20$ & 8,85 & 9,00 & $+0,15$ & 8,35 & 8,60 & $+0,25$ \\
\hline 06 & - & - & - & 8,60 & 9,20 & $+0,60$ & 7,10 & 7,50 & $+0,40$ \\
\hline 07 & - & - & - & 9,50 & 9,30 & $-0,20$ & 8,00 & 8,00 & 0.00 \\
\hline 08 & - & - & - & 9,35 & 9,60 & $+0,25$ & 9,65 & 9,50 & $-0,15$ \\
\hline 09 & - & - & - & 8,65 & 9,60 & $+0,95$ & - & - & - \\
\hline 10 & - & - & - & 8,20 & 7,90 & $-0,30$ & 5,05 & 5,00 & $-0,05$ \\
\hline 11 & 8,90 & 9,20 & $+0,30$ & 4,00 & 4,00 & 0,00 & & - & - \\
\hline 12 & 7,55 & 7,70 & $+0,15$ & - & - & - & - & - & - \\
\hline 13 & 8,40 & 8,40 & 0,00 & 9,35 & 9,50 & $+0,15$ & - & - & - \\
\hline 14 & - & - & - & 9,95 & 10,30 & $+0,35$ & - & - & - \\
\hline 15 & - & - & - & 9,20 & 9,90 & $+0,70$ & $6 ; 85$ & 7,00 & $+0,15$ \\
\hline 16. & - & - & - & 9,00 & 9,00 & 0,00 & 5,80 & 6,00 & $+0,20$ \\
\hline $17^{\circ}$ & 9,20 & 9,20 & 0,00 & 9,55 & 10,60 & $+1,05$ & 2,70 & 3,10 & $+0,40$ \\
\hline 18 & 6,80 & 6,80 & 0,00 & 8,80 & 8,80 & 0,00 & 5,80 & 5,60 & $-0,20$ \\
\hline 19 & 7,20 & 7,20 & 0,00 & 8,65 & 9,00 & $+0,35$ & 7,60 & 7,00 & $-0,60$ \\
\hline 20 & 9,20 & 10,20 . & $+1,00$ & - & - & - & 8,60 & 8,50 & $-0,10$ \\
\hline 21 & 10,95 & 10,10 & $-0,85$ & 2,50 & 2,60 & $+0,10$ & - & - & - \\
\hline 22 & 9,05 & 9,50 & $+0,45$ & 6,95 & 6,60 & $-0,35$ & - & - & - \\
\hline 23 & 9,60 & 9,70 & $+0,10$ & 6,85 & 7,00 & $+0,15$ & 6,00 & 6,30 & $+0,30$ \\
\hline 24 & 8,80 & 8,80 & 0,00 & - & - & - & 6,90 & 6,50 & $-0,40$ \\
\hline 25 & 10,45 & 10,40 & $-0,05$ & - & - & - & 7,40 & 8,00 & $+0,60$ \\
\hline 26 & 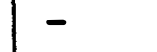 & - & - & 7,60 & 7,40 & $-0,20$ & 7,40 & 7,50 & $+0,10$ \\
\hline 27 & - & - & - & - & - & - & 7,35 & 7,80 & $+0,45$ \\
\hline 28 & - & - & - & - & - & - & 6,90 & 7,20 & $+0,30$ \\
\hline 29 & 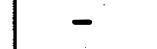 & - & - & - & - & - & - & - & - \\
\hline 30 & - & - & - & - & - & - & - & - & - \\
\hline 31 & 8,20 & 8,20 & 0,00 & - & - & - & - & - & - \\
\hline
\end{tabular}


40.

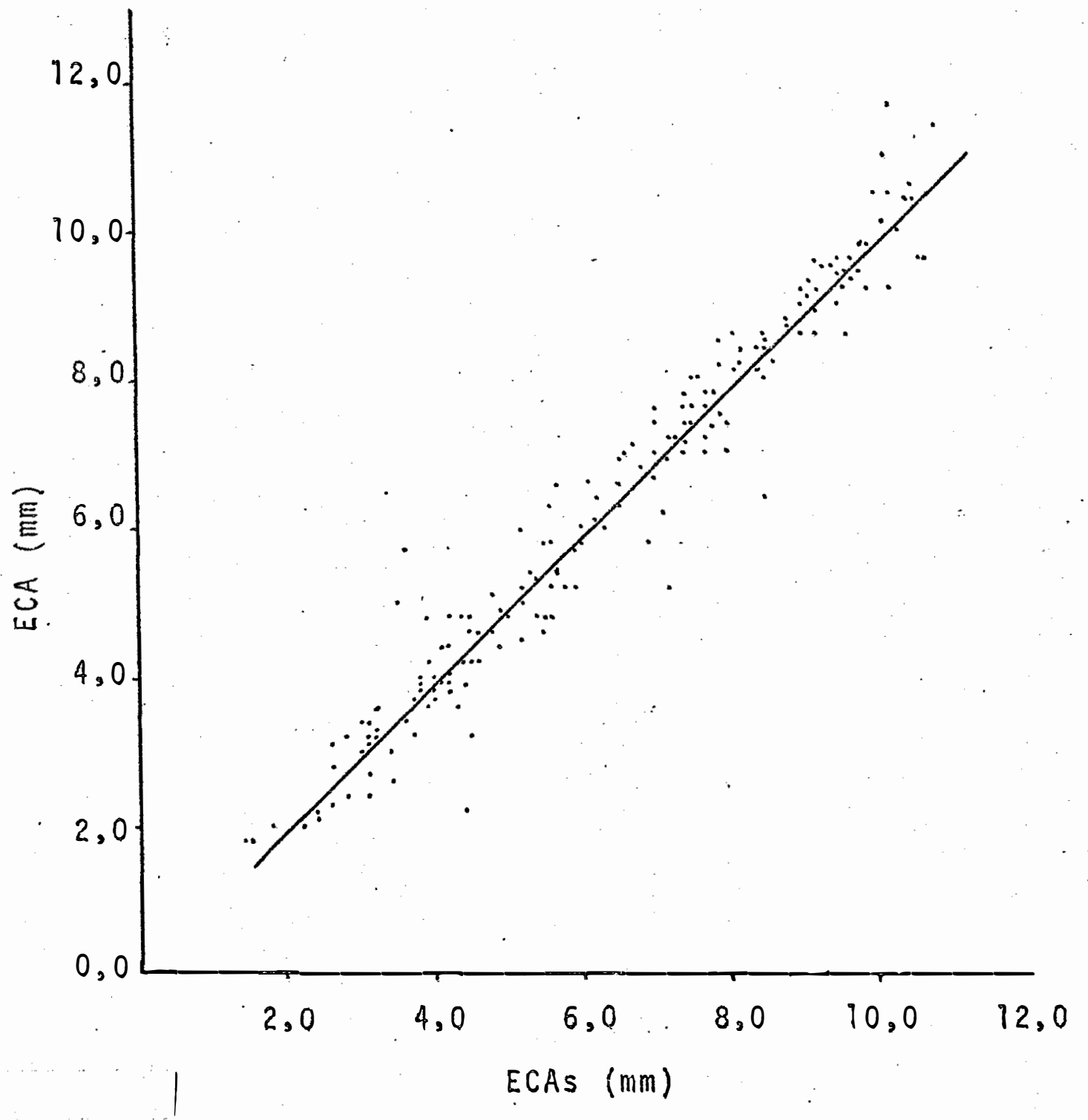

FIGURA 6. Gräfico representativo dos valores de evaporação em base diāria, medidos pelos tanques "rLASSE A" (ECA) e "CLASSE A" sifonado (ECAs) 
41 .

Tabela 2. Valores representativos de evaporação medidos pelos tanques "Classe A" (ECA), "Classe A" sifonado (ECAs) e respectivos desvios ( $d=E C A s-E C A$ ) em $\mathrm{mm}$, para mëdias de cinco (5) dias.

\begin{tabular}{|c|c|c|c|c|c|c|c|}
\hline PERIODO & ECA & ECAs & $\mathrm{d}$ & PERIODO & ECA & ECAs & d \\
\hline $01.06-06.06$ & 3,00 & 2,87 & $-0,13$ & $01.10-05.10$ & 8,39 & 8,52 & $+0,13$ \\
\hline $07.06-12.06$ & 3,20 & 3,26 & $+0,06$ & $06.10-11.10$ & 9,17 & 9,29 & $+0,12$ \\
\hline $13.06-17.06$ & 2,92 & 3,22 & $+0,30$ & $12.10-17.10$ & 7,15 & 7,03 & $-0,12$ \\
\hline $18.06-22.06$ & 3,43 & 3,47 & $7+0,04$ & $19.10-23.10$ & 8,11 & 8,01 & $-0,10$ \\
\hline $23.06-27.06$ & 3,21 & 3,51 & $+0,30$ & $24.10-01.11$ & 8,96 & 9,05 & $+0,09$ \\
\hline $28.06-02.07$ & 4,11 & 4,15 & $+0,04$ & $02.11-12.11$ & 6,70 & 6,95 & $+0,25$ \\
\hline $03.07-07.07$ & 3,47 & 3,51 & $+0,04$ & $13.11-19.11$ & 7,12 & 7,75 & $+0,63$ \\
\hline $08.07-12.07$ & 3,90 & 3,98 & $+0,08$ & $20.11-24.11$ & 7,64 & 7,76 & $+0,12$ \\
\hline $13.07-24.07$ & 3,45 & 3,73 & $+0,28$ & $25.11-30.11$ & 8,68 & 8,65 & $-0,03$ \\
\hline $25.07-29.07$ & 4,25 & 4,24 & $-0,01$ & $01.12 \cdots 11.12$ & 9,84 & 9,56 & $-0,28$ \\
\hline $30.07-06.08$ & 4,97 & 5,64 & $+0,67$ & $12.12-19.12$ & 7,83 & 7,86 & $+0,03$ \\
\hline $07.08-12.08$ & 5,28 & 5,39 & $+0,11$ & $20.12-24.12$ & 9,52 & 9,66 & $+0,14$ \\
\hline $13.08-18.08$ & 3,56 & 3,60 & $+0,04$ & $25.12-07.01$ & 9,12 & 9,22 & $+0,10$ \\
\hline $19.08-23.08$ & 3,69 & 4,65 & $+0,96$ & $08.01-13.01$ & 7,57 & 7,90 & $+0,33$ \\
\hline $24.08-28.08$ & 5,76 & 5,51 & $-0,25$ & $14.01-18.01$ & 9,30 & 9,72 & $+0,42$ \\
\hline $29.08-06.09$ & 5,44 & 5,25 & $-0,19$ & $19.01-26.01$ & 6,51 & 6,52 & $+0,01$ \\
\hline $08.09-12.09$ & 6,09 & 5,93 & $-0,16$ & $27.01-06.02$ & 8,03 & 8,20 & $+0,17$ \\
\hline $13.09-20.09$ & 5,62 & 5,98 & $-0,36$ & $07.02-16.02$ & 7,07 & 7,10 & $+0,03$ \\
\hline $21.09-25.09$ & 7,54 & 7,48 & $-0,06$ & $17.02-23.02$ & 6,14 & 6,10 & $-0,04$ \\
\hline $26.09-30.09$ & 7,44 & 7,59 & $+0,15$ & $24.02-28.02$ & 7,19 & 7,40 & $+0,21$ \\
\hline
\end{tabular}




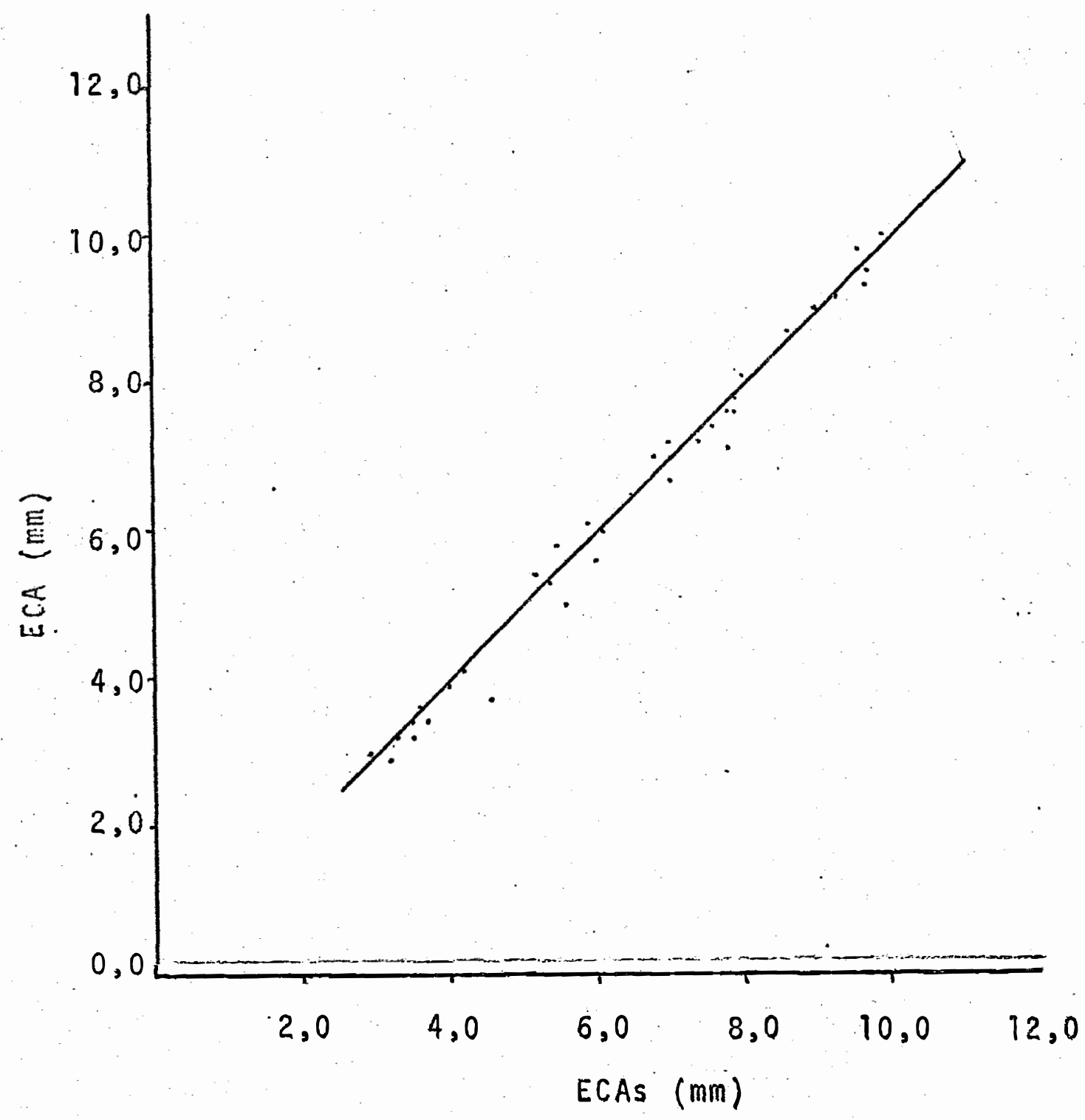

FIGURA 7: Grâfico representativo dos valores de evaporação medidos pelos tanques "Classe A" (ECA) e "CIasse $A^{\prime \prime}$ sifonado (ECAs) com base em mëdias de 5 dias. 
43 .

Tabela 3. Valiores representativos de evaporação diurna e evaporação noturna medidos pelos tanques "Classe A" (ECA), "Classe A" sifonado (ECAs) e a diferença entre os dois períodos (d), para mëdias de cinco (5) dias.

\begin{tabular}{|c|c|c|c|c|c|c|}
\hline \multirow[b]{2}{*}{ PERIODO } & \multicolumn{3}{|c|}{$\mathrm{ECA}$} & \multicolumn{3}{|c|}{ ECAs } \\
\hline & DIUR. & NOTUR & d & DIUR. & NOTUR & d \\
\hline $\begin{array}{l}01.06-06.06 \\
07.06-12.06 \\
13.06-17.06 \\
18.06-22.06 \\
23.06-27.06 \\
82.06-02.07 \\
03.07-07.07 \\
08.07-12.07 \\
13.07-24.07 \\
25.07-29.07 \\
30.07-06.08 \\
07.08-12.08 \\
13.08-18.08 \\
19.08-23.08 \\
24.08-28.08 \\
29.08-06.09 \\
08.09-12.09 \\
13.09-20.09 \\
21.09-25.09 \\
26.09-30.09 \\
01,10-05.10 \\
06.10-11.10 \\
12.10-17.10 \\
19.10-23.10 \\
24.10-01.11 \\
02.11-12.11 \\
13.11-19.11 \\
20.11-24.11 \\
25.11-30.11 \\
01.12-11.12\end{array}$ & $\begin{array}{l}1,64 \\
1,61 \\
1,46 \\
1,92 \\
1,58 \\
2,18 \\
1,76 \\
2,10 \\
2,05 \\
2,51 \\
2,91 \\
3,30 \\
2,30 \\
2,09 \\
3,67 \\
3,30 \\
4,05 \\
3,43 \\
5,02 \\
5,04 \\
5,76 \\
6,70 \\
5,29 \\
5,93 \\
6,35 \\
4,72 \\
5,05 \\
5,74 \\
6,27 \\
7,64\end{array}$ & $\begin{array}{l}1,36 \\
1,59 \\
1,46 \\
1,51 \\
1,63 \\
1,93 \\
1,71 \\
1,80 \\
1,40 \\
1,74 \\
2,06 \\
1,98 \\
1,26 \\
1,60 \\
2,09 \\
2,14 \\
2,04 \\
2,19 \\
2,52 \\
2,40 \\
2,63 \\
2,47 \\
1,86 \\
2,18 \\
2,61 \\
1,98 \\
2,07 \\
1,90 \\
2,41 \\
2,20\end{array}$ & $\begin{array}{l}+0,28 \\
+0,02 \\
0,00 \\
+0,41 \\
-0,05 \\
+0,25 \\
+0,05 \\
+0,30 \\
+0,65 \\
+0,77 \\
+0,85 \\
+1,32 \\
+1,04 \\
+0,49 \\
+1,58 \\
+1,16 \\
+2,01 \\
+1,24 \\
+2,50 \\
+2,64 \\
+3,07 \\
+4,23 \\
+3,43 \\
+3,75 \\
+3,74 \\
+2,74 \\
+2,98 \\
+3,84 \\
+3,86 \\
+5,44\end{array}$ & $\begin{array}{l}1,79 \\
1,77 \\
1,52 \\
1,82 \\
1,85 \\
2,12 \\
1,97 \\
2,32 \\
2,10 \\
2,48 \\
3,32 \\
3,34 \\
2,33 \\
3,00 \\
3,93 \\
3,37 \\
4,03 \\
3,84 \\
5,00 \\
4,99 \\
5,88 \\
6,85 \\
5,31 \\
5,81 \\
6,36 \\
4,96 \\
5,30 \\
5,75 \\
6,26 \\
7,64\end{array}$ & $\begin{array}{l}1,08 \\
1,49 \\
1,70 \\
1,65 \\
1,66 \\
2,03 \\
1,54 \\
1,66 \\
1,63 \\
1,76 \\
2,32 \\
2,05 \\
1,27 \\
1,65 \\
1,58 \\
1,88 \\
1,90 \\
2,14 \\
2,48 \\
2,60 \\
2,64 \\
2,44 \\
1,72 \\
2,20 \\
2,69 \\
1,99 \\
2,45 \\
2,01 \\
2,39 \\
1,92\end{array}$ & $\begin{array}{l}+0,71 \\
+0,28 \\
+0,18 \\
+0,17 \\
+0,19 \\
+0,09 \\
+0,43 \\
+0,66 \\
+0,47 \\
+0,72 \\
+1,00 \\
+1,29 \\
+1,06 \\
+1,35 \\
+2,35 \\
+1,49 \\
+1,13 \\
+2,13 \\
+1,70 \\
+2,52 \\
+2,39 \\
+3,24 \\
+4,41 \\
+4 \\
+3,59 \\
+3,61 \\
+3,61 \\
+3,67 \\
+2,97 \\
+2,85 \\
+3,74 \\
+3,87 \\
+3,72\end{array}$ \\
\hline
\end{tabular}


44.

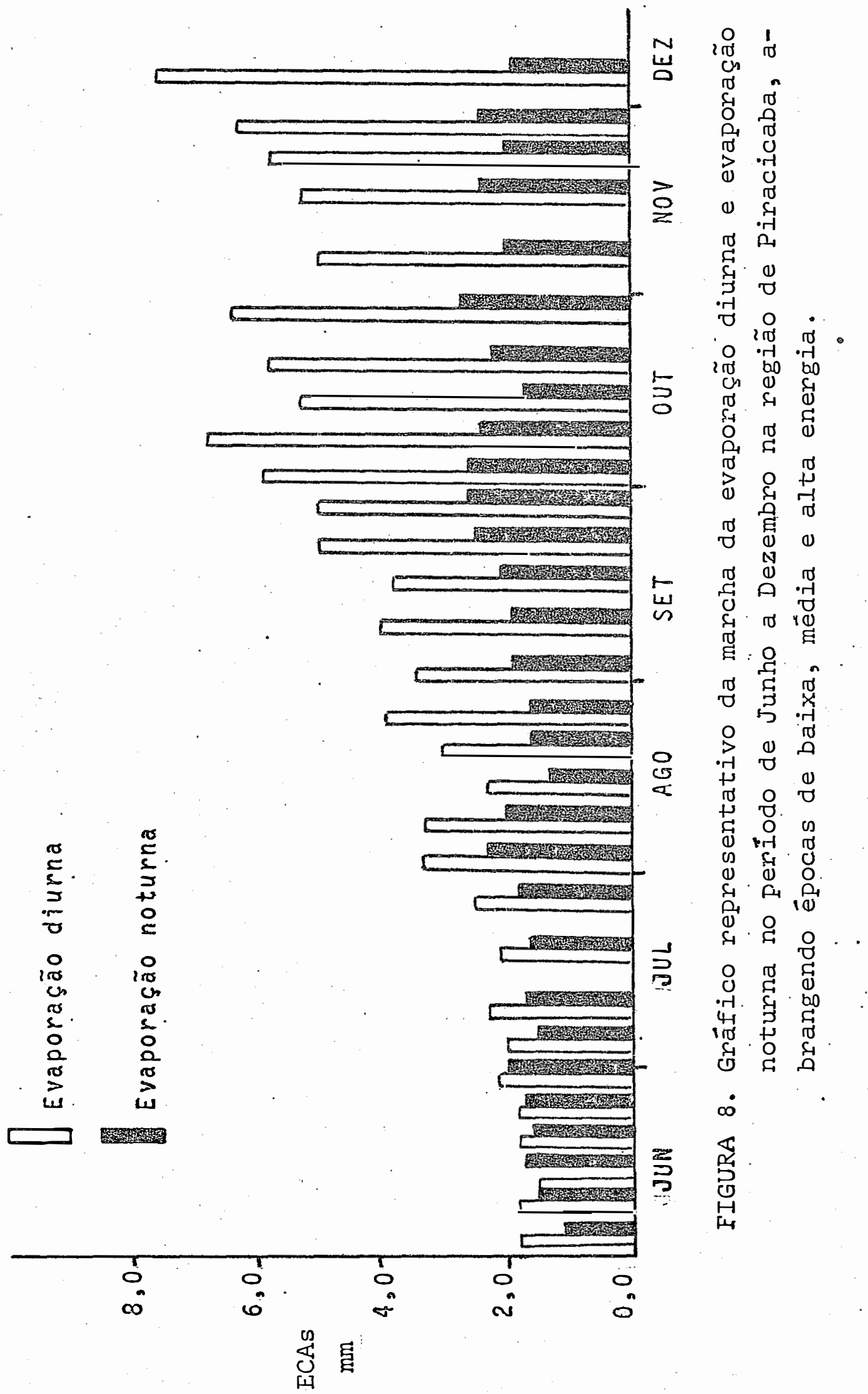


45.

5.2. Relativos à utilização do evaporímetro Piche na estimativa do componente aerodinâmico da fórmula de Penman.

No decorrer do trabalho estudou-se a equa ção proposta por Penman na sua forma original e uma simplificação da mesma utilizando o evanorímetro Piche na determinação. do componente aerndinâmico daquela, de modo a eliminar as limitações da falta de anemômetro a 2,0 m do nível do solo, na maioria das estações meteorológicas.

Fundamentado no trabalho desenvolvido por STANHILL (1962) em Israel, empregou-se o evaporimetro Piche operando-o da maneira tradicional, ou seja, com recarga de água após a evaporação total do volume disponivel, trocando - disco de papel apenas nessas ocasiões, ao contrário do que foi feito por aquele pesquisador, com recarga e trocas do disco diāriamente.

o termo aerodinâmico é calculado pelas seguin tes expressões:

a) para a evaporação da ãgua

EaV $=0,35\left(0,5+U_{2} / 160,9\right)\left(e_{s}-e_{a}\right) \mathrm{mm}$

b) para a evapotranspiração

EaT $=0,35\left(1,0+U_{2} / 160,9\right)\left(e_{s}-e_{a}\right) \quad m m$

nas quais, $U_{2}$ representa a velocidade média do vento "l em $\mathrm{km} \cdot \mathrm{dia}^{-1}$ e $\left(e_{\mathrm{s}}-e_{\mathrm{a}}\right)$ representa o défice de saturação do vapor no ar.

Aplicando um coeficiente multiplicativo (fun-

ção unicamente da temperatura do ar 1 ) ao termo . EaV $\frac{I}{\frac{\Delta}{\gamma}+1}$ ao termo

(ou EaT), temos representada a contribuição da temperatura no termo aerodinâmico.

Tais correlarões são possiveis porque a eva poração que ocorre no evaporimetro Piche colocado à sombra, 
tambëm è bàsicamente uma função da velocidade do ventó:e do dêfice de saturação no ar atmosfêrico.

Relacionando os valores estimados pelas fôn mulas propostas por PENMAN (1963) com os valores fornecido s por aquele evaporimetro, verificou-se uma dispersão dos pontos segundo uma reta.

o estudo da regressão obtida forneceu o seguin te resultado:

a) para a evaporação da âgua

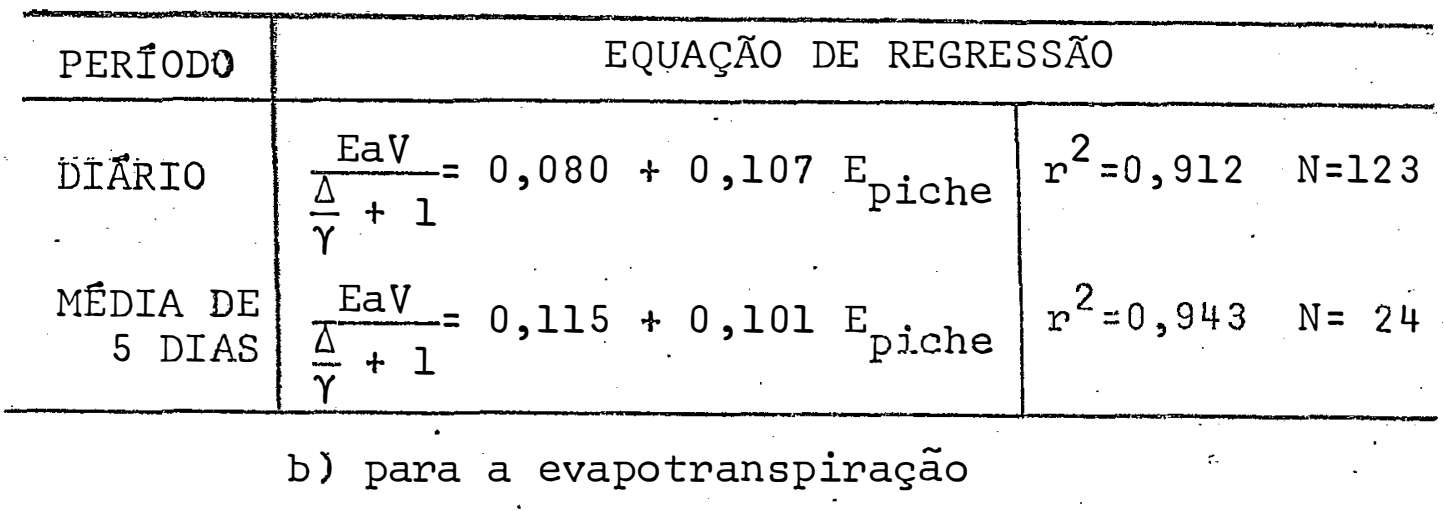

\begin{tabular}{|c|c|c|c|c|c|c|}
\hline PERIODO & \multicolumn{6}{|c|}{ EQUAÇÃO DE REGRESSÃO } \\
\hline DIÂRIO & $\frac{\mathrm{EaT}}{\frac{\Delta}{\gamma}+\frac{7}{t}}=$ & 0,230 & $+0,130$ & $E_{\text {piche }}$ & $r^{2}=0,840$. & $N=123$ \\
\hline $\begin{array}{l}\text { MEDIA DE } \\
5 \text { DIAS }\end{array}$ & $\frac{\mathrm{EaT}}{\frac{\Delta}{\gamma}+1}=$ & 0,224 & $+0,12$ & $E_{\text {piche }}$ & $r^{2}=0,958$ & $\mathrm{~N}=24$ \\
\hline
\end{tabular}

Os valores de $\frac{E a V}{\frac{\Delta}{\gamma}+1}$ e $\frac{E a T}{\frac{\Delta}{\gamma}+1}$ estimados atravês das equações originais e os valores de evaporação obtidos com - evaporimetro Piche, dos quais se lançou mão para a determinação das equações de regressão, constam da Tabela 4 em base diāria e da Tabela 5 com base em médias de cinco (5) dias. As Figuras 9 e 10 apresentam a dispersão dos pontos em base diāria respectivamente para a evaporação como para a evapotranspiração, bem como as retas representativas das equações de re 
gressão para cada caso; as Figuras II e 12 tem o mesmo objetivo para cada caso levando,porêm, em co-sideração as médias de cinco (5) dias.

A anảlise estatistica dos desvios entre os va lores do termo aerodinâmico estimados pelas equações origi nais e pelas equações encontradas no presente trabalho através das médias de cinco (5) dias e constantes das Tabelas 6 e 7 em base diäria e na Tabela 8 com base em mëdias de cinco (5) dias, é apresentada a seguir:

a) para a evaporação

\begin{tabular}{|c|c|c|c|c|c|c|}
\hline PERIODO & $r$ & $t$ & $t_{10 \%}$ & $t_{5 \%}$ & $t_{1 \%}$ & $\begin{array}{c}\text { CV } \\
\text { orig. } f\left({ }^{E_{p}}\right)\end{array}$ \\
\hline DIARIO & 0,9638 & 0,018 & 1,65 & 1,98 & 2,62 & $47,44,44,87$ \\
\hline $\begin{array}{l}\text { MEDIAS DE } \\
5 \text { DIAS }\end{array}$ & 0,9374 & 0,094 & 1,72 & 2,07 & 2,82 & $28,9527,27$ \\
\hline
\end{tabular}

b) para a evapotranspiração

\begin{tabular}{|c|c|c|c|c|c|c|}
\hline PERIODO & $r$ & $t$ & $t_{10 \%}$ & $t_{5 \%}$ & $t_{1 \%}$ & orig. $f\left({ }^{E_{p}}\right)$ \\
\hline DIÂRIO & 0,9692 & 0,095 & 1,65 & 1,98 & 2,62 & $43,9339,45$ \\
\hline $\begin{array}{c}\text { MEDIAS DE } \\
5 \text { DIAS }\end{array}$ & 0,9777 & 0,030 & 1,71 & 2,07 & 2,81 & $25,2325,23$ \\
\hline
\end{tabular}

Observa-se assim, que os desvios apresenta dos entre os valores dn termo aerodinâmico calculados da ma neira como foi proposta originalmente e o mesmo termo cal culado atravēs da equação de regressão com base em média.s de cinco (5) dias, apresentam uma alta correlação, os des vios entre os dois métodos não diferem de zero e os coefi cientes de variação são similares, podendo-se assumir, sem grande margem de erro que, para cada região, è possível de terminar uma equação de regressão com observações locais dạ. quele evaporímetro, de modo a eliminar as limitações da inexistência de anemômetros ao nivel de $2,0 \mathrm{~m}$ da superfície do solo na maioria das estações meteorolögicas, a fim de 
possibilitar o emprego do método de Penman.

Confrontando-se a equação encontrada por STANHILL (1962) com a obtida para a regĩão de Piracicaba,

$$
\begin{aligned}
& \frac{E a V}{\frac{\Delta}{\gamma}+1}=0,1118+0,1469 E_{\text {piche }} \text { (Israel) } \\
& \frac{E a V}{\frac{\Delta}{\gamma}+1}=0,115+0,101 \cdot E_{\text {pirhe }} \text { (Piracicaba) }
\end{aligned}
$$

nota-se que os coeficientes lineares praticamente não dife rem entre si e a diferença existente entre os, coeficientes angulares, acredita-se que possa ser atribuida ao manuseio do aparêlho, a diferenças nas condições climäticas dos dois locais, diferença na quantidade de valores utilizados e no pro cessamento dos mesmos.

Determinadas as equações de regressão jä re feridas, tomou-se para ambos os casos as equações obtidas por médias de cinco (5) diass, adaptando-as às equações para a es timativa da evaporação e da evapotranspiração pelo método de Penman.

Os resultados da evaporação da ägua e da evapotranspiração potencial assim estimados, forám então con frontados com os estimados pelo método original, estando representados na Tabela 9 com base em médias de cinco (5) di -

\begin{tabular}{|c|c|c|c|c|c|c|c|c|}
\hline \multirow{2}{*}{ PERIOODO } & \multirow[b]{2}{*}{$x$} & \multirow[b]{2}{*}{ t } & \multirow[b]{2}{*}{$t_{10 \%}$} & \multirow[b]{2}{*}{$t_{5 \%}$} & \multirow[b]{2}{*}{$t_{1 \%}$} & \multicolumn{2}{|c|}{$\mathrm{CV}$} & \multirow{2}{*}{ OBS. } \\
\hline & & & & & & orig & simp. & \\
\hline MEDIA DE & 0.9899 & 0.205 & 1.75 & 3 & 95 & 960 & 9.30 & FV \\
\hline $\begin{array}{r}\text { MEDDIA DE } \\
5 \text { DIAS }\end{array}$ & 0,9847 & 0,008 & 1,78 & 2,18 & 3,06 & 10,34 & 10,06 & ETP \\
\hline
\end{tabular}
as e a análise estatística apresentou o seguinte resultado:

respectivamente para a evaporação e a evapotranspiração. 
Em face dos resultados da anālise estatisti ca, pode-se verificar que houve alta correlação para as si tuações estudadas; os desvios não apresentaram significância e os coeficientes de variação se equivaleram, de modo : a confirmar a similaridade dos dois métodos dentro do rigor exigido.

Desde que a equação de Penman seja separa da em seus dois termos (energêtico e aerodinâmico) para quaisquer dos objetivos, verifica-se que o termo aerodinâmico con tribuiư durante os nove (9) mese de trabalho com uma mé dia de $19 \%$, variando de $26 \%$ a $12 \%$ e durante o periodo de correlação com o evaporímetro Piche, com uma média de $16 \%$, vari ando de $19 \%$ a $12 \%$, conforme mostra o quadro abaixo:

\begin{tabular}{l|cllllllll}
\hline CONTRIBUIÇÃO & JUN & JUL & AGO & SET & OUT & NOV & DEZ & JAN & FEV \\
\hline $\begin{array}{c}\text { Evaporação } \\
f\left(U_{2}, \Delta e\right)\end{array}$ & $23 \%$ & $.22 \%$ & $26 \%$ & $22 \%$ & $19 \%$ & $16 \%$ & $15 \%$ & $17 \%$ & $12 \%$ \\
\hline
\end{tabular}

Assim, : iesse fato vem aumentar a viabilida de da simplificação do mëtodo pois, considerando-se os desvi os como "ERROS", estes serão minimos de modo a não prejudicar a estimativa de quaisquẹ̣ dos fenômenos. 
Tabela 4. Valores representativos de evaporação fornecida pe

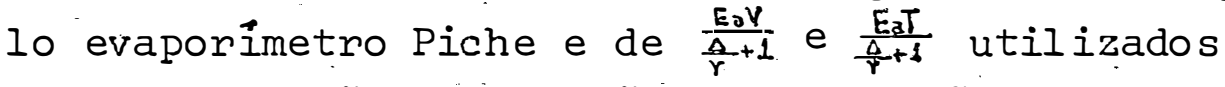
na determinação da equação de regressão a fim de empregar aquele evaporimetro para a estimativa do componente aerodinâmico da equação de Penman.

\begin{tabular}{|c|c|c|c|c|c|c|c|c|c|}
\hline \multirow[b]{2}{*}{ DIA } & \multicolumn{3}{|c|}{ OUTUBRO } & \multicolumn{3}{|c|}{ NOVEMBRO } & \multicolumn{3}{|c|}{ DEZEMBRO } \\
\hline & $\frac{\frac{E_{a} V}{\partial}}{\frac{\partial}{\gamma}+1}$ & $\frac{\frac{E_{e} T}{P}}{\frac{\Delta}{+1}}$ & $\mathrm{E}_{\mathrm{pi}}$ & $\frac{\frac{E_{a} V}{\frac{A}{r}+1}}{\frac{1}{3}}$ & $\frac{E_{a} T}{\frac{\Delta}{V}+1}$ & $\mathrm{E}_{\mathrm{pi}}$ & $\frac{\frac{E V}{\partial}}{\frac{a}{r}+1}$ & $\frac{\frac{E a T}{\Delta}}{\frac{\Delta}{r}+1}$ & $\mathrm{E}_{\mathrm{pi}}$ \\
\hline 01 & - & - & - & 1,11 & 1,40 & 7,30 & 1,28 & 1,75 & 11,80 \\
\hline 02 & - & - & - & 1,36 & 1,67 & 11, & 0,83 & 1,15 & \\
\hline 0 & - & - & - & 0,66 & 0,85 & 4, & 1,18 & 1,57 & 8,70 \\
\hline 04 & - & - & - & 0,43 & 0,56 & 2, & & - & 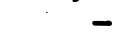 \\
\hline 05 & - & - & - & 0,15 & 0,21 & 1, & - & - & - \\
\hline 06 & - & - & - & 0,56 & 0,81 & & 0,48 & 0,66 & 3,50 \\
\hline 07 & - & - & - & 1,02 & 1,36 & 8, & 0,27 & 0,36 & 1,7 \\
\hline $0 \varepsilon$ & - & - & - & 0,87 & 1,21 & & 0,20 & 0,32 & 1,40 \\
\hline 09. & - & - & - & 1,23 & 1,68 & 8, & 0,15 & 0,22 & 1,00 \\
\hline $10^{\circ}$ & - & - & - & 0,22 & 0,32 & & 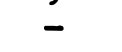 & - & , \\
\hline 11 & - & - & - & 0,31 & 0,40 & 2 , & 1,59 & 1,96 & 12,70 \\
\hline 12 & - & - & - & 0,33 & 0,47 & & 1,04 & 1,37 & 8, \\
\hline 13 & - & - & - & 0,95 & 1,27 & 6 , & 0,82 & 1,16 & 7, \\
\hline 14 & 0,40 & 0,57 & 3,30 & 0,77 & 1,37 & & 0,42 & 0,92 & $3, \varepsilon$ \\
\hline 15 & 0,96 & 1,25 & 7,30 & 1,09 & 1,45 & 8, & 0,38 & 0,57 & 3,30 \\
\hline 16 & 0,73 & 0,98 & 5,70 & 0,15 & 0,19 & 1 , & 0,46 & 0,64 & 3,5 \\
\hline 17 & 1,10 & 1,41 & 8,90 & 0,78 & 1,03 & 4,50 & 0,95 & 1,24 & 6 , \\
\hline 18 & & - & - & & & & 0,91 & 1,21 & 5, \\
\hline 1.9 & - & - & - & 1,06 & 1,39 & 7, & 0,94 & 1,24 & 7, \\
\hline 20 & 0,78 & 1,06 & 6,60 & 0,74 & 1,01 & & 0,96 & 1,36 & \\
\hline 21 & 1,01 & 1,31 & 10,00 & 0,73 & 1,01 & 5, & 1,49 & 2,04 & 13, \\
\hline 22 & 0,88 & 1,21 & & 0,61 & 0,87 & & 1,53 & 1,95 & 12, \\
\hline 23 & 0,96 & 1,38 & 0 & $0,9.5$ & 1,24 & 6 , & 1,03 & 1,34 & 8,4 \\
\hline 24 & 1,47 & 2,05 & 13,10 & 1,02 & 1,34 & 11 , & 1,02 & 1,38 & 7,6 \\
\hline 2 & 1,44 & 1,99 & & 0,84 & 1,17 & 7,00 & & & \\
\hline 26 & 1,34 & 1,91 & 11 , & 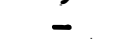 & 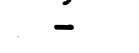 & 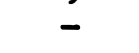 & 0,18 & 0,25 & 0 , \\
\hline 27 & 0,66 & 0,88 & 4, & & 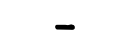 & - & 0,13 & 0,22 & 1, \\
\hline 28 & 0,62 & 0,8 & 4, & - & - & - & 0,17 & 0,29 & 1,70 \\
\hline 25 & 0,38 & 0,5 & 2,20 & 1,06 & 1,38 & 9,60 & 0,19 & 0,29 & \\
\hline 30 & 0,55 & 0,81 & 4,30 & 0,93 & 1,24 & 9,10 & 0,42 & 0,64 & 3,80 \\
\hline 31 & & & & & & & 0,68 & 1,01 & 6,20 \\
\hline
\end{tabular}


Tabela 4. Comtinuação.

\begin{tabular}{|c|c|c|c|c|c|c|c|c|c|}
\hline \multirow[b]{2}{*}{ DIA. } & \multicolumn{3}{|c|}{ JANEIRO } & \multicolumn{3}{|c|}{ FEVEREIRO } & \multicolumn{3}{|c|}{ MARÇO } \\
\hline & $\frac{E_{j} V}{\frac{A}{Y} 1}$ & $\frac{\frac{E_{0} T}{\frac{B}{P}}+2}{P}$ & $E_{p i}$ & $\frac{E_{a} V}{\frac{\Delta}{r}+1}$ & $\frac{E_{0} T}{\frac{\Delta}{\gamma}+1}$ & $E_{p i}$ & $\frac{E_{a} V}{\frac{A}{r}+1}$ & $\frac{E_{e} T}{\frac{\Delta}{\gamma}+1}$ & $E_{p i}$ \\
\hline 01 & 0,44 & 0,64 & 3,00 & 0,82 & 1,11 & 7,40 & 0,54 & 0,60 & 2,60 \\
\hline 02 & 0,26 & 0,41 & 2,30 & 0,76 & 1,06 & 6,40 & 1,09 & 1,35 & 8,30 \\
\hline 03 & 0,31 & 0,49 & 2,60 & 1,30 & 1,65 & 10,60 & 1,02 & 1,32 & 8,60 \\
\hline 04 & 0,83 & 1,06 & 6,20 & 0,83 & 1,12 & 8,00 & - & - & - \\
\hline 05 & 1,23 & 1,55 & 9,20 & 0,65 & 0,94 & 6,00 & - & - & - \\
\hline 06 & 1,48 & 1,84 & 11,70 & 0,54 & $0 ; 85$ & 5,30 & - & - & - \\
\hline 17 & 1,31 & 1,69 & 12,70 & 0,70 & 1,08 & 6,90 & - & - & - \\
\hline 08 & 1,14 & 1,52 & 8,50 & 0,94 & 1,31 & 9,50 & - & - & - \\
\hline 09 & 1,52 & 1,90 & 12,60 & 0,63 & 0,90 & 6,40 & - & - & - \\
\hline 10 & 0,96 & 1,34 & 8,60 & 0,41 & 0,60 & 3,60 & - & - & - \\
\hline 12 & 0,49 & 0,70 & 3,90 & 0,35 & 0,50 & 3,30 & - & - & - \\
\hline 12 & 0,76 & 0,97 & 5,10 & 0,66 & 0,83 & 3,00 & - & - & - \\
\hline 13 & 1,33 & 1,68 & 11,40 & - & - & - & - & - & - \\
\hline 14 & 1,30 & 1,66 & 11,60 & 0,28 & 0,39 & 2,90 . & - & - & - \\
\hline 15 & 1,31 & 1,70 & 11,50 & - & - & - & - & - & - \\
\hline 16 & 1,12 & 1,46 & 10,80 & 0,52 & 0,78 & 5,30 & - & - & - \\
\hline 17 & 1,17 & 1,52 & 10,70 & 0,26 & 0,41 & 2,60 & - & - & - \\
\hline 18 & 1,21 & 1,54 & 10,40 & 0,41 & 0,66 & 3,90 . & - & - & - \\
\hline 19 & 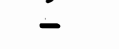 & - & 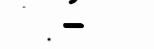 & 0,75 & 1,06 & 6,80 & - & - &. \\
\hline 20 & 0,40 & 1,73 & 3,60 & 0,92 & 1,36 & 7,00 & - & - & - \\
\hline 21 & 0,48 & 0,50 & 4,60 & $I, 01$ & 1,26 & 6,80 & - & - & - \\
\hline 22 & 1,10 & - & 8,90 & 0,34 & 0,45 & 2,70 & - & - & - \\
\hline 23 & 0,75 & 1,39 & 7,30 & 0,41 & 0,73 & 5,00 & - & - & - \\
\hline 24 & 0,60 & 1,07 & 5,90 & 0,62 & 0,91 & 5,90 & - & - & - \\
\hline 25 & - & - & - & 0,63 & 0,96 & 7,00 & - & - & - \\
\hline 26 & - & - & - & 0,81 & 1,22 & 7,70 & - & - & - \\
\hline 27 & 0,76 & 1,03 & 4,70 & 0,73 & $1,03$. & 5,30 & - & - & - \\
\hline 28 & 0,44 & 0,61 & 3,20 & 0,70 & 1,02 & 7,10 & - & - & - \\
\hline 29. & - & - & - & - & - & - & - & - & - \\
\hline 30 & - & - & - & - & - & - & - & - & - \\
\hline 31 & 1,13 & 1,42 & 10,00 . & - & - & - & - & - & - \\
\hline
\end{tabular}



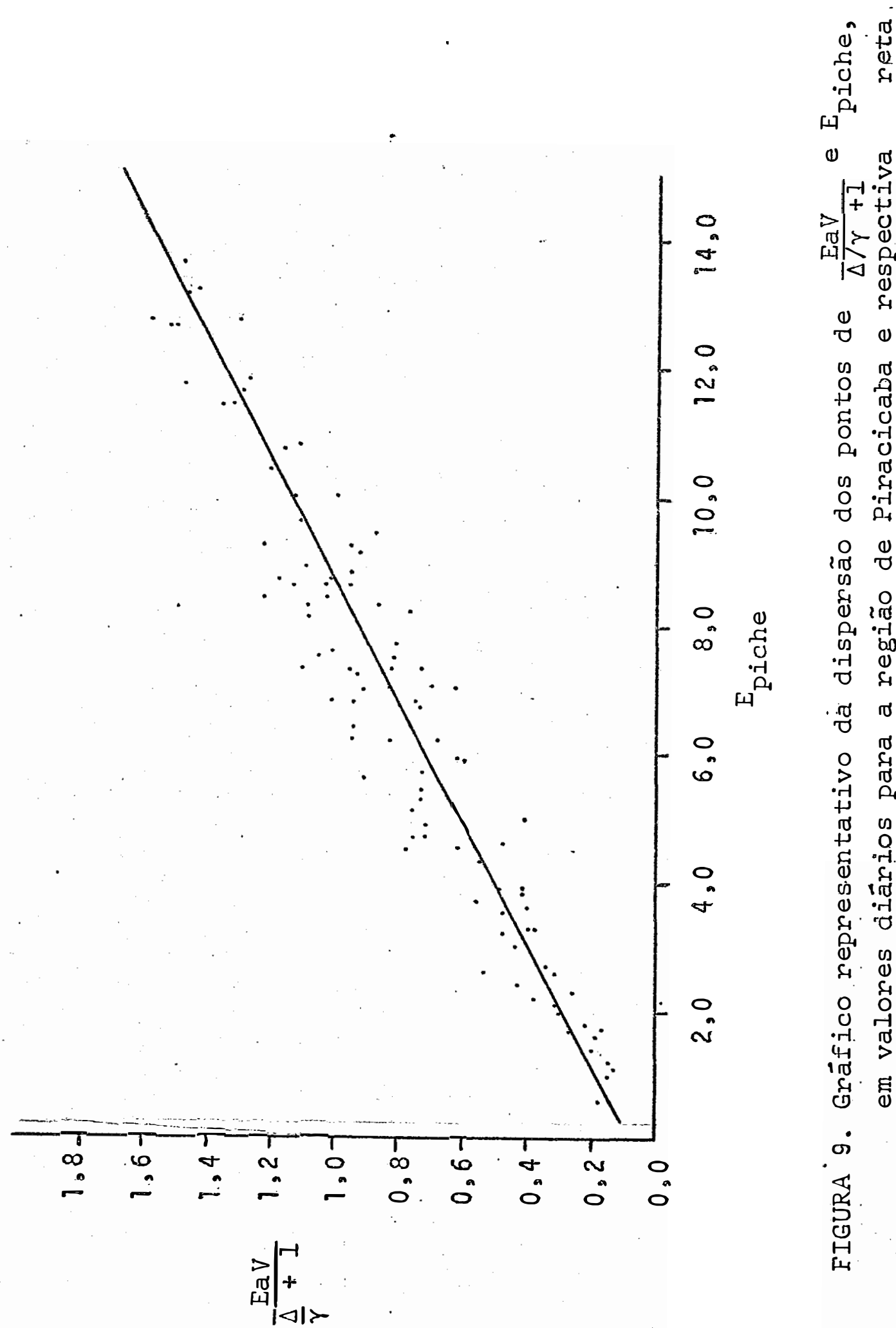

(1)

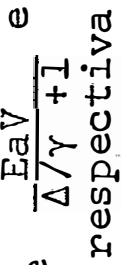

(1)

ต

둥

O 0

(1) ठठ

ग

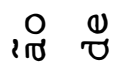

C

(1) $2 \mathrm{rot}$

1.

थ 0

ता 10

+

○

in

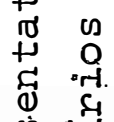

(i) 1 त्ष

द.

दि '

द. ज ज

\begin{tabular}{lll}
0 & \multicolumn{1}{c}{0} \\
0 & 0 & है
\end{tabular}

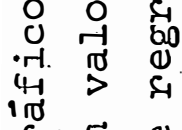

ชु हี

品 
53.

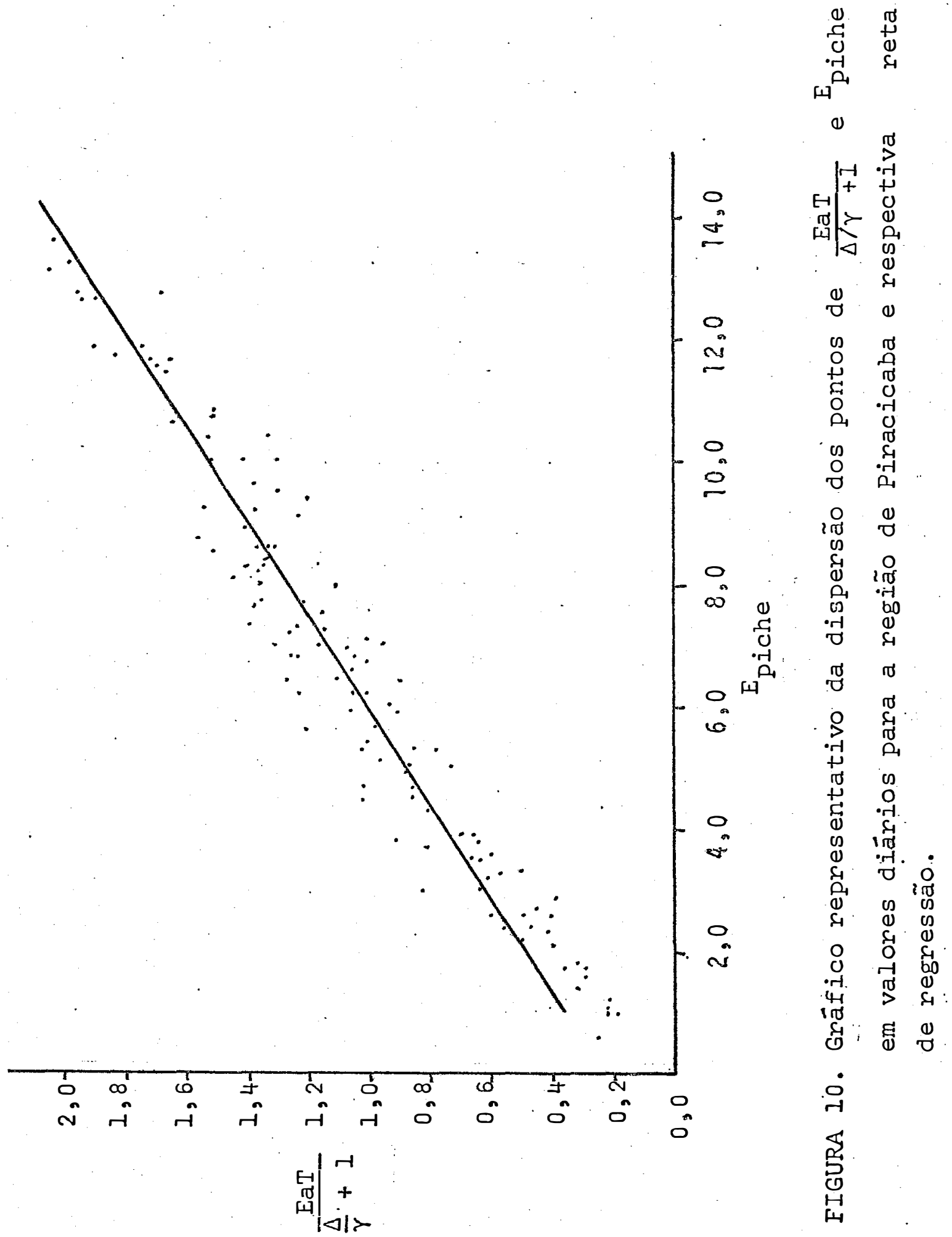


Tabela 5. Valores representativos de evaporação fornecidos pe Io evaporimetro Piche e de $\frac{E_{2 V} V}{\frac{A}{r}+1}$ e $\frac{\frac{E_{\partial} T}{\frac{\Delta}{\gamma}+1}}{\text { com base em }}$ médĩa de cinco (5) dias, utilizados na determinação da equação de regressão a fim de empregar aquele evaporimetro na estimativa do componente aerodinâmico da equação de Penman.

\begin{tabular}{|c|c|c|c|}
\hline PERIODO & $\frac{E J V}{\frac{\partial}{r}+1}$ & $\frac{E_{a} T}{\frac{\Delta}{Y}+1}$ & $E_{p i}$ \\
\hline $14.10-20.10$ & 0,79 & 1,05 & 6,36 \\
\hline $21.10-25.10$ & 1,15 & 1,59 & 10,98 \\
\hline $26.10-30.10$ & 0,71 & $0,-99$ & 5,54 \\
\hline $01.11-05.11$ & 0,74 & 0,94 & 5,40 \\
\hline $06.11-10.11$ & 0,78 & 1,08 & 6,18 \\
\hline $11.11-15.11$. & $0 ; 71$ & $0 ; 99$ & 5,44 \\
\hline $16.11-21.11$ & $0 ; 69$ & 0,93 & 5,02 \\
\hline $22.11-29.11$ & 0,90 & 1,20 & 7,96 \\
\hline $30.11-06.12$ & 0,94 & 1,27 & 8,08 \\
\hline $07.12-12.12$ & 0,65 & 0,85 & 5,08 \\
\hline $13.12-17.12$ & 0,61 & 0,91 & 4,86 \\
\hline $18.12-22.12$ & 1,17 & 1,57 & 9,56 \\
\hline $23.12-28.12$ & 0,51 & 0,70 & 3,88 \\
\hline $29.12-02.01$ & 0,40 & 0,60 & 3,38 \\
\hline $03.01-07.01$ & 1,03 & 1,33 & 8,48 \\
\hline $08.01-12.01$ & 0,97 & 1,29 & 7,74 \\
\hline $13.01-17.01$ & 1,25 & 1,60 & 11,20 \\
\hline $18.01-23.01$ & 0,79 & 1,16 & 6,96 \\
\hline $24.01-01.02$ & 0,75 & 1,05 & 6,24 \\
\hline $02.02-06.02$ & 0,82 & 1,12 & 7,26 \\
\hline $07.02-11.02$ & 0,61 & 0,81 & 5,94 \\
\hline $12.02-18.02$ & 0,43 & 0,61 & 3,54 \\
\hline $19.02-23.02$ & 0,69 & 0,97 & 5,66 \\
\hline $24.02-28.02$ & 0,70 & 1,03 & 6,60 \\
\hline
\end{tabular}



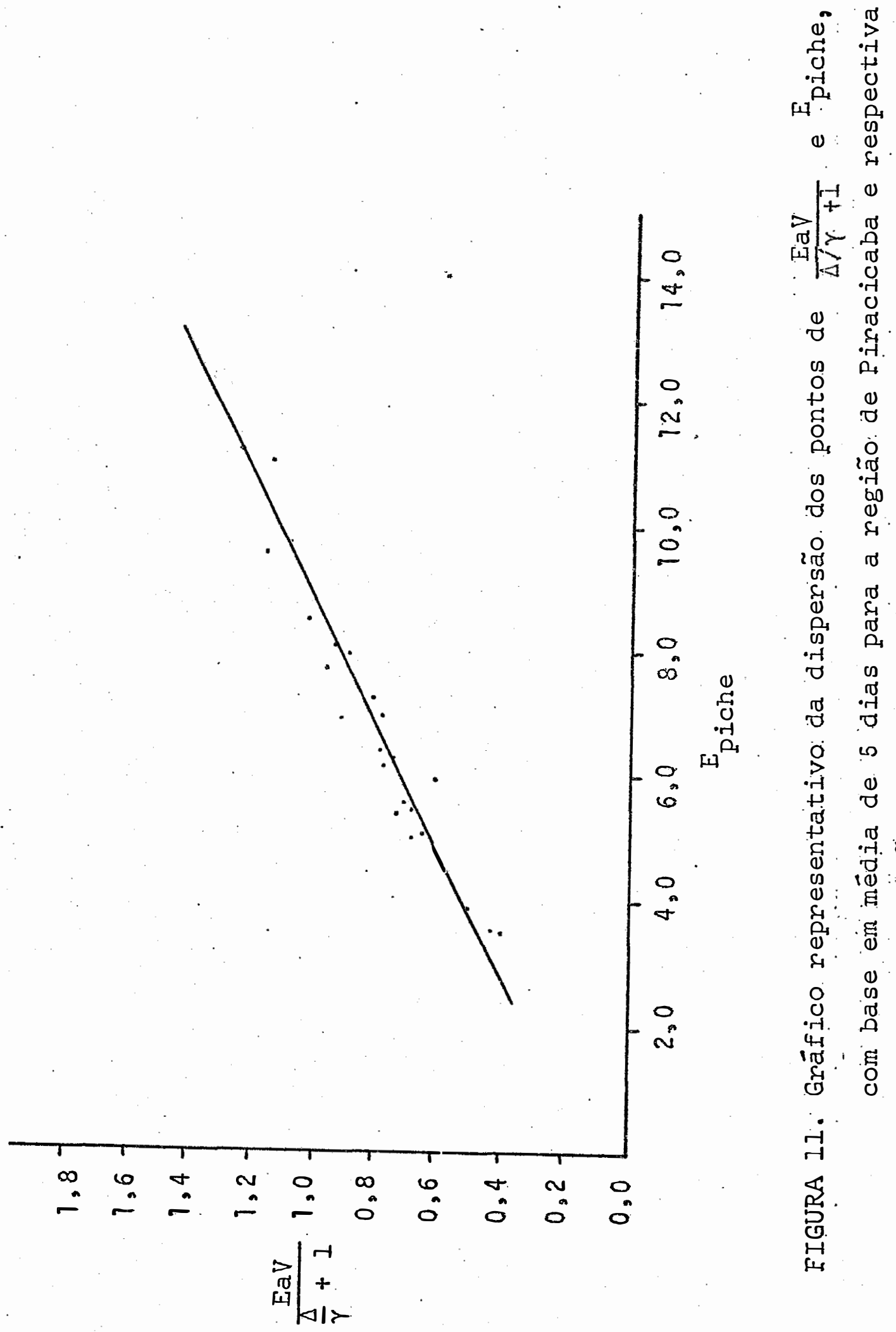

$2 \mid \begin{array}{ll}+1 & 0 \\ t & 0\end{array}$

4.

:

$\underset{\nabla}{0}$

Ư

क मि

芩

ค Ò

ต 2 .

.

이

2त

की.

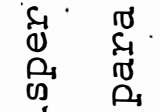

. 4 (

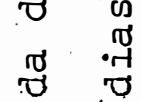

$\begin{array}{ll}0 & 0 \\ 0 & 0\end{array}$

蔡

क्ष : मि

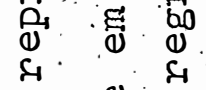

$\begin{array}{lll}\text { म } & 0 & \text { ज } \\ 0 & 0 & 0\end{array}$

. त. त्ठ

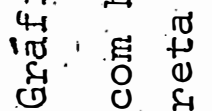

त्

峁 

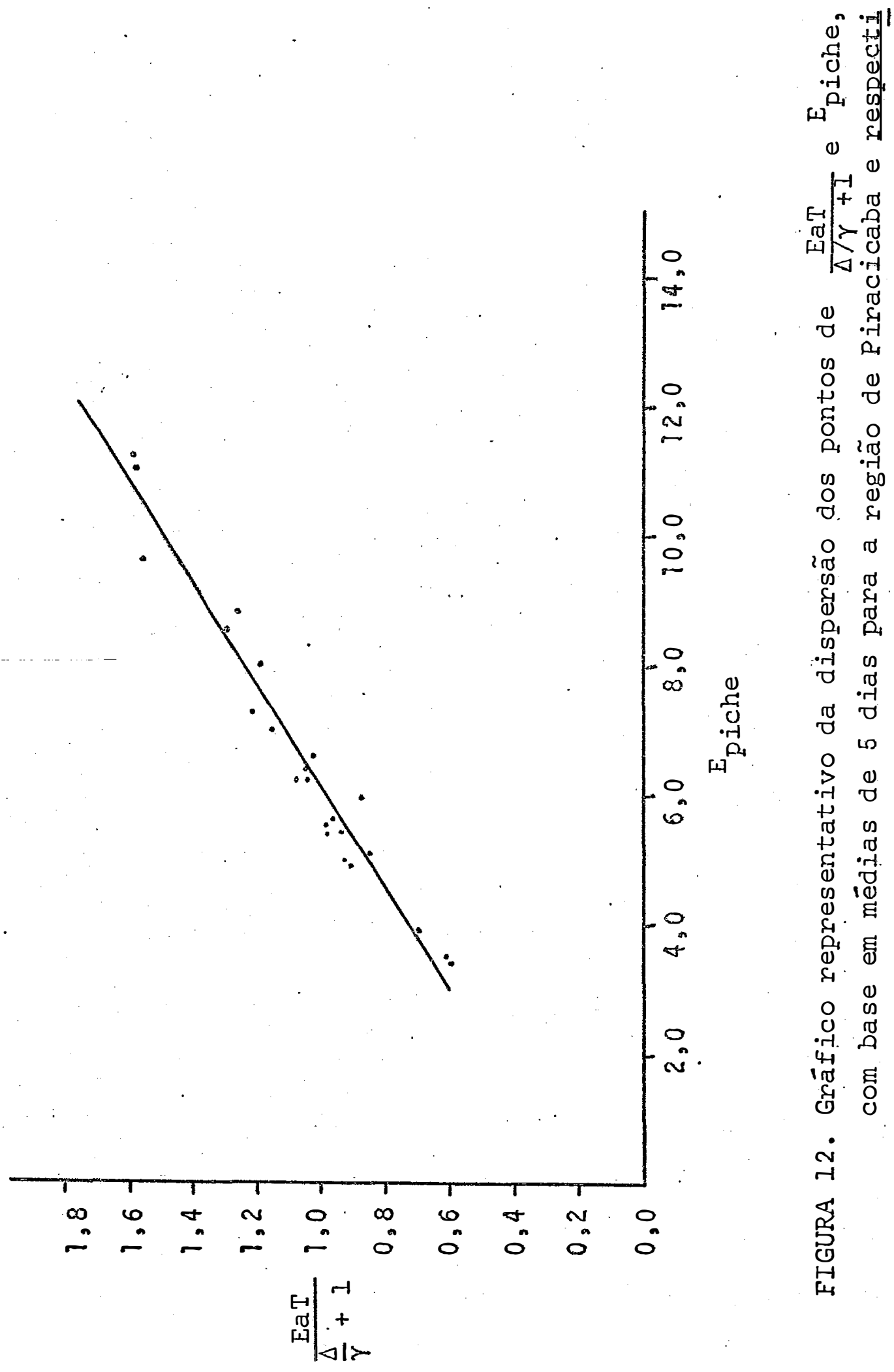

(1)

$\left[\begin{array}{ll}-1 & 0 \\ + & 0 \\ & 0\end{array}\right.$

舟两

$\Delta \cdot 4$

שै

क लि

今

D $2 \pi$

क 00

ठ্

20 r

क्वे क्ष

$D_{1} D_{1}$

•

ฮ

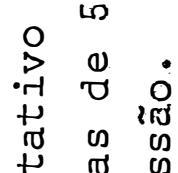

H 0

क

d. E \&

仓ै है

\begin{tabular}{lll}
\hline & 0 & 0 \\
0 & $\infty$ & 0
\end{tabular}

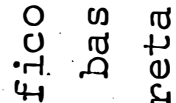

出 ह \&

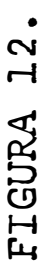


Tabela 6. Valores representativos do componente aerodinâmico da equação de Penman para a estimativa da evapora ção, calculados atravês da expressão original e em função do evaporímetro Piche e respectivos desvios. ( $d=f$ Piche-original).

\begin{tabular}{c|ccc|ccc|ccc}
\hline \multirow{2}{*}{ DIA } & \multicolumn{3}{|c}{ OUTUBRO } & \multicolumn{4}{|c}{ NOVEMBRO } & \multicolumn{3}{c}{ DEZEMBRO } \\
\cline { 2 - 9 } & $0 r$. & fPi & $\mathrm{d}$ & Or. & f.Pi & d & Or. & f.Pi & d \\
\hline 01 & - & - & - & 1,11 & 0,86 & $-0,25$ & 1,28 & 1,35 & $+0,07$ \\
02 & - & - & - & 1,36 & 1,30 & $-0,06$ & 0,83 & 0,86 & $+0,03$ \\
03 & - & - & - & 0,66 & 0,58 & $-0,08$ & 1,18 & 1,01 & $-0,17$ \\
04 & - & - & - & 0,43 & 0,34 & $-0,09$ & - & - & - \\
05 & - & - & - & 0,15 & 0,21 & $+0,06$ & - & - & - \\
06 & - & - & - & 0,56 & 0,48 & $-0,08$ & 0,48 & 0,46 & $-0,02$ \\
07 & - & - & - & 1,02 & 1,01 & $-0,01$ & 0,27 & 0,26 & $-0,01$ \\
08 & - & - & - & 0,87 & 0,97 & $+0,10$ & 0,20 & 0,23 & $+0,03$ \\
09 & - & - & - & 1,23 & 0,98 & $-0,25$ & 0,15 & 0,19 & $+0,04$ \\
10 & - & - & - & 0,22 & 0,27 & $+0,05$ & - & - & - \\
11 & - & - & - & 0,31 & 0,31 & 0,00 & 1,59 & 1,44 & $-0,15$ \\
12 & - & - & - & 0,33 & 0,34 & $+0,01$ & 1,04 & 1,00 & $-0,04$ \\
13 & - & - & - & 0,95 & 0,77 & $-0,18$ & 0,82 & 0,88 & $+0,06$ \\
14 & 0,40 & 0,43 & $+0,03$ & 0,77 & 0,96 & $+0,19$ & 0,42 & 0,49 & $+0,07$ \\
15 & 0,96 & 0,86 & $-0,10$ & 1,09 & 0,95 & $-0,14$ & 0,38 & 0,43 & $+0,05$ \\
16 & 0,73 & 0,69 & $-0,04$ & 0,15 & 0,19 & $+0,04$ & 0,46 & $0,46$. & 0,00 \\
17 & 1,10 & 1,04 & $-0,06$ & 0,78 & 0,56 & $-0,22$ & 0,95 & 0,75 & $-0,20$ \\
18 & - & - & - & - & - & - & - & - & - \\
19 & - & - & - & 1,06 & 0,88 & $-0,18$ & 0,94 & 0,85 & $-0,09$ \\
20 & 0,78 & 0,79 & $+0,01$ & 0,74 & 0,80 & $+0,06$ & 0,96 & 1,02 & $+0,06$ \\
21 & 1,01 & 1,15 & $+0,14$ & 0,73 & 0,66 & $-0,07$ & 1,49 & 1,54 & $+0,05$ \\
22 & 0,88 & 1,09 & $+0,21$ & 0,61 & 0,62 & $+0,01$ & 1,53 & 1,43 & $-0,10$ \\
23 & 0,96 & 1,07 & $+0,11$ & 0,95 & 0,81 & $-0,14$ & 1,03 & 0,98 & $-0,05$ \\
24 & 1,47 & 1,49 & $+0,02$ & 1,02 & 1,30 & $+0,28$ & 1,02 & 0,90 & $-0,12$ \\
25 & 1,44 & 1,50 & $+0,06$ & 0,84 & 0,83 & $-0,01$ & - & - & - \\
26 & 1,34 & 1,35 & $+0,01$ & - & - & - & 0,188 & 0,14 & $-0,04$ \\
27 & 0,66 & 0,61 & $-0,05$ & - & - & - & 0,13 & 0,20 & $+0,07$ \\
28 & 0,62 & 0,56 & $-0,06$ & - & - & - & 0,17 & 0,26 & $+0,09$ \\
29 & 0,38 & 0,32 & $-0,06$ & 1,06 & 1,11 & $+0,05$ & 0,19 & 0,25 & $+0,06$ \\
30 & 0,55 & 0,54 & $-0,01$ & 0,93 & 1,06 & $+0,13$ & 0,42 & 0,49 & $+0,07$ \\
31 & - & - & - & - & - & - & 0,68 & 0,75 & $+0,07$ \\
\hline
\end{tabular}


Tabela 6. Continuação

\begin{tabular}{c|ccc|ccc|cccc}
\hline & \multicolumn{3}{|c|}{ JAREIRO } & \multicolumn{3}{c|}{ FEVEREIRO } & \multicolumn{3}{c|}{ MARÇO } \\
\cline { 2 - 9 } DIA & $0 \mathrm{y}$. & fPi & $\mathrm{d}$ & Or. & fPi & $\mathrm{d}$ & Or. & fPi & d \\
\hline 01 & 0,44 & 0,40 & $-0,04$ & 0,82 & 0,87 & $+0,05$ & 0,54 & 0,36 & $-0,18$ \\
02 & 0,26 & 0,33 & $+0,07$ & 0,76 & 0,77 & $+0,01$ & 1,09 & 0,97 & $-0,12$ \\
03 & 0,31 & 0,36 & $+0,05$ & 1,30 & 1,22 & $-0,08$ & 1,02 & 1,00 & $-0,02$ \\
04 & 0,83 & 0,75 & $-0,08$ & 0,83 & 0,94 & $+0,11$ & - & - & - \\
05 & 1,23 & 1,07 & $-0,16$ & 0,65 & 0,72 & $+0,07$ & - & - & - \\
06 & 1,48 & 1,34 & $-0,14$ & 0,54 & 0,65 & $+0,11$ & - & - & - \\
07 & 1,31 & 1,44 & $+0,13$ & 0,70 & 0,82 & $+0,12$ & - & - & - \\
08 & 1,14 & 0,99 & $-0,15$ & 0,94 & 1,10 & $+0,16$ & - & - & - \\
09 & 1,52 & 1,43 & $-0,09$ & 0,63 & 0,77 & $+0,14$ & - & - & - \\
10 & 0,96 & 1,00 & $+0,04$ & 0,41 & 0,47 & $+0,06$ & - & - & - \\
11 & 0,49 & 0,50 & $+0,01$ & 0,35 & 0,43 & $+0,08$ & - & - & - \\
12 & 0,76 & 0,63 & $-0,13$ & 0,66 & 0,40 & $-0,26$ & - & - & - \\
13 & 1,33 & 1,30 & $-0,03$ & - & - & - & - & - & - \\
14 & 1,30 & 1,32 & $+0,02$ & 0,28 & 0,39 & $+0,11$ & - & - & - \\
15 & 1,31 & 1,31 & 0,00 & - & - & - & - & - & - \\
16 & 1,12 & 1,24 & $+0,12$ & 0,52 & 0,65 & $+0,13$ & - & - & - \\
17 & 1,17 & 1,23 & $+0,06$ & 0,26 & 0,36 & $+0,10$ & - & - & - \\
18 & 1,21 & 1,20 & $-0,01$ & 0,41 & 0,50 & $+0,09$ & - & - & - \\
19 & - & - & - & 0,75 & 0,81 & $+0,06$ & - & - & - \\
20 & 0,40 & 0,47 & $+0,07$ & 0,92 & 0,83 & $-0,09$ & - & - & - \\
21 & 0,48 & 0,57 & $+0,09$ & 1,01 & 0,81 & $-0,20$ & - & - & - \\
22 & 1,10 & 1,04 & $-0,06$ & 0,34 & 0,37 & $+0,03$ & - & - & - \\
23 & 0,75 & 0,86 & $+0,11$ & 0,41 & 0,62 & $+0,21$ & - & - & - \\
24 & 0,60 & 0,71 & $+0,11$ & 0,62 & 0,71 & $+0,09$ & - & - & - \\
25 & - & - & - & 0,63 & 0,83 & $+0,20$ & - & - & - \\
26 & - & - & - & 0,81 & 0,91 & $+0,10$ & - & - & - \\
27 & 0,76 & 0,58 & $-0,18$ & 0,73 & 0,65 & $-0,08$ & - & - & - \\
28 & 0,44 & 0,42 & $-0,02$ & 0,70 & 0,84 & $+0,14$ & - & - & - \\
29 & - & - & - & - & - & - & - & - & - \\
30 & - & - & - & - & - & - & - & - & - \\
31 & 1,13 & 1,15 & $+0,02$ & - & - & - & - & - & - \\
\hline
\end{tabular}


Tabela 7. Valores representativos do componente :aerodinâmico da equação de Penman para a estimativa da evapotranspiração potencial, calculados através da expressão original e em função do evaporimetro Piche e respectivos desvios ( $d=f P$ iche-original)

\begin{tabular}{|c|c|c|c|c|c|c|c|c|c|}
\hline \multirow{2}{*}{ DIA } & \multicolumn{3}{|c|}{ OUTUBRO } & \multicolumn{3}{|c|}{ NOVEMBRO } & \multicolumn{3}{|c|}{ DEZ EMBRO } \\
\hline & Or. & fPi & $d$ & Or. & fPi & $d$ & Or. & fPi & $d$ \\
\hline 01 & - & - & - & $1,40^{\circ}$ & 1,18 & $-0,22$ & 1,75 & 1,76 & $+0,01$ \\
\hline 02 & - & - & - & 1,67 & 1,71 & $+0,04$ & 1,15 & 1,18 & $+0,03$ \\
\hline 03 & - & - & - & 0,85 & 0,84 & $-0,01$ & 1,57 & 1,36 & $-0,21$ \\
\hline 04 & - & - & - & 0,56 & 0,54 & $-0,02$ & - & - & - \\
\hline 05 & - & - & - & 0,21 & 0,39 & $+0,18$ & - & - & - \\
\hline 06 & - & - & - & 0,81 & 0,71 & $-0,10$ & 0,66 & 0,69 & $+0,03$ \\
\hline 07 & - & - & - & 1,36 & 1,36 & 0,00 & 0,36 & 0,45 & $+0,09$ \\
\hline 08 & - & - & - & 1,21 & 1,31 & $+0,10$ & 0,32 & 0,41 & $+0,09$ \\
\hline 09 & - & - & - & 1,68 & 1,32 & $-0,36$ & 0,22 & 0,36 & $+0,14$ \\
\hline 10 & - & - & - & 0,32 & 0,46 & $+0,14$ & - & - & - \\
\hline 11 & - & - & - & 0,40 & 0,50 & $+0,10$ & 1,96 & 1,88 & $-0,08$ \\
\hline 12 & $\cdot-$ & - & - & 0,47 & 0,54 & $+0,07$ & 1,37 & 1,35 & $-0,02$ \\
\hline 13 & - & - & - & 1,27 & 1,06 & $-0,21$ & 1,16 & 1,21 & $+0,05$ \\
\hline 14 & 0,57 & 0,66 & $+0,09$ & 1,37 & 1,30 & $-0,07$ & 0,92 & 0,72 & $-0,20$ \\
\hline 15 & 1,25 & 1,18 & $-0,07$ & 1,45 & 1,28 & $-0,17$ & 0,57 & 0,66 & $+0,09$ \\
\hline 16 & 0,98 & 0,97 & $-0,01$ & 0,19 & 0,36 & $+0,17$ & 0,64 & 0,69 & $+0,05$ \\
\hline 17 & 1,41 & 1,39 & $-0,02$ & 1,03 & 0,82 & $-0,21$ & 1,24 & 1,04 & $-0,20$ \\
\hline 18 & - & - & - & - & - & & 1,21 & 0,96 & $-0,25$ \\
\hline 19 & - & - & - & 1,39 & 1,21 & $-0,18$ & 1,27 & 1,17 & $-0,10$ \\
\hline 20 & 1,06 & 1,09 & $+0,03$ & 1,01 & 1,10 & $+0,09$ & 1,36 & 1,37 & $+0,01$ \\
\hline 21 & 1,31 & 1,53 & $+0,22$ & 1,01 & 0,93 & $-0,08$ & 2,04 & 2,00 & $-0,04$ \\
\hline 22 & 1,21 & 1,45 & $+0,24$ & 0,87 & 0,88 & $+0,01$ & 1,95 & 1,87 & $-0,08$ \\
\hline 23 & 1,38 & 1,43 & $+0,05$ & 1,24 & 1,11 & $-0,13$ & 1,34 & 1,32 & $-0,02$ \\
\hline 24 & 2,05 & 1,93 & $-0,12$ & 1,34 & 1,71 & $+0,37$ & $1 ; 38$ & 1,22 & $-0,16$ \\
\hline 25 & 1,99 & 1,95 & $-0,04$ & 1,17 & 1,14 & $-0,03$ & - & - & - \\
\hline 26 & 1,91 & 1,76 & $-0,15$ & - & - & - & 0,25 & 0,31 & $+0,06$ \\
\hline 27 & 0,88 & 0,87 & $-0,01$ & - & - & - & 0,22 & 0,37 & $+0,15$ \\
\hline 28 & 0,86 & 0,82 & $-0,04$ & - & - & - & 0,29 & 0,45 & $+0,16$ \\
\hline 29 & 0,50 & 0,52 & $+0,02$ & 1,38 & 1,48 & $+0,10$ & 0,29 & 0,44 & $+0,15$ \\
\hline 30 & 0,81 & 0,79 & $-0,02$ & 1,24 & 1,41 & $+0,17$ & 0,64 & 0,72 & $+0,08$ \\
\hline 31 & - & - & - & - & - & - & 1,01 & 1,04 & $+0,03$ \\
\hline
\end{tabular}


Tabela 7 . Continuação.

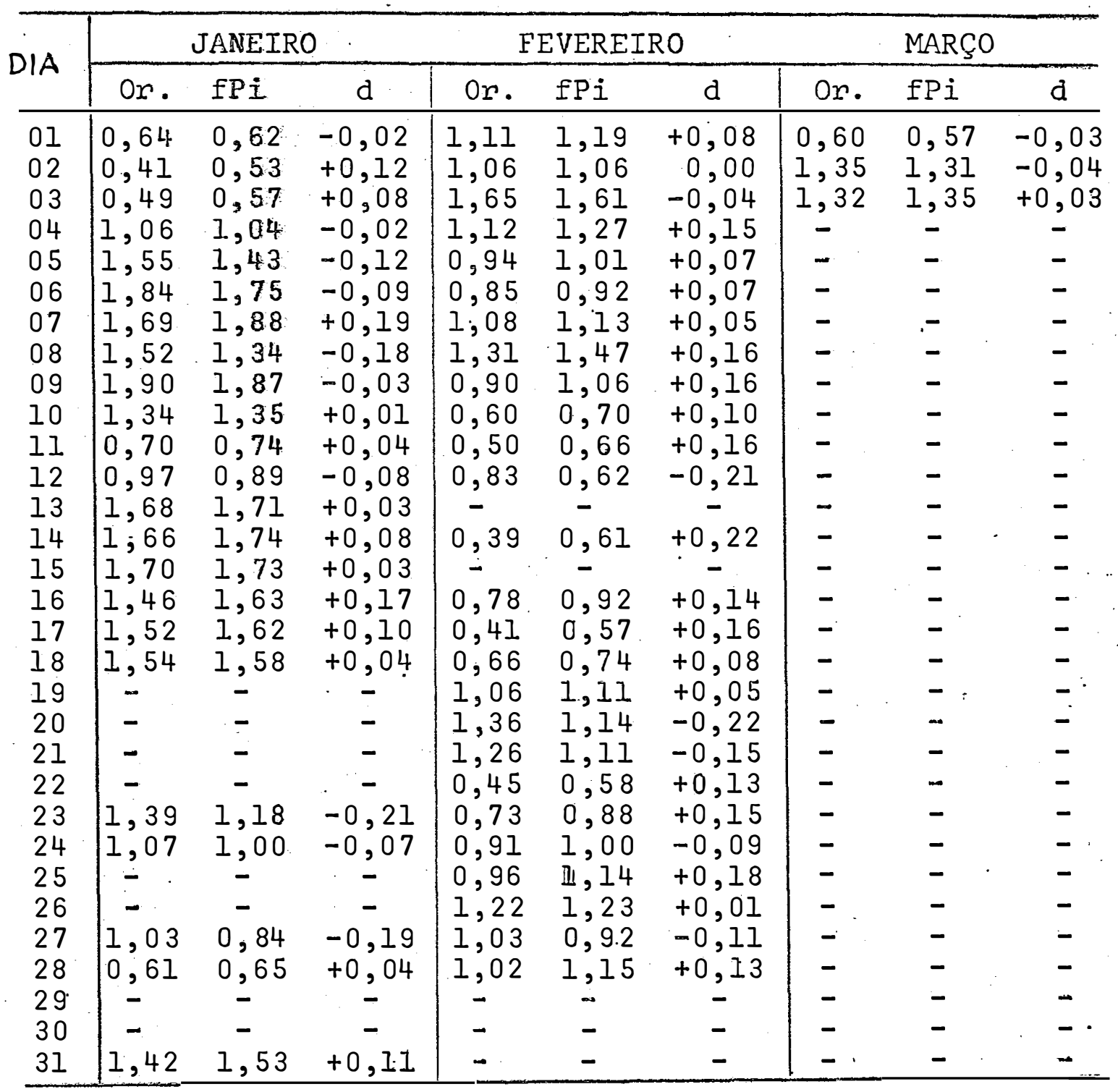


Tabela 8. Valores representativos do componente aerodinâmico da equação de Penman para a estimativa da evapora ção e da : evapotranspiração potencial, calculados atrawês das expressões originais e em função do evaporimetro Piche e respectivos desvios ( $d=$ fPiche-ori gimal).

\begin{tabular}{|c|c|c|c|c|c|c|}
\hline \multirow[b]{2}{*}{ PERIODO } & \multicolumn{3}{|c|}{ p/EVAPORAÇÃO } & \multicolumn{3}{|c|}{$\mathrm{p} / \mathrm{EVAPOTRANSPIRAÇÃO}$} \\
\hline & Or. & $\mathrm{fPi}$ & d & Or. & $f P i$ & $\mathrm{~d}$ \\
\hline $14.10-20.10$ & 0,79 & 0,76 & $\div 0,03$ & 1,05 & 1,04 & $-0,01$ \\
\hline $21,10-25.10$ & 1,15 & 1,22 & $+0,07$ & 1,59 & $1 ; 64$ & $+0,05$ \\
\hline $26.10-30.10$ & 0,71 & 0,67 & $-0,04$ & 0,99 & 0,94 & $-0,05$ \\
\hline $01.11-05.11$ & 0,74 & 0,66 & $\div 0,08$ & 0,94 & 0,92 & $-0,02$ \\
\hline $06.11-10.11$ & 0,78 & 0,74 & $-0,04$ & 1,08 & 1,02 & $-0,06$ \\
\hline $11.11-15.11$ & 0,74 & 0,66 & $-0,08$ & 0,99 & 0,93 & $-0,06$ \\
\hline T. $6.11-21.11$ & $0,69^{\circ}$ & 0,62 & $-0,07$ & 0,93 & 0,87 & $-0,06$ \\
\hline $22.11-29.11$ & 0,70 & $0 ; 92$ & $+0,22$ & 1,20 & 1,25 & $+0,05$ \\
\hline $30.11-06.12$ & $.0,94$ & 0,93 & $-0,01$ & 1,27 & 1,27 & 0,00 \\
\hline $07.12-12.12$ & 0,65 & 0,63 & $-0,02$ & 0,85 & 0,88 & $+0,03$ \\
\hline $13.12-17.12$ & 0,61 & 0,61 & 0,00 & 0,91 & 0,85 & $-0,06$ \\
\hline $18.12-22.12$ & 1,17 & 1,08 & $-0,09$ & 1,57 & 1,46 & $-0,11$ \\
\hline $23.12-28.12$ & 0,51 & 0,51 & 0,00 & $0 ; 70$ & 0,72 & $+0,02$ \\
\hline $29.12-02.01$ & 0,40 & 0,46 & $+0,06$ & 0,60 & 0,66 & $+0,06$ \\
\hline $03.01-07.01$ & 0,97 & 0,90 & $-0,07$ & 1,33 & 1,32 & $-0,01$ \\
\hline $08.01-12.01$ & 1,03 & 0,97 . & $-0,06$ & 1,29 & 1,22 & $-0,07$ \\
\hline $13.01-17.01$ & 1,25 & 1,25 & 0,00 & 1,60 & $i, 67$ & $+0,07$ \\
\hline $18.01-23.01$ & 0,79 & 0,82 & $+0,03$ & 1,16 & 1,12 & $-0,04$ \\
\hline $24.01-01.02$ & 0,75 & 0,75 & 0,00 & 1,05 & 1,03 & $-0,02$ \\
\hline $02.02-06.02$ & 0,82 & 0,85 & $+0,03$ & 1,12 & 1,16 & $+0,04$ \\
\hline $07.02-11.02$ & 0,61 & 0,71 & $+0,10$ & 0,88 & 0,99 & $+0,11$ \\
\hline $12.02-18.02$ & 0,43 & 0,47 & $+0,04$ & $0,61$. & 0,68 & $+0,0.7$ \\
\hline $19.02-23.02$ & 0,69 & 0,69 & 0,00 & 0,97 & 0,95 & $-0,02$ \\
\hline $24.02-28.02$ & 0,70 & 0,78 & $+0,08$ & 1,03 & 1,08 & $+0,05$ \\
\hline
\end{tabular}


Tabela 9. Valores representativos de evaporação e de evapo transpiração potencial estimados pelo método de Pen man original e pela simplificação do mesmo proposta no presente trabalho, com respectivos desvios (d) do mëtodo simplificado em relação ao original.

\begin{tabular}{|c|c|c|c|c|c|c|c|}
\hline \multirow{2}{*}{ PERIODO } & \multicolumn{3}{|c|}{ EVAPORAÇ $\widetilde{A} O$} & \multirow{2}{*}{ PERIODO } & \multicolumn{3}{|c|}{ EVAPOTR.POTENC. } \\
\hline & Or. & Simp & $\mathrm{d}$ & & Or. & Simp & $\mathrm{d}$ \\
\hline $14.10-20.10$ & 5,14 & $5,7,3$ & $-0,01$ & $01.11-08.11$ & 5,40 & 5,35 & $-0,05$ \\
\hline $21.10-25.10$ & 6,51 & 6,64 & $+0,13$ & $09.11-19.11$ & 5,23 & 5,10 & $-0,13$ \\
\hline $26.10-06.11$ & 6,02 & 5,85 & $-0,17$ & $20.11-24.11$ & 5,12 & 5,36 & $+0,24$ \\
\hline $07.11-14.11$ & 5,52 & 5,48 & $-0,04$ & $25.11-03.12$ & 6,21 & 6,20 & $-0,0 I$ \\
\hline $15.11-22.11$ & 6,00 & 5,93 & $-0,07$ & $04.12-18.12$ & 5,67 & 5,55 & $-0,12$ \\
\hline $23.11-01.12$ & 6,51 & 6,50 & $-0,01$ & $19.12-23.12$ & 6,22 & 6,16 & $-0,06$ \\
\hline $02.12-17.12$ & 6,49 & 6,37 & $-0, \square 2$ & $24.12-07.01$ & 6,12 & 6,07 & $-0,05$ \\
\hline $18.12-22.12$ & 6,43 & 6,36 & $-0,07$ & $08.01-13.01$ & 5,64 & 5,57 & $-0,07$ \\
\hline $23.12-06.01$ & 6,69 & 6,58 & $-0,11$ & $14.01-18.01$ & 6,47 & 6,53 & $+0,06$ \\
\hline $07.01-12.01$ & 6,19 & 6,12 & $-0,07$ & $19.01-03.02$ & 5,42 & 5,39 & $-0,03$ \\
\hline $13.01-17.01$ & 7,04 & 7,04 & 0,00 & $04.02-08.02$ & 5,93 & $6 ; 02 \%$ & $+0,09$ \\
\hline $18.01-31.01$ & 5,17 & 5,19 & $+0,02$ & 09.02 .19 .02 & 4,32 & 4,41 & $+0,09$ \\
\hline $01.02-06.02$ & 6,32 & 6,37 & $+0,05$ & $20.02-26.02$ & 5,31 & 5,34 & $+0,03$ \\
\hline $07.02-17.02$ & 5,24 & 5,35 & $+0,11$ & $\theta$ & & & \\
\hline $18.02-24.02$ & 5,59 & 5,64 & $+0,05$ & & & & \\
\hline $25.02-02.03$ & 5,79 & 5,83 & $+0,04$ & & & & \\
\hline
\end{tabular}


5.3. Relativos à confronto entre a Evapotranspiração po tencial estimada pelo método de Penman simplificado e a Evapotranspiração potencial medida.

Os valores de evapotranspiração potencial estimada pelo método de Penman simplificado e a evapotranspi ração potencial observada na bateria de evapotranspirôme tros com grama Batatais (Paspalum notatum, Fluegg) estão repre sentados na Tabela 10 em. base diária e na Tabela 11 com base em alores médios de cinco (5) dias.

0 confronto direto entre os valores estimados e os valores observados nos ofereceu o seguinte resultado da anālise:

\begin{tabular}{|c|c|c|c|c|c|c|}
\hline \multirow{2}{*}{ PERIODO } & \multirow{2}{*}{$r$} & \multirow[t]{2}{*}{+} & \multirow{2}{*}{\multicolumn{2}{|c|}{$t_{10 \%} t_{5 \%}$}} & \multirow{2}{*}{$t_{1 \%}$} & $\mathrm{CV}$ \\
\hline & & & & & & estim obser \\
\hline DIÄRIO & 0,7996 & 1,349 & 1,67 & 2,01 & 2,67 & $14,04 \quad 17,23$ \\
\hline $\begin{array}{r}\text { MEDIA DE } \\
5 \text { DIAS }\end{array}$ & 0,7817 & 2,228 & 1,83 & 2,26 & 3,25 & $5,71: 11,20$ \\
\hline
\end{tabular}

Pode-se observar que quando se tomou valore:s diārios para a análise, os desvios entre os mesmos não diferiram de zero ao passo que para ns valores com base em mé dias de cinco (5) dias, os desvios foram significantes ao $\underline{\mathrm{n} i}$ vel de $5 \%$ e ao nîvel de $10 \%$, não o sendo apenas ao nivel de $1 \%$.

Durante o periodo de observações, os valo res fornecidos pela bateria de evapotranspirômetrns sempre estiveram abaixo dos valores estimados.

Dado a erros cometidos principalmente na avaliação de horas do brilho solar; na determinação da umidad e relativa média do dia; na leitura do evaporimetro Piche e nas medidas fornecidas pela bateria de evapotranspirômet ros, pode-se afirmar que a simplificação proposta no presente trá balho è perfeitament vâlida dentro do rigor que se exige: 
Pabela 10: Vałopes peppesentativos da evapotranspinação po= teneial estimada pelo método de Penman simplifi cado (ETPe), medida na bateria de evapotranspirômetros (ETPm) e respectivos desvios (d) em ibase

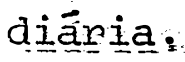

\begin{tabular}{|c|c|c|c|c|c|c|c|c|c|}
\hline \multirow{2}{*}{ DIA } & \multicolumn{3}{|c|}{ N.:i NOVEMBRO } & \multicolumn{3}{|c|}{ DEZEMBRO } & \multicolumn{3}{|c|}{ JANEIRO } \\
\hline & ETPe & EPPIn & $d$ & ETPe & ETPm & $\mathrm{a}$ & ETPe & ETPm & d \\
\hline 01 & $=$ & $=$ & $=$ & 6,66 & 5,81 & $-0,85$ & - & - & - \\
\hline 02 & $=$ & $=$ & $=$ & $=$ & - & - & - & - & - \\
\hline 03 & $=$ & $=$ & $=$ & 5,99 & 4,62 & $-1,37$ & - & - & - \\
\hline 04 & $=$ & $=$ & $=$ & $=$ & - & - & - & - & - \\
\hline 05 & $=$ & $=$ & $=$ & $=$ & - & - & - & - & - \\
\hline 06 & $=$ & $=$ & - & $=$ & - & - & - & - & - \\
\hline 07 & 5,62 & 5,02 & $=0,60$ & $=$ & - & - & - & - & - \\
\hline 08 & 5,88 & 4,89 & $=0,99$ & $=$ & 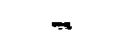 & - & - & - & - \\
\hline 09 & $=$ & $=$ & - & $=$ & - & - & 6,34 & 5,50 & $-0,84$ \\
\hline 10 & $=$ & $=$ & $=$ & $=$ & - & - & - & - & - \\
\hline 11 & $=$ & $=$ & $=$ & 6,20 & 5,38 & $-0,82$ & - & - & - \\
\hline 12 & $=$ & $=$ & $=$ & 5,50 & 4,86 & $-0,64$ & 3,29 & 3,90 & $+0,61$ \\
\hline 13 & $=$ & $=\cdot$ & $=$ & - & - & - & 6,10 & 5,10 & $-1,00$ \\
\hline 14 & 5,57 & 4,27 & $-1,30$ & $=$ & - & - & 6,47 & 6,70 & $+0,23$ \\
\hline 15 & 5,80 & 4,75 & $-1,05$ & $=$ & - & - & 6,51 & 6,30 & $-0,21$ \\
\hline 16 & $=$ & $=$ & $=$ & $=$ & - & - & 6,62 & 6,80 & $+0,18$ \\
\hline 17 & $=$ & $=$ & - & $5, .43$ & 5,50 & $+0,07$ & 6,63 & 5,90 & $-0,73$ \\
\hline 18 & $=$ & - & $=$ & 4,56 & 4,32 & $-0,24$ & 6,44 & 5,50 & $-0,94$ \\
\hline 19 & $=$ & - & $=$ & 5,44 & 4,86 & $-0,58$ & - & - & - \\
\hline 20 & $=$ & $=$ & - & 6,15 & 6,03 & $-0,12$ & - & - & - \\
\hline 21 & $=$ & $=$ & $=$ & 6,50 & 5,52 & $-0,98$ & - & - & - \\
\hline 22 & 5,06 & 4,15 & $-0,91$ & 6,51 & 5,62 & $-0,89$ & - & - & - \\
\hline 23 & 5,80 & 3,94 & $=1,86$ & 6,19 & 5,20 & $-0,99$ & 4,93 & 4,00 & $-0,93$ \\
\hline 24 & $6,0,5$ & 4,95 & $-1,10$ & 6,39 & 4,92 & $-1,37$ & - & - & - \\
\hline 25 & 5,86 & 4,50 & $=1,36$ & $=$ & - & - & - & - & - \\
\hline 26 & $=$ & $=$ & $=$ & $=$ & - & - & - & - & - \\
\hline 27 & $=$ & $=$ & $=$ & $=$ & - & - & $\neg$ & - & - \\
\hline 28 & $=$ & $=$ & $=$ & $=$ & - & - & - & - & - \\
\hline 29 & 6,46 & $5,0.4$ & $=1,42$ & $=$ & - & - & - & - & - \\
\hline 30 & 6,04 & 4,73 & $=1,31$ & $=$ & - & - & - & - & - \\
\hline 31 & $=$ & $=$ & $=$ & 6,40 & 5,10 & $-1,30$ & - & - & - \\
\hline
\end{tabular}


Tabela 10. Continuação

\begin{tabular}{|c|c|c|c|c|c|c|}
\hline \multirow{2}{*}{ DIA } & \multicolumn{3}{|c|}{ FEVEREIRO } & \multicolumn{3}{|c|}{ MARÇO } \\
\hline & ETPe & $\mathrm{ETPm}$ & d & ETPe & ETPm & $d$ \\
\hline $0 \mathbb{1}$ & - & - & $\dot{-}$ & - & - & - \\
\hline 02 & 5,43 & 4,60 & $-0,83$ & 4,66 & 4,60 & $-0,06$ \\
\hline 03 & 6,03 & 5,70 & $-0,33$ & 5,60 & 4,95 & $-0,65$ \\
\hline 04 & 6,17 & 5,60 & $-0,57$ & - & - & - \\
\hline 05 & 5,65 & 6,00 & $+0,35$ & - & - & - \\
\hline 06 & 5,61 & 5,40 & $-0,21$ & - & - & - \\
\hline 07 & 6,22 & 6,00 & $-0,22$ & - & - & - \\
\hline 08 & 6,44 & 6,40 & $-0,04$ & - & 一 & 一 \\
\hline 09 & - & - & - & - & - & - \\
\hline 10 & 4,02 & 3,00 & $-1,02$ & - & - & - \\
\hline .11 & - & - & - & - & - & - \\
\hline 12 & - & - & - & - & - & - \\
\hline 13 & - & - & - & - & - & - \\
\hline 14 & - & - & - & - & - & - \\
\hline 15 & - & - & - & - & - & - \\
\hline 16 & 4,64 & 4,40 & $-0,24$ & - & - & - \\
\hline 17 & 3,11 & 2,30 & $-0,81$ & - & - & - \\
\hline 18 & 4,50 & 3,50 & $-1,00$ & - & - & - \\
\hline 19 & 5,79 & 4,80 & $-0,99$ & - & - & - \\
\hline 20 & 5,51 & 5,30 & $-0,21$ & - & - & - \\
\hline 21 & - & - & - & - & - & - \\
\hline 22 & - & - & - & - & - & - \\
\hline 23 & - & - & - & - & - & - \\
\hline 24 & 5,50 & 4,20 & $-1,30$ & - & - & - \\
\hline 25 & 5,71 & 4,90 & $-0,81$ & - & - & - \\
\hline 26 & 5,73 & 4,90 & $-0,83$ & - & - & - \\
\hline 27 & 4,95 & 4,50 & $-0,45$ & - & - & - \\
\hline 28 & 5,49 & 5,00 & $-0,49$ & - & - & - \\
\hline 29 & - & - & - & - & - & - \\
\hline 30 & - & - & - & - & - & - \\
\hline 31 & - & - & $\dot{-}$ & - & - & - \\
\hline
\end{tabular}


Tabela 1I. Valores representativos da evapotranspiração potencial estimada pelo mëtodo de Penman simplificado (ETPe), medida na bateria de evapotranspirómetros (ETPM) e respectivos desvios (d) com base base em médias de cinco (5) dias.

\begin{tabular}{c|ccc}
\hline PERIODO & ETPe & ETPm & d \\
\hline $01.11-22.11$ & 5,59 & 4,62 & $-0,97$ \\
$23.11-30.11$ & 6,04 & 4,63 & $-0,41$ \\
$01.12-17.12$ & 5,96 & 5,23 & $-0,73$ \\
$18.12-22.12$ & 5,83 & 5,27 & $-0,56$ \\
$23.12-12.01$ & 5,72 & 4,92 & $-0,80$ \\
$13.01-17.01$ & 6,47 & 6,16 & $-0,31$ \\
$18.01-04.02$ & 5,80 & 5,08 & $-0,72$ \\
$05.02-10.02$ & 5,59 & 5,36 & $-0,23$ \\
$11.02-20.02$ & 5,31 & 4,06 & $-0,25$ \\
$21.02-28.02$ & 5,48 & 4,70 & $-0,78$ \\
\hline
\end{tabular}


5.4. Relativros ao teste da equação do termo aerodinâmico proposta por Penman para a estimativa da Evaporação da água e sua aplicabilidade às condições locais.

PENMAN (1963) em sua equação para a estimativa da evaporação da água, indica para a determinação do termo aerodinâmico EaV a seguinte expressão:

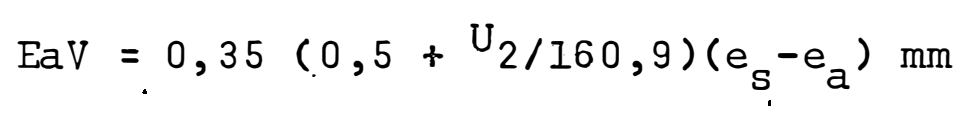

Essa expressão tem sido aplicada em todas as regiões, não se tendo conhecimento de testes realizados a fim de verificar até que ponto é válida a sua aplicação com os coeficientes propostos.

Assim, durante o experimento, tentnu-se simular condições de sombreamento ao tanque "Classe A" sifonado, colocando-se uma cobertira de lençol plástico de superficie refletora branca, com $3,0 \mathrm{~m} \mathrm{X} 2,0 \mathrm{~m}$ e com sua maior dimen são disposta no sentido Leste-Oeste. Desse modo, pretendeu - se que a evaporação ali ocorrida, fosse apenas função da velocidade do vento e do défice de saturação de vapor no ar.

Com esses dois elementos e mais os valores de evaporação fornecidos por aquele evaporịmetro, tomando-se mé dias de cinco (5) dias, determinou-se a equação de regressão que melhor se ajustasse aos pontos no grágico, resultando na seguinte expressão:

$$
\operatorname{ECAs}(s m b)=\left(0,43+0,30^{U} 2 / 160,9\right)\left(e_{s}-e_{a}\right)
$$

Quando se compara uma equação com a outra, no. ta-seque seus coeficientes angulares se aproximam, com um des vio de 0,05, mostrando que as duas retas são praticamente paralelas, admitindo-se que pequenos erros de leitura tenham $a$ carretado tal diferença; já os coeficientes lineares mostram uma diferença de $0,255^{\circ}$ em favor da equação encontrada para Piracicaba, superestimando o fenômeno. 
Antes de afirman que o fenômeno para esta re = gião segue a equação encontrada, ề de bom alvitre tecer comen= târios sobre as condiçōes em que foi montado o teste, sugerindo que essas differenças encontradạs nọ teṛmos dạ equação de= va $=$ se:

a) à cobertura empregada para sombrear o eva porimetro, a qual, possivelmente, não deve ter sido tão ex tensa quanto necessâria, de modo a proteger a superfície evaporante apenas da radiação direta e não da radiação difusa de grande faixa do cêu;

b) à pröpria radiação direta, quando o sol a baixas alturas atingia diretamente tanto as paredes do tanque como a prôpria superfície evaporante durante determinado tempo, o que poderá ser apreciado no quadro abaixo:

\begin{tabular}{c|l}
\hline ELEVAÇÃO DO SOL & PARTE DO CONJUNTO ATINGIDA PELA RADIAÇĀO \\
\hline $13,5 \%$ & Superficie evaporante e parede do tanque \\
$29,0 \%$ & Apenas a parede do tanque \\
$40,0 \%$ & sombreamento completo do conjunto \\
\hline
\end{tabular}

c) à altura em que foi colocada a cobertura pa ra sombreamento ( $50,0 \mathrm{~cm}$ da borda do tanque) pois o balanço de energia entre a supenficie e o teto deve ter influenciado in crèmentando o fenômeno;

d) à própria cor da face inferior da cobertura (branco brilhante em lugar de preto fôsco), refletindo energia em direção à massa líquida.

Entretanto, à maneira como as retas apresen = tam-se no gráfico (Figura 13), sugere a viabilidade de tal ti po de estudo, devendo o mesmo ser repetido em melhores condições de simulação de sombra total e para um periodo maior de. observações.

Os valores empregados na determinação da equação de regressão constam da Tabela $12 \mathrm{com}$ base em mẻdias de cinco (5) dias. 
Tabela 12. Valores representativos dos termos em $Y$ e em X em pregados na determinação da equação de regressão: tomados como médias de cinco (5) dias.

\begin{tabular}{c|c}
\hline$Y=$\begin{tabular}{c|c} 
ECAs (sombra) \\
\hline$e_{s}-e_{a}$
\end{tabular} & $X=\frac{U_{2}}{160,9}$ \\
\hline 0,698 & 0,940 \\
0,555 & 0,702 \\
0,699 & 0,805 \\
0,733 & 0,982 \\
0,684 & 0,772 \\
0,603 & 0,486 \\
0,791 & 1,170 \\
0,755 & 1,062 \\
0,864 & 1,248 \\
0,753 & 1,226 \\
0,717 & 0,943 \\
0,698 & 0,814 \\
0,668 & 0,774 \\
0,613 & 0,598 \\
0,648 & 0,634 \\
\hline
\end{tabular}

$$
\begin{aligned}
\frac{\operatorname{ECAs}(\text { sombra })}{\left(e_{s}-e_{a}\right)} & =0,43+0,30 \frac{U_{2}}{160,9} \\
r^{2} & =0,81 \\
n & =15 \\
\operatorname{ECAs}(\text { sombra }) & =\left(0,43+0,30 \frac{U_{2}}{160,9}\right)\left(e_{s}-e_{a}\right)
\end{aligned}
$$




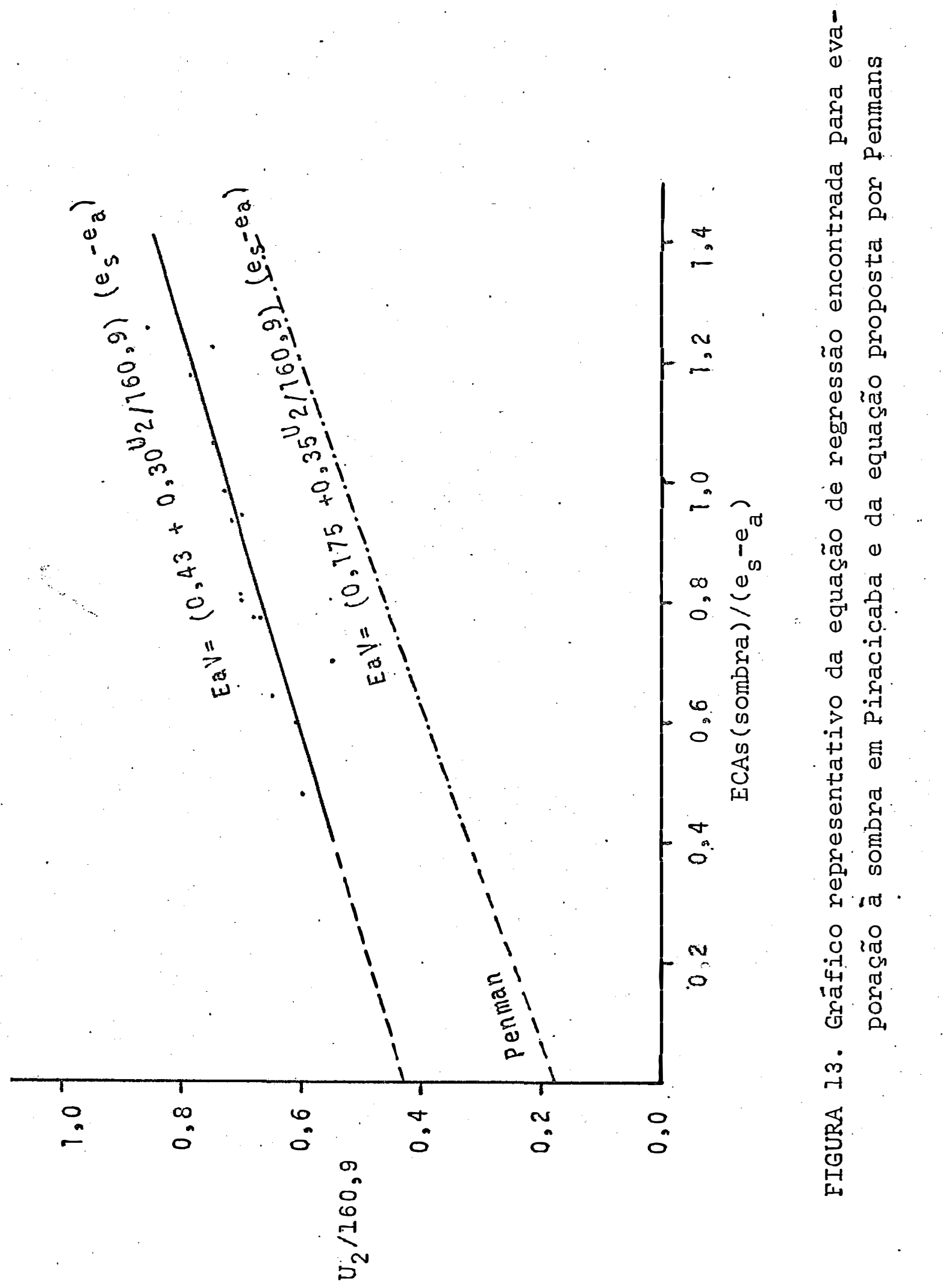


5.5. Relativos aos coeficientes determinado's para a relação Evæporação estimada/Evaporação medida.

OLIVEIRA (I97I), estudando o comportamento de evaporimetros (Classe A e GGI-3000) e as relações entre a evaporação estimada e a evaporaçao medida, chegou a coeficientes mensais entre a evaporação estimada pelo mëtodo de penman original e a evaporação medida por aqueles dois (2) evaporímetros em diferentes condições de exposição e.com cobertura de tela protetora.

No presente trabalho, alëm das relaçöes estabelecidas pelo autor acima para a região de Piracicaba com referência ao tanque "Classe A", procurou-se estabelecer os coeficientes levando em consideração a modificaçao proposta para o sistema de medidas e a smmplıficaçao do metodo de Penman, resultando no seguinte quadro:

\begin{tabular}{c|cc|cc|cc|cc|c}
\hline MÊS & $\mathrm{A}$ & $\pm \sigma$ & $\mathrm{B}$ & $\pm \sigma$ & $\mathrm{C}$ & $\pm \sigma$ & $\mathrm{D}$ & $\pm \sigma$ & $\mathrm{E}$ \\
\hline JUN & 0,70 & 0,14 & 0,68 & 0,17 & & & & & 0,85 \\
JUL & 0,67 & 0,14 & 0,67 & 0,12 & & & & & 0,70 \\
AGO & 0,72 & 0,19 & 0,69 & 0,14 & & & & & 0,70 \\
SET & 0,71 & 0,12 & 0,72 & 0,11 & & & & & 0,67 \\
OUT & 0,71 & 0,11 & 0,71 & 0,12 & 0,77 & 0,12 & 0,78 & 0,14 & 0,71 \\
NOV & 0,84 & 0,16 & 0,81 & 0,12 & 0,84 & 0,16 & 0,80 & 0,12 & $0,79$. \\
DEZ & 0,75 & 0,07 & 0,75 & 0,06 & 0,75 & 0,07 & 0,75 & 0,06 & 0,73 \\
JAN & 0,83 & 0,22 & 0,79 & 0,16 & 0,82 & 0,32 & 0,78 & 0,17 & 0,72 \\
FEV & 0,83 & 0,10 & 0,79 & 0,16 & 0,82 & 0,22 & 0,78 & 0,17 & 0,72 \\
\hline
\end{tabular}

onde A representa EVPen or/ECA

$\begin{array}{lll}\text { B } & " & \text { EVPen, or/ECAs } \\ \text { C } & \text { representa } & \text { EVPen sp/ECA } \\ \text { D } & " & \text { EVPen sp/ECAs } \\ \sigma & " & \text { Desvio padrão } \\ \text { E } & " & \text { EVPen or/ECA (Oliveira, 1971) }\end{array}$


5.6. Relativos à marcha da Evapotranspiração potencial diărua para o período Fevereiro/Março em Piracicaba.

No decorrer da operação com a bateria de evapotranspirômetros, por vezes ocorreram problemas no funcio namento da mesma, tanto por entupimento dos condutos de abastecimento de ägua pelo crescimento de algas, como pelo pllas raizes da grama que penetravam na entrada de água da caixa, obstruindo a mesmá.

Tais problemas foram sanados com a adapta ção de um "poço de visitä" de PVC rígido formando uma câmara onde apenas a água penetrava, impedindo assim que raizes e a areia do fundo da caixa obstruissem a entrada de água.

Apartir de 15 de Fevereiro, as repetições A, $B$ e $D$ foram reunidas atravēs de uma só caiaa de passagem, acoplando-a a um reabastecedor com relação de $1: 30$ e ao qu al. foi adaptado um registrador para obtenção da curva representativa da Evapotranspiração acumulada a cada 24 horas.

Estabelecendo as tangentes a essa curva nos pontos representativos de cada hora do dia, obteve-se um valor de $\Delta$ ETP/ $\Delta t$ em $\mathrm{mm} / \mathrm{h}$ para cada ponto. Tomando-se o valor médio para cada hora no período de 15.02 .79 a 04.03 .79 e os respectivos desvios, levantou-se a curva mêdia da evapotrans piração potencial para aquele perïodo.

0 emprego do sistema de registro possibilitou assim detectar 0 instante do pico de evapotranspiração poten cial diâria, a qual ocorre após a passagem mérddiana do sol. (13:00 horas), observando-se assim um tempo de retardo entre o instante de máxima energia incidente e o instante da perda máximá de água pelo fenômeno.

A tabela 13 mostra os diversos valores de de $\Delta$ ETP/At e a Figura 14 representa a curva média da evapotrans piração potencià diāria nos períodos diurno e noturno. 


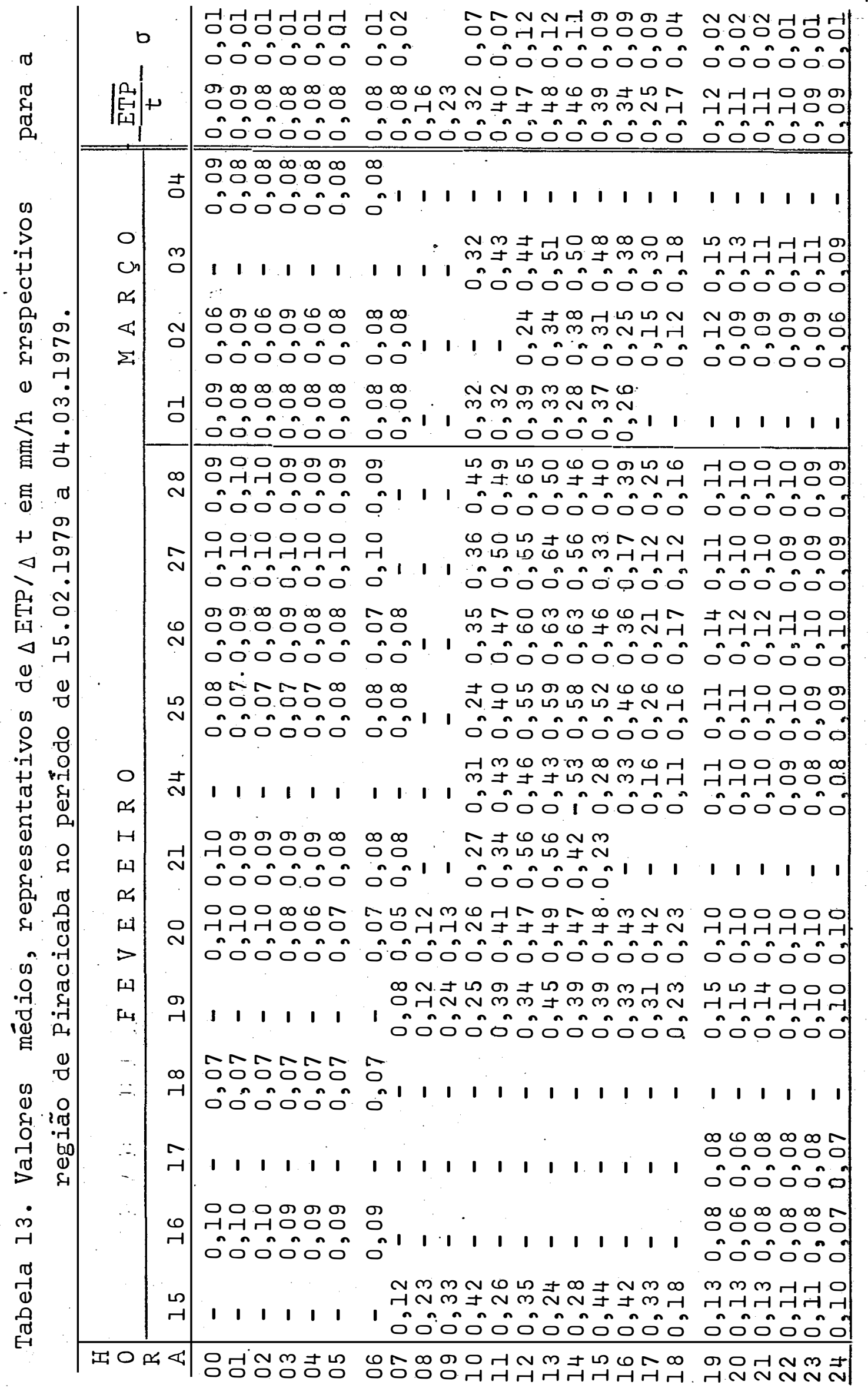




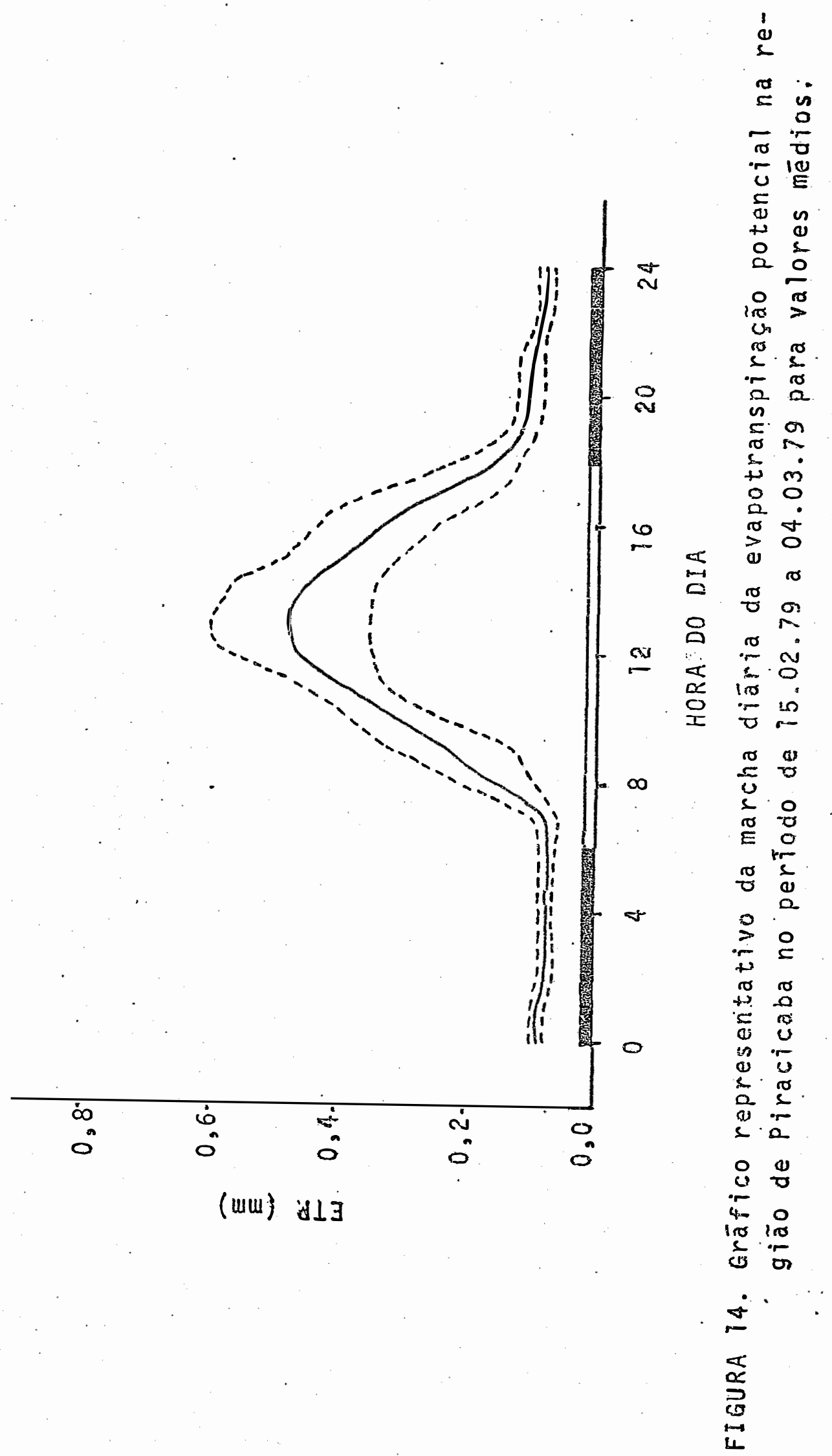


5.7. Relativos à utilização do tanque "Classe A" sifonado na determinação da Evapotranspiração potencial.

Uma maneira bastante prätica de determinação da evapotranspiração potencial e recomendada pela FAO, segundo DOORENBOS e PRUIT (1975) em práticas de irrigação, è a aplicação de um coeficiente nas leituras fornecidas pelo tanque "Classe A".

Esse mëtodo ê de fäcil acesso ao agricultor, não muito afeito a equações matemätivas por mais simples que elas sejam.

Nele, a evapotranspiração é calculada do seguinte modo:

$$
E T P=k_{p} \cdot E_{\text {tanque }}
$$

onde $k_{\mathrm{p}} \vec{e}$ um fator de conversão que depende de classes de vento e de umidade relativa e do tipo de exposição do evapo rimetro.

Assim, no presente trabalho, adotando-se os limites estabelecidos pela FAO (1975) foram determinados os valores de $k_{p}$, empregando mëdias de três ( 3 ) dias para os valores de velocidade do vento ao nível de $2,0 \mathrm{~m}$ do solo e para os valores de umidade relativa mëdia, para a evaporação e para a evapotranspiração potencial medida obtendo-se os resul tados relativos no quadro abaixo, para as condições de exposição do evaporímetro dentro de um ärea gramada num raio de atê $10 \mathrm{~m}$.

\begin{tabular}{|c|c|c|c|c|c|}
\hline \multicolumn{2}{|c|}{$\begin{array}{l}\text { Vento leve } \\
\text { U.Relativa alta }\end{array}$} & \multicolumn{2}{|c|}{$\begin{array}{l}\text { Vento leve } \\
\text { U.Relativa mêdia }\end{array}$} & \multicolumn{2}{|c|}{$\begin{array}{l}\text { Vento moderado } \\
\text { U.Relativa média }\end{array}$} \\
\hline $\begin{array}{r}\text { FAO } \\
0,75\end{array}$ & $\begin{array}{l}\text { Determ } \\
0,66\end{array}$ & $\begin{array}{r}\text { FAO } \\
0,65\end{array}$ & $\begin{array}{l}\text { Determ } \\
0,64\end{array}$ & $\begin{array}{r}\text { FAO } \\
0,60\end{array}$ & $\begin{array}{l}\text { Determ } \\
0,61\end{array}$ \\
\hline
\end{tabular}

De acordo com os resultados, pode-se admi tippe lo menos para fins práticos, que o mëtodo preconizado é aceitável, embora tais resultados tenham sido obtidos com um re duzido número de dados. 
Tabela 14. Vạones representativos de eva oração (ECAs) em rṇ, evapotranspinação potencial medida (ETPm) em mm, velocidade mëdia do vento $\left(U_{2}\right)$ em $\mathrm{km}$. dia $=1$, umidade relativa média do dia (UR) em $\%$, coefici= enteses de ETPm/ECAs e de classes de vento e de umidade relativa, com base em mêdias de três (3) dịas.

\begin{tabular}{|c|c|c|c|c|c|c|}
\hline \multirow{2}{*}{ ECAs } & \multirow{2}{*}{ ETPm } & \multirow{2}{*}{$\mathrm{U}_{2}$} & \multirow{2}{*}{ UR } & \multirow{2}{*}{$\begin{array}{l}\text { ETPm } \\
\text { ECAs }\end{array}$} & \multicolumn{2}{|c|}{ CLASSES } \\
\hline & & & & & $U_{2}$ & UR \\
\hline 7,27 & 4,35 & 154,12 & 75,1 & 0,60 & Leve & Alta \\
\hline 8,008 & 4,46 & 160,40 & 72,8 & 0,55 & $"$ & Mëdia \\
\hline 7,73 & 4,89 & 165,24 & 71,6 & 0,63 & $"$ & $n$ \\
\hline 8,07 & 5,07 & 141,43 & 68,4 & 0,63 & $"$ & $"$ \\
\hline 9,17 & 5,30 & 131,60 & 61,8 & 0,58 & $"$ & $"$ \\
\hline 9,93 & 5,56 & 152,72 & 60,4 & 0,56 & $"$ & $"$ \\
\hline 9,77 & 5,28 & 176,52 & 63,6 & 0,54 & Mode. & $"$ \\
\hline 9,33 & 5,25 & 182,74 & 69,5 & 0,56 & $"$ & $"$ \\
\hline 9,90 & 6,03 & 209,79 & 66,8 & 0,61 & $"$ & $"$ \\
\hline 9,73 & 6,60 & 196,56 & 67,2 & 0,68 & $"$ & $"$ \\
\hline 9,83 & 6,33 & $1.86,77$ & 67,7 & 0,64 & $"$ & $"$ \\
\hline 9,47 & 6,07 & 194,67 & 69,7 & 0,64 & $"$ & $"$ \\
\hline 8, 30 & 5,30 & 164,22 & 73,1 & 0,64 & Leve & $"$ \\
\hline 8,73 & 5,77 & 157,57 & 73,3 & 0,66 & $"$ & $"$ \\
\hline 8,20 & 5,67 & 103,17 & 74,4 & 0,69 & $"$ & $"$ \\
\hline 8,03 & 5,80 & 76,95 & 72,6 & 0,72 & $"$ & $"$ \\
\hline 8,33 & 5,93 & 82,53 & 70,6 & 0,71 & $"$ & $"$ \\
\hline 4,90 & 3,50 & 62,15 & 80,1 & 0,71 & $"$ & Alta \\
\hline 5,23 & 3,53 & 73,76 & 79,4 & 0,67 & $"$ & $"$ \\
\hline 7,03 & 4,53 & 82,67 & 71,3 & 0,64 & $"$ & Mëdia \\
\hline 7,33 & 4,67 & 81,65 & $7.1, ?$ & 0,64 & $"$ & " \\
\hline 7,77 & 4,77 & $8.9,35$ & 70,8 & 0,61 & $"$ & $"$ \\
\hline 7,50 & 4,80 & 96,80 & 71,2 & 0,64 & $"$ & $"$ \\
\hline
\end{tabular}


6. CONCLUSÕES

Em face dos resultados apresentados, o presen te trabalho leva as seguintes conclusões:

1. A modificação proposta para o sistema de medidas do tanque "Classe A" mostrou-se tão viāvel quanto. o sistema tradicional que se utiliza de um micrômetro e: poço tranquilizador, com a vantagem de apresentar facilidade nas leituras, podendo ser operado por pessoal menos qualificado.

2. O sistema trabalha com uma variação minima do nível da água, permanecendo praticamente com a mesma massa e após a recarga diâria, o nỉvel de referência é sempre o mesmo, facilitando o trabalho do operador.

3. Em cerca de $60 \%$ dos casos, o sistema modificado apresentou valores mais elevados do que o sistema tra dicional.

4. 0 sistema modificado, por vezes, - se viu prejudidado no seu funcionamento quando a velocidade do vento a $0,50 \mathrm{~m}$ da superficie do solo era superior a $4,0 \mathrm{~m} / \mathrm{s}$.

5. As leituras ao nascer e ao por do sol pos:sibilitaram verificar as contribuições diurnas e noturnas pa ra a evaporação da ágụa no período de 24 horas, sendo que dü rante $\circ$ inverno os valores dos dois periodos se equipararam e durante o verão a contribuição diurna chegou a ser de $80 \%$ da 
do total do dia, supondo-se que a partir de mëdias latitudes, com a ocornência de invernos mais acentuados, os valores de evaporação noturna naquela epoca chegue a alcançar os valo = res diurnos.

6.0 evaporimetro Piche mostrou-se eficiente na determinação do componente aerodinâmico da equação de Penınan para a estimativa da evaporação de superfícies de âgua e pa= ra a estimativa da evapotranspiração potencial; as diferen = ças apresentadas entre o'método original e o simplificado, são perfeitamente desprezíveis jâ que a contribuição do vento e do défice de saturação foi em mëdia de apenas $16 \%$ do total estimado.

7.0s evapotranspirômetros dotados de sistema de registro mostraram-se eficientes na determinação do compor tamento diârio da evapotranspiração potencial, a despeito de em algumas ocasiões terem apresentado funcionamento irregu lar, tendo possibilitado detectar o pico máximo daquele fe nômeno durante o dia.

8. Os coeficientes determinados pela relação EVPen/ECA tanto para os originais como para as simplifica ções propostas, mostraram-se consistentes com aqueles determinados por OLIVEIRA.

9. Considerando o critêrio adotado pela FAO quanto às classes de velocidade de vento e de umidade rela. tiva, sem observar o rigor dos limites, pode-se afirmar que os coeficientes de tanque $\left(k_{p}\right)$ para o evaporimetro com a modificação proposta, estiveram de acordo com ós indicados por aquela para a determinação da evapotranspiração potencial a través do tanque "Classe A"

$$
E T P=k_{p} \cdot E C A s
$$


7. SUMMARY

Simplifications in measurement and estimation methods of water evaporation and potential evapotranspiration were the main objectives of this research work.

A "Class A" pan modification was adopted with siphons maintaining the zero reference level by the time of pan refilling. This procedure minimized errors and simplified the water level observations without loss of precision.

A modified Penman's equation is presented for water evaporation and evapotranspiration estimates.

The simplified formulas were developed for the Piracicaba region and presented in the following form:

$$
\begin{aligned}
\frac{E a V}{\frac{\Delta}{\gamma}+1} & =0,115+0,101 \mathrm{E}_{\text {piche }} \text { (evaporation) } \\
r^{2} & =0,943 \\
\frac{E a T}{\frac{\Delta}{\gamma}+1} & =0,224+0,129 \mathrm{E}_{\text {piche }} \text { (evapotranspira- . tion) } \\
r^{2} & =0,958
\end{aligned}
$$


Evaporation estimated by the Penman's method in its original form or in its simplified version showed to be consistent with the results found by OLIVEIRA (1971), if compared with "Class A" par.

The aerodynamic term in Penman's equation is discussed and tests were performed with the siphoned "ClassAr pans, under shade conditions.

Potential evapotranspiration estimated by Penman's simplified version formula agreed with evapotranspirometer data, observd in the same period. 
8. LITERATURA CITADA

- ASSIS, F.N. de, 1978. O uso do Evapotranspirômetro no estudo de algumas relações entre a Evapotranspiração medida e estimada. Piracicaba, ESALQ-USP. $73 p$. (Dissertação de Mestrado).

- BRUTSAERT, W'e G.YEH, 1970. Implications of a type of empirical Evaporation formula for lakes and pans. Water Resources Research. 6:1202-1208.

- BURMAN, R.D., 1976. Intercontinental comparison of Evaporation estimates. Journal of the Irrigation and Drainage Di vision. IR-1.102:109-117.

- CAMARǴ, A.P. de 1966. Contribuição para a determinação da Evapotranspiração potencial no Estado de São Paulo. Campinas. IAC, 54 p. BC-16I

- CAMPBELL, R.B. e C.J.PHENE, 1976. Estimating potential Evapotranspiration from screened pan Evaporation. Agricul tural Meteorology. Amsterdam. 16:343-352.

- DAGG, M, 1970. A study of the water use of tea in East Afri ca using a hydraulic lysimeter. Agricultural Meteorology Amsterdam. 07:303-320. 
- DENMEAD, O.T. e R.H.SHAW, 1962. Avaiability of soil water to plamts as affected by soil moisture content and me teorological conditions. Agronomy Journal. Madison. 54 ( 5$): 385-390$.

- DOORENBOS, J. e W.O.PRUIT, 1975. Guidelines for predicting crop water requirements, ROMA, FAO, 180 p. (Irrigation and Drainage Paper no 24).

- EAGLEMAN, J.R. e W.L.DECKER, 1965. The role of soil mois ture content and meteorological conditions. Agronomy Journal. Madison. 57(6):626-629.

- EKERN, P.C., 1966. Evapotranspiration by Bermuda grass Sod (Cynodon dactylon, L.Pers.), in Hawaii. Agronomy Jour -

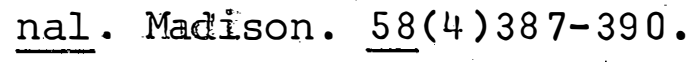

- FITZPATRICK, E.A. e W.R.STERN, 1966. Estimates of potential Evaporation using alternativ data in Penman's formula. Agricultural Metieorology. Amsterdam. 3:225-239.

- FRITSCHEN, L. e R.H. SHAW, 1966. Evapotranspiration from corn as related to Pan evaporation. Agronomy Journal Madison. 53(3):149-150.

- GANGOPADHYAYA, M et alii, 1966. Measurement and estimation of evaporation an evapotranspiration. Genebra, WMO.12lp (Technical Note n: 83).

- HALSTED, M.H. e W.COVEY, 1957. Some meteorolngical aspects of evapotranspiration. Soil Science Soc. of America. Ma dison. $21(5): 461-464$.

- HANKS, R.J. e R.W.SHAWCROFT, 1965. An economical lysimeter for evapotranspirations studies. Agronomy Journal. Madison. $57(6): 634-636$.

- HANSON, C.L. e F.RAUZI,1977 Class A Pan evaporation as affected by shelter and daily prediction equation. Agricultural Meteorology. Amsterdam. 18:27-35. 
- LEMON, E.R., A.H.GLASER e L.E.SATTERWHITE, 1957. Some aspe pects of the reaaiionship of soil, plant and meteorological factors to evapotranspiration. Soil science Soc. of America Proceedings. Madison. 21 (5):464-468

--LINACRE, E.T., 1977. A simple formula for estimating evaporation rates in various climates, using temperatura a lone. Agricultural Meteorology. Amsterdam.18:409-424

- OLIVEIRA, A.S., 1971. Estudos comparaiivos da evaporação po tencial estimada por tanques e pelo mëtodo de Penman . Piracicaba. ESALQ-USP. II 3p. (Tese de Livre Docência).

- OMETTO, J.C., 1973. Etude des relations entre le rayonne ment solaire global, le rayonnement net et l'esoleillement. Apresentado no Congresso Internacional "Le soleil au service de l'Homme" - Hulho - Paris.

- ORTOLANI, A.A., A.P.de CAMARGO e N.V.Villa NOVA, 1966. Cor relação entre evapotranspiração potencial calculada segundo os mëtodos de Penman e de Thornthwaite e de dados de evapotranspirômetros, na região de Ribeirão Preto.In: Bragantia. Vol 25. Campinas-IAC. Nota 15.65-68.

- PENMAN, H.L., 1963. Vegetation and Hydrology. Londres.Commonwealth Agricultural Bureaux. 124 p. (Technical Communication no 53 ).

- PETERS, D.B., 1960. Relative magnitude of evaporation and transpiration. Agronomy Journal. Madison. 52(9):536-538.

- PHENE, C.J. e R.B. CAMPBELL, 1975. Automating Pan evaporation measurements for irrigation control. Agricultural Meteorloogy: Amsterdam. 15:181-191.

- PRUITT, W.0., 1966. Empirical methods of estimating evapo transpiration using primarily evaporation Pans. Proceedings of Conf. Evapotranspiration, America Soc. Agric. Eng., Chicago, PP 57-6I. 
= RANZANE, G:Q: , O, FREERE e T.KENJO, 1966. Carta de sölos do municIPig de Piracicaba. Piracicaba. ESALQ-USR. $85 \mathrm{p}$.

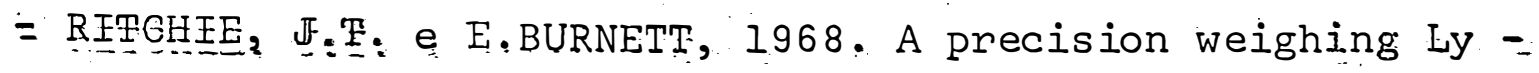
simetege Eon row crop water studies. Agronomy Journal Madison: $60(5): 545=549$.

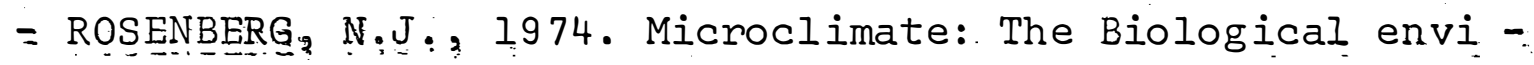
ronment. New York. John Wiley \& Sons. 301 p.

- SANTOS; J.MP 1957. -Contribuiçäo aos estudos para a determinação do albedo. Piracicaba. ESALQ-USP. 48 p. ( Tese de Doutoramentol).

- SEGINER, I. 1969. The effect of albedo on the evapotrans piration nate. Agricultural Meteorology. Amsterdam. $6: 05-31$ :

= SELLERS, W:D:, 1965. Physical Climatology. Chicago. The University of Chicago Press. 272 p.

- SLATYER, R.O. e I.C. McILROY, 1961: Evaporation and the principles of its measurements. In: Practical Microclimatology - with special reference to the water factors in soil-plant-atmosphere relationship. Australia.CSIRO. Unesco: PP $3 \cdot 14=3.20$.

- STANHEEL, G., 1962. The use of the Piche evaporimeter in the calculation of evaporation. Quaterly Journal of Royal Meteorological Society. Londres. 88(375):80-82.

- FANNER, C.B. e E.R.LEMON, 1962. Radiant energy utilized in evapotranspiration. Agronomy Journal. Madison.54(3):2072! 2:

= THORNTHWAETE, C.W, e F.K.HARE, 1965. The loss of water to the ain. Meteorological Monographs. 6:163-170.

- van BAVEE, C.H.M. e D.H.HIRRIS, 1962. Evapotranspiration rate from Bremuda grass and corn at Raleigh, N.Carolina. Agronomy Journal. Madison. 54(4):319-322. 
- van BAVEL, C.H.M. e D.H.HILLEL, 1976. Calculating potential and actual evaporation from a bare soil surface: by simulation of concurrent flow of water and heat. Agri cultural Meteorology. Amasterdam. 17:453-476.

- VILLA NOVA, N.A. e J.C.OMETTO, 1975. Adaptação e simplificação do mëtodo de Penman às condições climäticas do Estado de São Paulo. A ser publicado. 19p.

- WARTENA, L. e A.J.W.BORGHORST, 196i. The energy balance of an evaporation pan and the measurements of the reflec iivity of its bottom. Quaterly Journal of Royal Meteoro logical Society. Londres. 87(372):245-249. 
86.

9. APÊNDICE 
Apêndice 1. Valores de $\Delta$ para o intervalo de temperaturas de. $0,09 \mathrm{C}$ a $28,9 \circ \mathrm{C}$, obtidos derivando a expressäo de Tetens.

\begin{tabular}{l|rrrrrrrrrr}
\hline toc & 0,0 & 0,1 & 0,2 & 0,3 & 0,4 & 0,5 & 0,6 & 0,7 & 0,8 & 0,9 \\
\hline 00 & 0,33 & 0,34 & 0,34 & 0,34 & 0,34 & 0,34 & 0,35 & 0,35 & 0,35 & 0,35 \\
01 & 0,36 & 0,36 & 0,36 & 0,36 & 0,36 & 0,37 & 0,37 & 0,37 & 0,37 & 0,38 \\
02 & 0,38 & 0,38 & 0,38 & 0,39 & 0,39 & 0,39 & 0,39 & 0,40 & 0,40 & 0,40 \\
03 & 0,40 & 0,41 & 0,41 & 0,41 & 0,41 & 0,42 & 0,42 & 0,42 & 0,42 & 0,43 \\
04 & 0,43 & 0,43 & 0,43 & 0,44 & 0,44 & 0,44 & 0,45 & 0,45 & 0,45 & 0,45 \\
05 & 0,46 & 0,46 & 0,46 & 0,47 & 0,47 & 0,47 & 0,47 & 0,48 & 0,48 & 0,48 \\
06 & 0,49 & 0,49 & 0,49 & 0,49 & 0,50 & 0,50 & 0,50 & 0,51 & 0,51 & 0,51 \\
07 & 0,52 & 0,52 & 0,52 & 0,53 & 0,53 & 0,53 & 0,54 & 0,54 & 0,54 & 0,54 \\
08 & 0,55 & 0,55 & 0,55 & 0,56 & 0,56 & 0,56 & 0,57 & 0,57 & 0,57 & 0,58 \\
09 & 0,58 & 0,59 & 0,59 & 0,59 & 0,60 & 0,60 & 0,60 & 0,61 & 0,61 & 0,61 \\
10 & 0,62 & 0,62 & 0,62 & 0,63 & 0,63 & 0,64 & 0,64 & 0,64 & 0,65 & 0,65 \\
11 & 0,66 & 0,66 & 0,67 & 0,67 & 0,68 & 0,68 & 0,68 & 0,68 & 0,69 & 0,69 \\
12 & 0,69 & 0,70 & 0,70 & 0,71 & 0,71 & 0,71 & 0,72 & 0,72 & 0,73 & 0,73 \\
13 & 0,74 & 0,74 & 0,74 & 0,75 & 0,75 & 0,76 & 0,76 & 0,77 & 0,77 & 0,77 \\
14 & 0,78 & 0,78 & 0,79 & 0,79 & 0,80 & 0,80 & 0,81 & 0,81 & 0,81 & 0,82 \\
15 & 0,82 & 0,83 & 0,83 & 0,84 & 0,84 & 0,85 & 0,85 & 0,86 & 0,86 & 0.87 \\
16 & 0,87 & 0,88 & 0,88 & 0,89 & 0,89 & 0,90 & 0,91 & 0,91 & 0,92 & 0,92 \\
17 & 0,92 & 0,93 & 0,93 & 0,94 & 0,94 & 0,95 & 0,95 & 0,96 & 0,96 & 0,97 \\
18 & 0,97 & 0,98 & 0,98 & 0,99 & 1,00 & 1,00 & 1,01 & 1,01 & 1,02 & 1,02 \\
19 & 1,03 & 1,03 & 1,04 & 1,05 & 1,05 & 1,06 & 1,06 & 1,07 & 1,07 & 1,08 \\
20 & 1,09 & 1,09 & 1,10 & 1,10 & 1,11 & 1,12 & 1,12 & 1,13 & 1,13 & 1,14 \\
21 & 1,15 & 1,15 & 1,16 & 1,16 & 1,17 & 1,18 & 1,18 & 1,19 & 1,20 & 1,20 \\
22 & 1,21 & 1,21 & 1,22 & 1,23 & 1,23 & 1,24 & 1,24 & 1,25 & 1,26 & 1,27 \\
23 & 1,27 & 1,28 & 1,29 & 1,30 & 1,30 & 1,31 & 1,32 & 1,32 & 1,33 & 1,34 \\
24 & 1,34 & 1,35 & 1,36 & 1,36 & 1,37 & 1,38 & 1,39 & 1,39 & 1,40 & 1,41 \\
25 & 1,42 & 1,42 & 1,43 & 1,44 & 1,45 & 1,45 & 1,46 & 1,47 & 1,48 & 1,48 \\
26 & 1,49 & 1,50 & 1,51 & 1,51 & 1,52 & 1,53 & 1,54 & 1,55 & 1,55 & 1,56 \\
27 & 1,57 & 1,58 & 1,59 & 1,59 & 1,60 & 1,61 & 1,62 & 1,63 & 1,63 & 1,64 \\
28 & 1,65 & 1,66 & 1,67 & 1,68 & 1,68 & 1,69 & 1,70 & 1,71 & 1,72 & 1,73 \\
\hline
\end{tabular}


Apêndice 2. Valores de $\sigma \mathrm{Ta}^{4}$ pana intervalos de temperatura de $0,09 \mathrm{C}$ a $28,99 \mathrm{C}$, em cal. $\mathrm{cm}^{-2} \cdot \mathrm{dia}^{-1}$

\begin{tabular}{l|rlllllllll}
\hline t:C & 0,0 & 0,1 & 0,2 & 0,3 & 0,4 & 0,5 & 0,6 & 0,7 & 0,8 & 0,9 \\
\hline 00 & 650 & 651 & 652 & 652 & 654 & 654 & 656 & 656 & 657 & 658 \\
01 & 659 & 660 & 661 & 662 & 663 & 664 & 665 & 666 & 667 & 668 \\
02 & 669 & 670 & 671 & 672 & 673 & 674 & 675 & 676 & 677 & 678 \\
03 & 679 & 680 & 681 & 682 & 683 & 684 & 685 & 686 & 687 & 688 \\
04 & 689 & 690 & 691 & 692 & 693 & 694 & 695 & 696 & 697 & 698 \\
05 & 699 & 700 & 701 & 702 & 703 & 704 & 705 & 706 & 707 & 708 \\
06 & 709 & 710 & 711 & 712 & 713 & 714 & 715 & 716 & 717 & 718 \\
07 & 719 & 720 & 721 & 722 & 723 & 724 & 725 & 726 & 727 & 728 \\
08 & 729 & 730 & 731 & 732 & 733 & 734 & 736 & 737 & 738 & 739 \\
09 & 740 & 741 & 742 & 743 & 744 & 745 & 746 & 747 & 748 & 749 \\
10 & 750 & 751 & 752 & 754 & 754 & 755 & 756 & 757 & 759 & 760 \\
11 & 761 & 762 & 763 & 764 & 765 & 7766 & 767 & 768 & 770 & 771 \\
12 & 772 & 773 & 774 & 775 & 776 & 777 & 778 & 779 & 780 & 782 \\
13 & 783 & 784 & 785 & 786 & 787 & 788 & 789 & 790 & 791 & 792 \\
14 & 794 & 795 & 796 & 797 & 798 & 799 & 800 & 801 & 802 & 804 \\
15 & 805 & 806 & 807 & 808 & 809 & 810 & 812 & 813 & 814 & 815 \\
16 & 816 & 817 & 818 & 819 & 820 & 822 & 823 & 824 & 825 & 826 \\
17 & 827 & 828 & 830 & 831 & 832 & 833 & 834 & 835 & 836 & 838 \\
18 & 839 & 840 & 841 & 842 & 843 & 845 & 846 & 847 & 848 & 849 \\
19 & 850 & 852 & 853 & 854 & 855 & 856 & 857 & 859 & 860 & 861 \\
20 & 862 & 863 & 864 & 866 & 867 & 868 & 869 & 870 & 872 & 873 \\
21 & 874 & 875 & 876 & 878 & 879 & 880 & 881 & 882 & 883 & 885 \\
22 & 886 & 887 & 888 & 890 & 891 & 892 & 893 & 894 & 896 & 897 \\
23 & 898 & 899 & 900 & 902 & 903 & 904 & 905 & 906 & 908 & 909 \\
24 & 910 & 911 & 913 & 914 & 915 & 916 & 918 & 919 & 920 & 921 \\
25 & 922 & 924 & 925 & 926 & 927 & 929 & 930 & 931 & 932 & 934 \\
26 & 935 & 936 & 937 & 939 & 940 & 941 & -942 & 944 & 945 & 946 \\
27 & 948 & 949 & 950 & 951 & 952 & 954 & 955 & 956 & 958 & 959 \\
28 & 960 & 961 & 9631 & 964 & 965 & 967 & 968 & 969 & 970 & 972 \\
\hline
\end{tabular}


Apêndice 3 . Valores da radiação solar que atinge uma área horizontal unitäria em um dia, admitindo-se a ausência da atmosfera e a constante solar (S) equivalente a. 2 cal. $\mathrm{cm}^{-2} \cdot \mathrm{dia}^{-1}$; para a latitude 22: 43,0'S, de Junho/78 a Fevereiro/79.

\begin{tabular}{l|rrrrrrrrr}
\hline DIA & JUN & JUL & AGO & SET & OUT & NOV & DEZ & JAN & FEV \\
\hline 01 & 571 & 553 & 619 & 742 & 871 & 976 & 1031 & 1043 & 1009 \\
02 & 569 & 554 & 623 & 746 & 875 & 978 & 1032 & 1042 & 1005 \\
03 & 568 & 554 & 626 & 751 & 879 & 981 & 1033 & 1042 & 1003 \\
04 & 566 & 556 & 630 & 755 & 883 & 983 & 1034 & 1041 & 1001 \\
05 & 564 & 557 & 633 & 760 & 887 & 986 & 1035 & 1041 & 999 \\
06 & 563 & 559 & 637 & 765 & 891 & 988 & 1036 & 1040 & 997 \\
07 & 561 & 560 & 640 & 769 & 894 & 990 & 1037 & 1040 & 995 \\
08 & 560 & 562 & 644 & 773 & 898 & 993 & 1038 & 1039 & 993 \\
09 & 559 & 563 & 647 & 778 & 902 & 995 & 1038 & 1038 & 990 \\
10 & 556 & 565 & 651 & 782 & 905 & 997 & 1039 & 1038 & 988 \\
11 & 555 & 566 & 655 & 786 & 910 & 999 & 1040 & 1037 & 985 \\
12 & 554 & 568 & 659 & 791 & 914 & 1001 & 1040 & 1036 & 983 \\
13 & 553 & 570 & 663 & 795 & 917 & 1003 & 1041 & 1035 & 980 \\
14 & 553 & 572 & 667 & 799 & 921 & 1005 & 1041 & 1034 & 978 \\
15 & 552 & 574 & 671 & 803 & 924 & 1008 & 1042 & 1034 & 975 \\
16 & 551 & 576 & 675 & 809 & 927 & 1010 & 1043 & 1032 & 972 \\
17 & 550 & 578 & 679 & 813 & 931 & 1011 & 1043 & 1031 & 969 \\
18 & 550 & 580 & 683 & 817 & 934 & 1013 & 1043 & 1030 & 966 \\
19 & 550 & 582 & 687 & 821 & 937 & 1015 & 1043 & 1029 & 964 \\
20 & 549 & 585 & 691 & 826 & 940 & 1016 & 1043 & 1028 & 960 \\
21 & 549 & 587 & 695 & 830 & 943 & 1018 & 1043 & 1026 & 956 \\
22 & 549 & 590 & 699 & 834 & 947 & 1020 & 1044 & 1025 & 953 \\
23 & 549 & 592 & 703 & 838 & 950 & 1021 & 1044 & 1024 & 950 \\
24 & 549 & 595 & 708 & 842 & 953 & 1022 & 1044 & 1022 & 947 \\
25 & 550 & 598 & 712 & 846 & 956 & 1024 & 1044 & 1021 & 944 \\
26 & 550 & 600 & 716 & 850 & 959 & 1025 & 1044 & 1019 & 940 \\
27 & 550 & 603 & 721 & 854 & 962 & 1026 & 1044 & 1017 & 937 \\
28 & 551 & 606 & 725 & 859 & 965 & 1028 & 1044 & 1016 & 934 \\
29 & 551 & 610 & 729 & 863 & 968 & 1029 & 1043 & 1014 & - \\
30 & 552 & 613 & 734 & 867 & 970 & 1030 & 1043 & 1012 & - \\
31 & - & 617 & 738 & - & 973 & - & 1043 & 1010 & - \\
\hline & & & & & & & & & \\
\hline
\end{tabular}


Apêndice 4. Valores de duração do dia em horas e décimos para a região de Piracicaba, latitude 220 43.0'S:

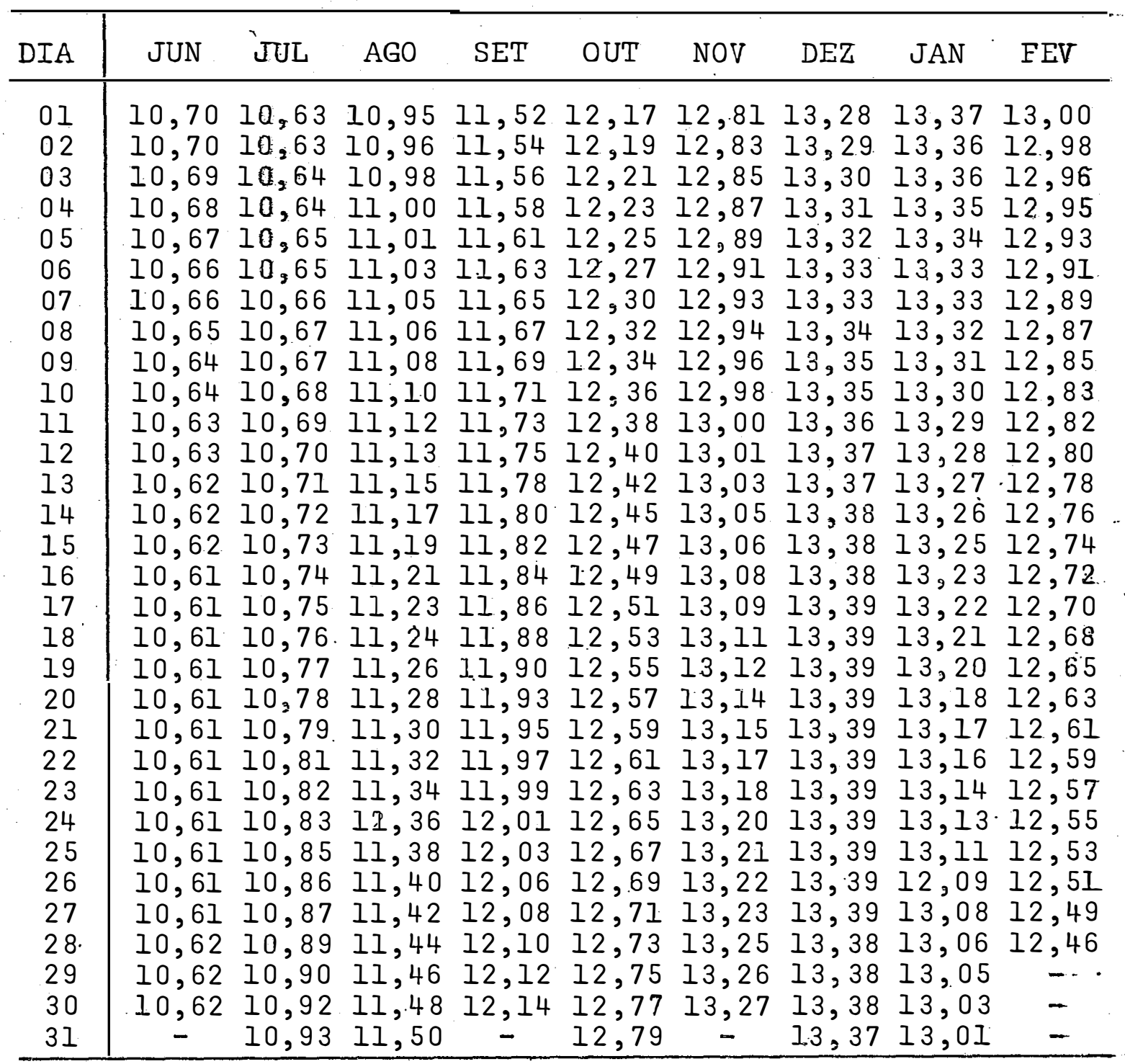


Apêndice 5. Valores de razão de insolação $(n / N)$ para a região de Piracicaba, latitude $23 \%$ 43,0's

\begin{tabular}{l|rcccccccc}
\hline DIA & JUN & JUL & AGO & SET & OUT & NOV & DEZ & JAN & FEV \\
\hline 01 & 0,42 & 0,88 & 0,74 & 0,30 & 0,77 & 0,43 & 0,85 & 0,18 & 0,62 \\
02 & 0,23 & 0,78 & 0,75 & 0,28 & 0,82 & 0,89 & 0,78 & 0,10 & 0,60 \\
03 & 0,78 & 0,56 & 0,79 & 0,78 & 0,80 & 0,33 & 0,71 & 0,15 & 0,71 \\
04 & 0,58 & 0,84 & 0,75 & 0,59 & 0,82 & 0,08 & 0,66 & 0,00 & $0,8 I$ \\
05 & 0,86 & 0,44 & 0,73 & 0,00 & 0,81 & 0,00 & 0,74 & 0,52 & 0,73 \\
06 & 0,78 & - & 0,88 & 0,46 & 0,85 & 0,60 & 0,23 & 0,72 & 0,74 \\
07 & 0,66 & 0,61 & 0,90 & 0,45 & 0,84 & 0,86 & 0,06 & 0,86 & $0,8 I$ \\
08 & 0,17 & 0,70 & 0,45 & 0,47 & 0,74 & 0,83 & 0,00 & 0,90 & 0,79 \\
09 & 0,31 & 0,75 & 0,59 & 0,89 & 0,77 & 0,54 & 0,01 & 0,86 & $0,7.5$ \\
10 & 0,85 & 0,73 & 0,92 & 0,72 & 0,06 & 0,22 & 0,51 & 0,83 & 0,27 \\
11 & 0,86 & 0,84 & 0,90 & 0,90 & 0,57 & 0,00 & 0,69 & 0,27 & $0,31$. \\
12 & 0,64 & 0,75 & 0,81 & 0,85 & 0,85 & 0,00 & 0,62 & 0,02 & 0,19 \\
13 & 0,68 & 0,63 & 0,00 & 0,78 & 0,59 & 0,74 & 0,76 & 0,69 & 0,03 \\
14 & - & 0,62 & 0,03 & 0,17 & 0,14 & 0,84 & 0,31 & 0,87 & 0,16 \\
15 & 0,73 & 0,19 & 0,91 & 0,08 & 0,56 & 0,78 & 0,42 & 0,88 & $0,4 I$ \\
16 & 0,57 & 0,28 & 0,90 & 0,62 & 0,54 & 0,00 & 0,47 & 0,89 & 0,55 \\
17 & 0,63 & - & 0,90 & 0,06 & 0,80 & 0,29 & 0,69 & 0,88 & 0,11 \\
18 & 0,83 & - & 0,76 & 0,82 & 0,68 & 0,56 & 0,44 & 0,84 & 0,51 \\
19 & 0,82 & - & 0,72 & 0,82 & 0,46 & 0,77 & 0,72 & 0,57 & 0,75 \\
20 & 0,71 & - & 0,65 & 0,56 & 0,76 & 0,26 & 0,85 & 0,02 & 0,82 \\
21 & 0,47 & - & 0,41 & 0,23 & 0,91 & 0,59 & 0,75 & 0,00 & - \\
22 & 0,74 & - & 0,83 & 0,79 & 0,91 & 0,46 & 0,65 & 0,24 & 0,15 \\
23 & 0,55 & - & 0,38 & 0,80 & 0,89 & 0,36 & 0,70 & 0,57 & 0,37 \\
24 & 0,57 & - & 0,02 & 0,80 & 0,89 & 0,68 & 0,79 & 0,75 & 0,76 \\
25 & 0,66 & 0,55 & 0,90 & 0,83 & 0,89 & 0,73 & 0,59 & -1 & 0,81 \\
26 & 0,80 & 0,89 & 0,83 & 0,71 & 0,79 & 0,55 & 0,00 & 0,73 & 0,82 \\
27 & 0,85 & 0,89 & 0,79 & 0,70 & 0,46 & 0,02 & 0,01 & 0,56 & 0,62 \\
28 & 0,89 & 0,78 & 0,52 & 0,67 & 0,35 & 0,70 & 0,00 & 0,30 & 0,72 \\
29 & 0,89 & 0,64 & 0,57 & 0,74 & 0,31 & 0,87 & 0,15 & 0,00 & - \\
30 & 0,83 & 0,71 & 0,64 & 0,82 & 0,64 & 0,68 & 0,44 & 0,35 & - \\
31 & - & 0,90 & 0,00 & - & 0,27 & - & 0,82 & 0,48 & - \\
\hline
\end{tabular}

